\title{
Diabetic foot disease in European perspective : results from the Eurodiale study
}

Citation for published version (APA):

Prompers, L. (2008). Diabetic foot disease in European perspective : results from the Eurodiale study. [Doctoral Thesis, Maastricht University]. Datawyse / Universitaire Pers Maastricht. https://doi.org/10.26481/dis.20080529lp

Document status and date:

Published: 01/01/2008

DOI:

10.26481/dis.20080529lp

Document Version:

Publisher's PDF, also known as Version of record

\section{Please check the document version of this publication:}

- A submitted manuscript is the version of the article upon submission and before peer-review. There can be important differences between the submitted version and the official published version of record.

People interested in the research are advised to contact the author for the final version of the publication, or visit the DOI to the publisher's website.

- The final author version and the galley proof are versions of the publication after peer review.

- The final published version features the final layout of the paper including the volume, issue and page numbers.

Link to publication

\footnotetext{
General rights rights.

- You may freely distribute the URL identifying the publication in the public portal. please follow below link for the End User Agreement:

www.umlib.nl/taverne-license

Take down policy

If you believe that this document breaches copyright please contact us at:

repository@maastrichtuniversity.nl

providing details and we will investigate your claim.
}

Copyright and moral rights for the publications made accessible in the public portal are retained by the authors and/or other copyright owners and it is a condition of accessing publications that users recognise and abide by the legal requirements associated with these

- Users may download and print one copy of any publication from the public portal for the purpose of private study or research.

- You may not further distribute the material or use it for any profit-making activity or commercial gain

If the publication is distributed under the terms of Article $25 \mathrm{fa}$ of the Dutch Copyright Act, indicated by the "Taverne" license above, 
Diabetic foot disease in European perspective

Results from the Eurodiale study 
The studies presented in this dissertation were conducted under the auspices of the school for Public Health and Primary Care: CAPHRI at Maastricht University, The Netherlands. CAPHRI is part of the Netherlands School of Primary Care Research (CaRe), which has been acknowledged since 1995 by The Royal Netherlands Academy of Art en Sciences (KNAW).

The Eurodiale project was supported by an unrestricted grant of Smith\&Nephew.

(C) Leonne Prompers, Maastricht 2008

ISBN: 978-90-5278-717-6

Layout: Tiny Wouters

Cover: Sjef Hutschemakers

Production: Datawyse | Universitaire Pers Maastricht

Printing of this thesis was supported by Novo Nordisk, Probalance, Eli Lilly, Novartis, Sanofi-Aventis, $\mathrm{KCl}$, Convatec, and ING Bank. 


\title{
Diabetic foot disease in European perspective
}

\author{
Results from the Eurodiale study
}

\author{
Proefschrift
}

ter verkrijging van de graad van doctor aan de Universiteit Maastricht, op gezag van de Rector Magnificus, Prof. mr. G.P.M.F. Mols, volgens het besluit van het College van Decanen, in het openbaar te verdedigen op donderdag 29 mei 2008 om 16.00 uur

door

Leonne Prompers

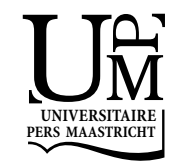




\section{Promotor:}

Prof. dr. N.C. Schaper

\section{Copromotor:}

Dr. M.S.P. Huijberts

Beoordelingscommissie:

Prof. dr. P.J.E.H.M. Kitslaar (voorzitter)

Dr. W.H. van Houtum, (Spaarne Ziekenhuis, Heemstede)

Dr. A.P. Sanders

Prof. dr. C. Spreeuwenberg

Prof. dr. C.D.A. Stehouwer 
Aan Elise 



\section{Contents}

Chapter 1 Introduction and outline of the thesis 9

Chapter 2 Optimal organization of health care in diabetic foot disease. 19 Introduction to the Eurodiale study

Chapter 3 High prevalence of ischaemia, infection and serious comorbidity 33 in patients with diabetic foot disease in Europe.

Baseline results from the Eurodiale study

Chapter 4 Prediction of outcome in individuals with diabetic foot disease. Focus on the differences between individuals with and without peripheral arterial disease. The Eurodiale study

Chapter 5 Non-healing in diabetic foot disease is predicted by ulcer size, peripheral arterial disease, polyneuropathy and co-morbidities. The Eurodiale risk score

Chapter 6 Resource utilisation and costs associated with the treatment of diabetic foot ulcers. Prospective data from the Eurodiale study

Chapter 7 Delivery of care to diabetic foot ulcer patients in daily practice: Results of the Eurodiale study, a prospective cohort study

Chapter 8 Are there best practices in the treatment of diabetic foot 103 disease?

Centre differences in outcome, health care organization and management strategies. The Eurodiale study

Chapter 9 Summary, conclusions and discussion

Samenvatting

Dankwoord

Curriculum vitae 



\section{Chapter 1}

Introduction and outline of the thesis 
$10 \mid$ Chapter 1 


\section{Diabetic Foot Disease}

Diabetes Mellitus is one of the important chronic diseases of our times. The World Health Organization predicts that the number of persons with diabetes worldwide will increase to 366 million by the year $2030^{1}$. A large part of the burden of disease, as well as health care costs, are related to the development of chronic complications of diabetes. One of the most feared complications of diabetes is diabetic foot disease. Diabetic foot ulcers have a major impact on the patient as well as on the health care system. These ulcers tend to heal slowly, need intensive care and healing can be complicated by infection and gangrene, leading to long-term in-hospital treatment and/or amputation ${ }^{2,3}$. Every 30 seconds a leg is lost due to diabetes somewhere in the world. Moreover, foot ulcers have major negative effects on quality of life, due to loss of mobility, loss of work and reduction of social activities ${ }^{4}$, one study has demonstrated that quality of life of diabetic foot ulcer patients was comparable to quality of life of patients with recurrent breast cancer ${ }^{5}$. After an amputation prognosis is poor and quality of life is further reduced ${ }^{6}$, in a 5 -year follow-up study, $49 \%$ had undergone a second amputation, $68 \%$ had died and only $19 \%$ of the patients with a lower leg amputation were able to walk $1 \mathrm{~km}^{7}$. In addition these ulcers and their consequences are associated with major health care consumption and high $\operatorname{costs}^{8,9}$. Despite these poor outcomes, the feet of diabetic patients have traditionally received relatively little attention from health care workers and scientists. However, in recent decades our knowledge on diabetic foot ulcers has clearly increased, with a rise in the number of scientific publications and the production of guidelines on prevention and management $^{2,10,11}$.

\section{Pathways to ulceration and amputation}

Diabetic foot ulcers are usually caused by several factors acting in concert, with polyneuropathy, altered biomechanics, peripheral vascular disease (PAD), and inadequate foot wear as major factors. The course of the disease may be complicated by the occurrence of infection ${ }^{12}$. Each of these components is usually not sufficient to cause ulceration, but it is the combination of two or more factors that typically results in a poorly healing foot ulcer ${ }^{13}$.

\section{Diabetic polyneuropathy and altered biomechanics}

In daily life our feet are continuously threatened by multiple minor and major insults, and loss of protective sensation is a cardinal event in the pathway to foot ulceration in many patients ${ }^{14}$. The sensory deficits include diminished 
perception of pain, temperature, light touch, and pressure ${ }^{15}$. Many patients do not have major symptoms and are not aware of the diminished protective sensation. The majority of neuropathic or neuro-ischemic ulcers are caused by chronic repetitive biomechanical stress with abnormal loading of the foot during standing and walking and/or ill-fitting shoes ${ }^{2}$. This abnormal loading of the foot can be the consequence of loss of muscle function due to neuropathy, foot deformities (such as claw toes or bony prominences), changes in shock absorbing capacity and limited joint mobility of the joints of the foot ${ }^{16,17}$. In the non-ischemic foot, the repetitive biomechanical stress induces the formation of callus at the sites of abnormal load. This callus further elevates pressures and is associated with a high risk of future ulceration in neuropathic patients ${ }^{18}$. Finally the skin breaks down, with the formation of a painless neuropathic ulcer $^{2}$. According to current guidelines total contact cast treatment is the treatment of choice for these neuropathic ulcers ${ }^{19}$. It is not known however, to what extent this standard treatment is embedded in daily clinical practice.

\section{Peripheral Vascular Disease}

The same pathways as described above are probably followed in neuroischemic ulcers. However, atherosclerotic, obstructive, peripheral arterial disease (PAD) is a major determinant of poor outcome of a diabetic foot ulcer $^{13}$. PAD is a common finding in patients with type 2 diabetes mellitus, with a prevalence of approximately 20 to $40 \%{ }^{20,21}$. In many patients the disease has no or few symptoms and runs a relatively benign course, but in others it leads to gangrene or impaired healing of foot ulcers. PAD in diabetes frequently has a specific anatomical pattern, which can be interpreted as a sign of premature ageing of the vascular tree. The proximal vessels are relatively spared, with less involvement of the aortic iliac arteries and more extensive disease in the arteries of the lower leg $^{22-24}$. In diabetic patients, the atherosclerotic changes seem to be more extensive and also more aggressive, with a faster progression of disease compared to non-diabetic patients. McDaniel showed that patients with claudication and diabetes had a $21 \%$ risk of major amputation, compared to $3 \%$, respectively, in non-diabetic patients ${ }^{25}$. Major risk factors for the development of PAD (other than diabetes) are older age, smoking, and possibly hypertension ${ }^{5}$. Recently, several novel risk factors have been identified in the general population for the development of PAD, such as hyperhomocysteinemia, elevated markers of inflammation, and possibly insulin resistance $^{26-30}$.

\section{Infection}

Infection in a diabetic foot ulcer is potentially a limb-threatening condition. It is generally assumed that poor metabolic control is associated with impaired 
immunity, but it is still a matter of debate whether patients with only moderately elevated blood glucose levels are more susceptible to infection. Neutrophil function is impaired in diabetic patients with poor metabolic control, resulting in defective chemotaxis, phagocytosis, and intracellular killing ${ }^{31-34}$.

Infection is characterised by tissue damage due to multiplying micro-organisms and the host response. As open wounds tend to become colonised with microorganisms and even virulent pathogens (e.g. Staphylococcus aureus) can sometimes be colonisers, isolating a micro-organism in a culture does not help to identify the patient with an infection and the diagnosis should be made on clinical grounds. Unfortunately, local signs of inflammation, such as erythema or pain, can be less apparent in diabetic patients with a foot infection, probably due to factors as ischemia and neuropathy ${ }^{2}$. Also systemic signs of infection can be markedly absent. In one study of patients with a deep foot infection approximately $50 \%$ of the patients did not have systemic signs of inflammation, such as elevated body temperature or $\mathrm{CRP}^{35}$. On the other hand, when increased body temperature or laboratory parameters of inflammation are present, a severe infection is more likely ${ }^{36}$. The specific anatomy of the foot can also affect the presentation and course of an infection. In case of a penetrating ulcer, infection of one of the muscle compartments of the foot can result in tissue oedema with a rise in compartmental pressure and subsequent microvascular occlusion. This foot compartment syndrome, with its vicious cycle of infection, oedema and microvascular failure, can result in extensive tissue necrosis ${ }^{37}$.

Superficial infections in patients not treated previously with antibiotics are usually caused by gram-positive micro-organisms, in particular Staphylococcus Aureus and bacteria such as $\beta$ haemolytic streptococci. Deep foot infections, chronic infections and wounds that have previously been treated with antibiotics often have a mixed flora of gram-positive and gram-negative aerobes and anaerobes ${ }^{38}$. Multiresistant micro-organisms and methicillinresistant $\mathrm{S}$. Aureus (MRSA) are a growing problem and in one recent large American trial in which two intravenous broad spectrum antibiotics were compared, MRSA was isolated in $20 \%$ of the cultures ${ }^{39}$.

\section{Current issues in diabetic foot disease}

The use of the term diabetic foot ulcer may be misleading. As described above, diabetic foot ulceration is in fact a very heterogeneous disease. Many patients also suffer from other diabetes related co-morbidities that may influence the course of the disease and its treatment. Furthermore, the presence or absence of PAD may be a major determinant of clinical outcome in 
foot ulcer patients ${ }^{40}$. Therefore, different patient and ulcer phenotypes are encountered in daily clinical practice. This diversity in the clinical presentation of diabetic foot patients has hampered clinical research in this area. In addition many different health care professionals are involved in the treatment of these patients, and some diabetic foot units are more surgically oriented, while in other centres diabetologists are leading multidisciplinary teams. This diversity may markedly influence the care that is being delivered to patient and may also affect clinical outcome. Representative data on patients characteristics, management strategies, clinical outcome and health care costs are of great importance to optimise the care that is being delivered to patients with diabetic foot disease. These data are also essential to design and perform multi-centre randomised controlled trial studies that are needed to evaluate new therapies in this disease area. Single centres mostly will not have sufficient patients to gather representative data and single centre studies may be influenced by typical phenotypes and management strategies. Many of the current outcome studies seem to be biased towards diabetic foot ulcer patients without PAD ${ }^{41}$.

In 1999 the Eurodiale group was created in order to improve the outcome of individuals with diabetic foot disease by performing collaborative studies in this field. The consortium has grown into a group of 14 European centres in 10 European countries. These centres are located in Belgium (Bornen), Czech Republic (Prague), Denmark (Copenhagen), Germany (Rheine, Werl), Italy, (Pisa, Rome), Slovenia (Ljubljana), Spain (Barcelona), Sweden (Malmö/Lund), the Netherlands (Almelo, Maastricht), and the United Kingdom (London, Ashton under Lyne). The first effort of this consortium was to perform a multi-centre prospective observational study addressing the following questions:

1.What are the patient demographics and foot and ulcer characteristics of individuals treated for diabetic foot disease?

2.What are the current clinical outcomes of these patients?

3. Which major factors influence clinical outcome?

4. What is the current resource utilization and associated costs in diabetic foot disease throughout Europe?

5.Are there differences in management strategies and clinical outcome? 


\section{Outline of the thesis}

The project "Optimal organisation of health care in diabetic foot disease" has been performed by the Eurodiale study group between October 2002 and October 2006 and was supported by an EC Fifth Framework grant (QLG4-CT2002-01524) This thesis represents a large part of the results of the Eurodiale study. In chapter 2 the rationale and protocol of the Eurodiale study are described.

In chapter 3 we investigated the baseline characteristics of patients with a new foot ulcer presenting at one of the 14 European foot clinics. It was our aim to describe the complete picture of patient characteristics, including co-morbidities and referral patterns, disease specific characteristics (including presence of peripheral arterial disease (PAD) or polyneuropathy) and ulcer characteristics. Furthermore, one of our objectives was to address disease severity according to the University of Texas Wound Healing Classifciation ${ }^{42}$, among European diabetic foot patients.

In chapter 4 and chapter 5 we describe overall outcome of the cohort in terms of healing, major amputation and death, and we identified, among a large set of variables, those that best predict clinical outcome of diabetic foot patients in terms of non-healing. We focused on the differences between patients with or without PAD. In addition we developed an easily applicable risk-scoring rule that could aid health care providers in the future to identify diabetic foot patients at higher risk of non-healing.

In chapter 6 we investigated resource utilisation and associated costs in patients with diabetic foot ulcers and we determined differences in resource utilisation according to disease severity.

In chapter 7 we determined the current management of diabetic foot ulcers among the Eurodiale patients, and we identified patient-related factors and specific barriers that influence management strategies. In this chapter we focussed on three domains that are addressed in the International Consensus document ${ }^{19}$ : early referral, offloading of the ulcer and restoration of skin perfusion.

In chapter 8 we investigated whether substantial differences in outcome are present between the participating centres when correcting for patient characteristics. Moreover, we addressed the question whether differences in outcome between centres can be explained by the management strategies used during follow-up or by local health care organizational aspects. 
Finally, in chapter 9 the main findings of the Eurodiale study are discussed in the context of the recent literature. Furthermore, the implications for daily care of diabetic foot patients are defined and some new directions for future research are proposed.

The current thesis describes a major part of the Eurodiale project, however, several questions remain to be answered and will be analysed in the future. In particular these analyses will focus in more detail on differences in individual and disease specific factors, outcome, management strategies, and health care organizational aspects of diabetic foot disease in Europe. Furthermore, the impact of diabetic foot ulcers and their treatment on quality of life will be analysed in subsequent studies. 


\section{References}

1. Wild S, Roglic G, Green A, Sicree R, King H. Global prevalence of diabetes: estimates for the year 2000 and projections for 2030. Diabetes Care 2004;27:1047-1053

2. Apelqvist J, Bakker K, van Houtum WH, Nabuurs-Franssen MH, Schaper NC. International Consensus on the Diabetic Foot. Schaper NC, Maastricht 1999

3. Apelqvist $\mathrm{J}$, Larsson $\mathrm{J}$. What is the most effective way to reduce incidence of amputation in the diabetic foot? Diabetes Metab Res Rev 2000;16 S1:S75-83

4. Brod M. Quality of life issues in patients with diabetes and lower extremity ulcers: patients and care givers. Qual Life Res 1998;7:365-372

5. Nabuurs-Franssen MH, Huijberts MS, Nieuwenhuijzen Kruseman AC, Willems J, Schaper NC. Health-related quality of life of diabetic foot ulcer patients and their caregivers. Diabetologia 2005;48:1906-1910

6. Ragnarson Tennvall G, Apelqvist J. Health-related quality of life in patients with diabetes mellitus and foot ulcers. J Diabetes Complications 2000;14:235-241

7. Larsson J, Agardh CD, Apelqvist J, Stenstrom A. Long-term prognosis after healed amputation in patients with diabetes. Clin Orthop Relat Res 1998:149-158

8. Ragnarson Tennvall G, Apelqvist J. Health-economic consequences of diabetic foot lesions. Clin Infect Dis 2004;39 S2:S132-139

9. Apelqvist J, Ragnarson-Tennvall G, Larsson J, Persson U. Long-term costs for foot ulcers in diabetic patients in a multidisciplinary setting. Foot Ankle Int 1995;16:388-394

10. Boulton AJ. The diabetic foot: from art to science. The 18th Camillo Golgi lecture. Diabetologia 2004;47:1343-1353

11. Cavanagh PR, Lipsky BA, Bradbury AW, Botek G. Treatment for diabetic foot ulcers. Lancet 2005;366:1725-1735

12. Frykberg RG. An evidence-based approach to diabetic foot infections. Am J Surg 2003;186: 44S-54S; discussion 61S-64S

13. Reiber GE, Vileikyte L, Boyko EJ, del Aguila M, Smith DG, Lavery LA, Boulton AJ. Causal pathways for incident lower-extremity ulcers in patients with diabetes from two settings. Diabetes Care 1999;22:157-162

14. Boulton AJ. The pathogenesis of diabetic foot problems: an overview. Diabet Med 1996;13 $\mathrm{S} 1: \mathrm{S} 12-16$

15. Ziegler D. Diagnosis and management of diabetic peripheral neuropathy. Diabet Med 1996;13 S1:S34-38

16. Ahroni JH, Boyko EJ, Forsberg RC. Clinical correlates of plantar pressure among diabetic veterans. Diabetes Care 1999;22:965-972

17. Fernando DJ, Masson EA, Veves A, Boulton AJ. Relationship of limited joint mobility to abnormal foot pressures and diabetic foot ulceration. Diabetes Care 1991;14:8-11

18. Murray HJ, Young MJ, Hollis S, Boulton AJ. The association between callus formation, high pressures and neuropathy in diabetic foot ulceration. Diabet Med 1996;13:979-982

19. Schaper NC, Apelqvist J, Bakker K. The international consensus and practical guidelines on the management and prevention of the diabetic foot. Curr Diab Rep 2003;3:475-479

20. Beks PJ, Mackaay AJ, de Neeling JN, de Vries H, Bouter LM, Heine RJ. Peripheral arterial disease in relation to glycaemic level in an elderly Caucasian population: the Hoorn study. Diabetologia 1995;38:86-96

21. Beach KW, Bedford GR, Bergelin RO, Martin DC, Vandenberghe N, Zaccardi M, Strandness DE Jr. Progression of lower-extremity arterial occlusive disease in type II diabetes mellitus. Diabetes Care 1988;11:464-472

22. Conrad MC. Large and small artery occlusion in diabetics and nondiabetics with severe vascular disease. Circulation 1967;36:83-91

23. Faglia E, Favales F, Quarantiello A, Calia P, Clelia P, Brambilla G, Rampoldi A, Morabito A. Angiographic evaluation of peripheral arterial occlusive disease and its role as a prognostic determinant for major amputation in diabetic subjects with foot ulcers. Diabetes Care $1998 ; 21: 625-630$ 
24. Jude EB, Oyibo SO, Chalmers N, Boulton AJ. Peripheral arterial disease in diabetic and nondiabetic patients: a comparison of severity and outcome. Diabetes Care 2001;24: 1433-1437

25. McDaniel MD, Cronenwett JL. Basic data related to the natural history of intermittent claudication. Ann Vasc Surg 1989;3:273-277

26. Vigna GB, Fellin R. Dyslipidemia in peripheral vascular disease. Curr Opin Lipidol 1996;7: 254-259

27. Clausell N, Kalil P, Biolo A, Molossi S, Azevedo M. Increased expression of tumor necrosis factor-alpha in diabetic macrovasculopathy. Cardiovasc Pathol 1999;8:145-151

28. O'Neal DN, Lewicki J, Ansari MZ, Matthews PG, Best JD. Lipid levels and peripheral vascular disease in diabetic and non-diabetic subjects. Atherosclerosis 1998;136:1-8

29. Pedersen TR, Kjekshus J, Pyörälä K, Olsson AG, Cook TJ, Musliner TA, Tobert JA, Haghfelt $T$. Effect of simvastatin on ischemic signs and symptoms in the Scandinavian simvastatin survival study (4S). Am J Cardiol 1998;81:333-335

30. Valentine RJ, Grayburn PA, Vega GL, Grundy SM. Lp(a) lipoprotein is an independent, discriminating risk factor for premature peripheral atherosclerosis among white men. Arch Intern Med 1994;154:801-806

31. Delamaire M, Maugendre D, Moreno M, Le Goff MC, Allannic H, Genetet B. Impaired leucocyte functions in diabetic patients. Diabet Med 1997;14:29-34

32. Mowat A, Baum J. Chemotaxis of polymorphonuclear leukocytes from patients with diabetes mellitus. N Engl J Med 1971;284:621-627

33. Davidson NJ, Sowden JM, Fletcher J. Defective phagocytosis in insulin controlled diabetics: evidence for a reaction between glucose and opsonising proteins. J Clin Pathol 1984;37: 783-786

34. Repine JE, Clawson CC, Goetz FC. Bactericidal function of neutrophils from patients with acute bacterial infections and from diabetics. J Infect Dis 1980;142:869-875

35. Eneroth M, Apelqvist J, Stenstrom A. Clinical characteristics and outcome in 223 diabetic patients with deep foot infections. Foot Ankle Int 1997;18:716-722

36. Lipsky BA, Berendt AR, Deery HG, Embil JM, Joseph WS, Karchmer AW, LeFrock JL, Lew DP, Mader JT, Norden C, Tan JS; Infectious Diseases Society of America. Diagnosis and treatment of diabetic foot infections. Clin Infect Dis 2004;39:885-910

37. Rauwerda JA. Foot debridement: anatomic knowledge is mandatory. Diabetes Metab Res Rev 2000;16 S1:S23-26

38. Lipsky BA. A report from the international consensus on diagnosing and treating the infected diabetic foot. Diabetes Metab Res Rev 2004;20 S1:S68-77

39. Lipsky BA, Armstrong DG, Citron DM, Tice AD, Morgenstern DE, Abramson MA. Ertapenem versus piperacillin/tazobactam for diabetic foot infections (SIDESTEP): prospective, randomised, controlled, double-blinded, multicentre trial. Lancet 2005;366:1695-1703

40. Armstrong DG, Lavery LA, Harkless LB. Validation of a diabetic wound classification system. The contribution of depth, infection, and ischemia to risk of amputation. Diabetes Care 1998;21:855-859

41. Margolis DJ, Allen-Taylor L, Hoffstad O, Berlin JA. Diabetic neuropathic foot ulcers: the association of wound size, wound duration, and wound grade on healing. Diabetes Care 2002;25:1835-1839

42. Armstrong DG, Lavery LA, Harkless LB. Validation of a diabetic wound classification system. The contribution of depth, infection, and ischemia to risk of amputation. Diabetes Care 1998;21:855-859 


\section{Chapter 2}

\section{Optimal organization of health care in diabetic foot disease}

Introduction to the Eurodiale study

Prompers L, Huijberts M, Apelqvist J, Jude E, Piaggesi A, Bakker K, Edmonds M, Holstein P, Jirkovska A, Mauricio D, Tennvall GR, Reike H, Spraul M, Uccioli L, Urbancic V, Van Acker K, Van Baal J, Van Merode F, Schaper $\mathrm{N}$.

International Journal of Lower Extremity Wounds 2007;6:1-7 


\section{Abstract}

This article describes the rationale and protocol of a large data collection study in patients with new diabetic foot ulcers by the Eurodiale study group, a consortium of centres of expertise in the field of diabetic foot disease within Europe. This study is a multicentre, observational, prospective data collection study. Its main aim is to determine the major factors determining clinical outcome and outcome in terms of health-related quality of life and health care consumption. Between September $1^{\text {st }}, 2003$, and October $1^{\text {st }}, 2004$, in 14 European centres, all consecutive patients with diabetes and a new foot ulcer were included in the study and followed until the end point or for a maximum of one year. End points were healing of the foot, major amputation, or death. Data were collected on patient, foot, and ulcer characteristics and on diagnostic and management procedures. Furthermore, data were collected on health care organization, quality of life, and resource use. A total of 1232 patients were included in the study. Sixty-three percent of the patients were referred by their general practitioner or were self-referrals. Twenty-seven percent of the patients were admitted at the time of inclusion; 1088 patients were followed until the end point. "Optimal Organization of Health Care in Diabetic Foot Disease" is one of the first large multicentre studies in the field of diabetic foot disease on clinical presentation, clinical outcome, quality of life, resource utilization, and health care organization and their interrelationships. These data will provide us with new insights that enable us to improve care for these patients and guide the development of new studies in this area. The results of this study are the subject of a separate presentation. 


\section{Introduction}

The prevalence of diabetes in Europe is increasing rapidly, and this in turn will lead to an increase in individuals with complications of chronic diabetes. Approximately $15 \%$ of all diabetic patients will develop a foot ulcer in the course of their disease ${ }^{1}$, and it is estimated that there are currently more than 600000 diabetic individuals in Europe with a foot ulcer ${ }^{2,3}$. Foot ulcers have major negative effects on the quality of life because of morbidity, loss of mobility, loss of work, loss of income, and reduction of social activities ${ }^{4}$. Moreover, these foot ulcers are associated with major health care consumption and high costs.

The use of the term diabetic foot ulcer may be misleading. Diabetic foot ulceration is in fact a very heterogeneous disease, in which several pathophysiological mechanisms may be involved. The major components are diabetic polyneuropathy, occurring in most patients $(>80 \%)$, and peripheral arterial disease $(P A D)^{5}$, which was reported in $10 \%$ to $60 \%$ of the patients ${ }^{2,6-11}$. Infection is often a complicating factor that can markedly alter the course of the disease $^{12}$. Many patients also suffer from other diabetes related co-morbidities that may influence the course of the disease and its treatment. Therefore, different patient and ulcer phenotypes are encountered in daily clinical practice. This diversity in the clinical presentation of diabetic foot patients has hampered clinical research in this area since large numbers of patients are needed to evaluate the most important determinants of outcome. Moreover, it is difficult to generalize data obtained in single-centre cohorts as they may be influenced by referral patterns or specific organizational aspects of these centres.

There are few prospective studies about the clinical outcomes of the causative factors of diabetic foot ulcers. When designing this study in 2000 to 2001, only a large Swedish study had reported on healing, amputation, and death rate in a longitudinally followed cohort ${ }^{13}$. Two studies from the United States have reported on major and minor amputation rates in larger cohorts ${ }^{6,14}$. Subsequently, Oyibo and colleagues have reported on healing, amputation, and death in a transatlantic cohort from Manchester and San Antonio'. Margolis et al have reported on healing in a very large group of purely neuropathic patients ${ }^{15}$. Recently, data have been published on larger cohorts from Germany and the United Kingdom ${ }^{7,16}$. The main determinants of outcome that were identified in these studies include gender, age, size, duration, and presence of PAD. When evaluating these studies, there are, however, striking differences in patient characteristics of the studied cohorts, as well as large differences in definitions of PAD, infection, and wound staging. Also, the assessment of general health status (co-morbidities) has not been taken into account in most studies. 
Relatively little attention has been given to the potentially large impact of the organization of health care on the outcome of diabetic foot ulcers. Usually several disciplines are involved simultaneously, and a coordinated multidisciplinary approach is probably the most efficient treatment strategy. Several retrospective studies have shown that the institution of specialized multidisciplinary foot clinics could result in a reduction of $45 \%$ to $80 \%$ in the number of amputations and days of hospital admission, with possibly an improvement of healing rates and reduction of costs ${ }^{17-21}$. These data suggest that in affluent societies, the organization of care is one of the main determinants of outcome of diabetic foot ulcers. However, given the variety of health care models in these countries, it remains unclear how health care should be organized for this group of patients.

A limited number of pharmacoeconomic studies of diabetic foot disease have been performed in the past. Studies on costs of foot ulcer treatment have mainly been performed in Sweden ${ }^{4,22-24}$. There are currently no data on costs in relation to outcome and whether there are differences in resource utilization between centres for a given outcome. Health-related quality of life (HR-QoL) in diabetic foot disease has been assessed by both generic and disease-specific instruments such as EQ-5d, SF-36, and VAS-QoL ${ }^{25,26}$. HR-QoL in diabetic foot patients is generally low and decreases as long as the ulcer does not heal ${ }^{26}$. Patients with current foot ulcers value their quality of life lower than do primary healed patients, and quality of life is reduced after major amputations ${ }^{25}$. There is, however, little insight into the patient characteristics and aspects of management that determine HR-QoL of foot ulcer patients.

In summary, the outcome of the treatment of diabetic foot ulcers seems to be determined by patient and ulcer characteristics, by the management strategies used, and by the local health care organization. This outcome can be described in clinical terms such as healing or amputation, in terms of quality of life, and in terms of resource utilization, as schematically depicted in Figure 2.1.

The studies described above leave a number of important questions unanswered:

1. What are the patient demographics and foot and ulcer characteristics of individuals treated with foot ulcers?

2. What are the current clinical outcomes of these patients?

3. Which major factors influence clinical outcome?

4. What are the differences in individual and disease specific factors, management strategies, and health care organizational aspects of diabetic foot disease in Europe?

5. What are the European differences in outcome in terms of clinical end points, quality of life, and health care consumption? 


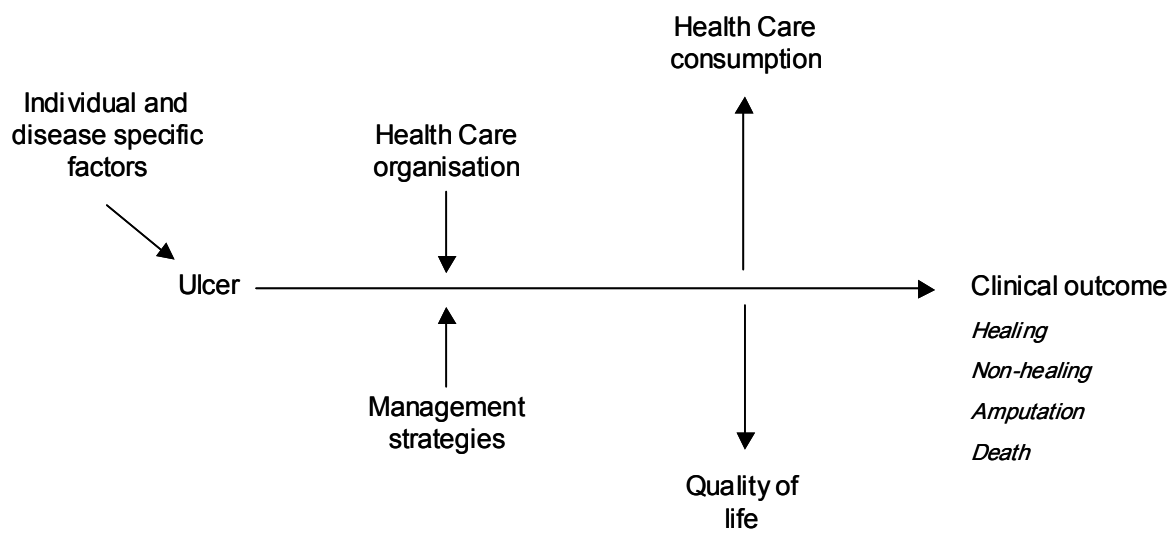

Figure 2.1 Model.

Currently, we do not have data to benchmark the quality of care, and we are unable to identify patients who are at risk of poor outcome following foot ulceration and who need intensive treatment and concomitant resources. Finally, several (inter)national guidelines have been produced that describe the care for patients with a diabetic foot ulcer. However, data are lacking on the level of care that is actually delivered in daily practice and on barriers to the implementation of care as recommended in guidelines.

The Eurodiale group is an independent, multidisciplinary research platform consisting of 14 European centres of excellence in diabetic foot disease. The members of this group joined forces to stimulate research in the field of diabetic foot disease and to address the topics that have been outlined above. The first initiative of the Eurodiale group is the project "Optimal Organization of Health Care in Diabetic Foot Disease," which was funded by the European Commission. This study is a multicentre prospective data collection study following the natural course of the disease in 1232 patients. Foot characteristics as well as patient characteristics (including co-morbidities), management strategies, and health care organization were assessed. Outcome parameters that were measured included clinical (healing of the entire foot, nonhealing, amputation, or death) and also outcome in terms of quality of life and health care consumption, as described in the next section. 


\section{Methods}

\section{Preparatory Phase}

Study design, organizational structure, definitions, and assessments as well as data collection forms were developed during a 2-year preparatory phase in which all participating centres were involved. The plenary meetings resulted in the development of two case record forms (CRFs; entry form and follow-up form) and an extensive manual about the CRF, definitions, and assessments. The data collection forms and the definitions were tested during a pilot study of three months.

\section{Study Design}

"Optimal Organization of Health Care in Diabetic Foot Disease" is a multicentre, observational, prospective, data collection study.

\section{Primary Study Objective}

The main study objective is to determine the major factors determining clinical outcome and outcome in terms of HR-QoL and health care consumption.

\section{Secondary Study Objectives}

1. To describe individual and disease-specific factors, management strategies, and health care organizational aspects of patients with diabetic foot disease in Europe.

2. To describe differences in individual and disease specific factors, management strategies, and health care organizational aspects of patients with diabetic foot disease in Europe.

3. To assess European differences in outcome in terms of clinical end points, quality of life, and health care consumption.

\section{Inclusion Criteria}

Diabetic patients with a foot ulcer who could be followed for one year, presenting for the first time within a period of twelve months at the outpatient or inpatient clinic of each participating centre, were included in the study.

\section{Exclusion Criteria}

Patients treated for an ulcer on the ipsilateral foot during the past twelve months in the participating centres were excluded. These patients were excluded because previous (recent) treatment might bias the analysis of 
resource utilization. Patients with a life expectancy shorter than one year were excluded on account of anticipated problems with follow-up.

\section{End Points}

All patients were followed for a maximum period of one year. Clinical end points were healing of the complete foot for a period of at least 6 weeks, death, and major amputation, defined as a lower extremity amputation below, through, or above the knee. HR-QoL was assessed by the EQ-5d questionnaire. A description and comparison of resource utilization was carried out in all centres, and in selected centres, a cost analysis was performed, which includes direct costs for procedures, antibiotics, and inpatient and outpatient care.

\section{Organizational Structure}

Between September $1^{\text {st }}, 2003$, and October $1^{\text {st }}, 2004$, all consecutive diabetic patients presenting with a new foot ulcer were asked to participate in the study in a multicentre setting of 14 European centres, in 10 European countries. These 14 centres are located in Belgium (Bornen), Czech Republic (Prague), Denmark (Copenhagen), Germany (Rheine, Werl), Italy, (Pisa, Rome), Slovenia (Ljubljana), Spain (Barcelona), Sweden (Malmö/Lund), the Netherlands (Almelo, Maastricht), and the United Kingdom (London, Ashton under Lyne). All consecutive inpatients and outpatients, treated in the participating centres, irrespective of the specialty involved, were included. The patients had to be followed on a monthly basis until healing of the foot, death, or major amputation or up to a maximum of one year. The local ethics committees of the 14 hospitals approved the study protocol, and all patients gave prior written informed consent.

\section{Data Collection}

At study entry, baseline data were collected using a standardized entry (case record) form. At the entry visit, data were collected on the patient and foot and ulcer characteristics, social background, previous (before study entry) management of the ulcer, referral patterns, and causes of the ulcer. All patients underwent a standardized examination according to the PEDIS (Perfusion/ Extent/Depth/Infection/Sensation) classification system ${ }^{27,28}$. This system was developed by the International Consensus on the Diabetic Foot to classify patients for clinical research purposes. During follow-up, observational data were collected every four weeks using a follow-up (case record) form; data were collected on patient, foot, and ulcer characteristics and ulcer management during the past four weeks (diagnostics, antibiotic use, interventions, offloading, 
admission, and wound care). Data about health care organization were collected during on-site visits and structured interviews; data were collected on the presence of competences, resources, protocols, and the organization of inpatient, outpatient, and emergency care.

HR-QoL was measured using the EuroQol quality of-life questionnaire (EQ-5d) at the first visit and at the last follow-up visit. Resource utilization and costs were evaluated using a standardized costing form designed by the Swedish Institute of Health Economics in cooperation with the Eurodiale study group. Data were collected on the number of diagnostic procedures, antibiotic use, type and number of offloading modalities, number of interventions, number of days of in-hospital stay, and number and type of dressings.

\section{Audit/Quality Control}

Before the start of the study, all participating centres were visited to train the health care professionals involved on how to use the CRF and how to interpret definitions. These visits were repeated during the first months of the study. All definitions and the design of the study were described in an extensive study manual. Completed CRFs were returned to the coordinating centre in Maastricht, where each form was checked manually, and queries were sent out to the participating centres in case of missing or inconsistent data. All forms were scanned automatically and transformed into ASCII files by the Memic Institute in Maastricht.

\section{Important Definitions and Assessments}

The most important definitions and assessments used in the study protocol are described below.

\section{Ulcer}

A foot ulcer was defined as a full thickness lesion below the ankle.

\section{Perfusion assessment and PAD}

Perfusion assessment, following PEDIS guidelines, included evaluation of the presence of pedal pulses and measurement of the ankle-brachial pressure index (ABPI) using a handheld Doppler device. The presence of PAD was defined as an $\mathrm{ABPI}<0.9$ and/or two absent foot pulses ${ }^{27}$. In addition, we graded an $\mathrm{ABPI}<0.5$ as severe limb ischemia. 


\section{Extent}

Extent was determined by multiplying the largest diameter by the second largest diameter perpendicular to the first ${ }^{27}$.

\section{Depth}

Depth was described as superficial or deep: a superficial ulcer was a full thickness lesion of the skin not extending through the subcutis and a deep ulcer a lesion of the skin extending through the subcutis.

\section{Infection}

Infection was diagnosed if two or more of the following signs were present: frank purulence, local warmth, erythema, lymphangitis, oedema, pain, fever, and malodor.

\section{Neuropathy}

Evaluation of sensation (neuropathy) included pressure sensation (10-g monofilament on plantar aspect of hallux, metatarsophalangeal joints 1 and 5), tactile sensation (cotton wisp on the dorsum of the foot), vibration sensation (128- $\mathrm{Hz}$ tuning fork on the dorsum of the hallux), and sharp/blunt discrimination (dorsum of the foot) ${ }^{27}$. Neuropathy was diagnosed if two or more of the aforementioned tests were abnormal ${ }^{27,28}$.

In addition, the location of the ulcer was described (six predefined areas: plantar toes, dorsal/interdigital aspect of the toes, dorsal/lateral aspect of the foot, plantar forefoot or midfoot, plantar hindfoot, heel). In all patients, serum glycosylated hemoglobin and serum creatinine levels were determined in the participating hospitals.

\section{Classification of foot disease}

The presence of PAD and infection in patients with diabetic foot ulcers are major factors contributing to clinical outcome in terms of healing rates, healing time, and amputation ${ }^{6}$. Foot ulcers were therefore categorized into four stages according to presence of infection and PAD; this classification is similar to the stages of the University of Texas classification, which uses in general the same diagnostic criteria as described above ${ }^{6}$. 


\section{Results}

Following a 13-month inclusion period, 1232 patients were included in the study. The mean number of patients per centre was 88 (range, 40-125; see Figure 2.2). Thirty-seven percent of these patients were referred by medical specialists; $63 \%$ were referred either by their general practitioners or were selfreferrals. Twenty-seven percent of the patients were admitted to the hospital at the time of inclusion. The baseline characteristics of the patients are described in Table 2.1. A total of 1088 subjects were followed until end point (healing, death, or major amputation) or for a maximum of one year. Twelve percent (144 subjects) dropped out of the study. Reasons for drop out were noncompliance, inability to follow the patient (lack of transportation, no social support, too sick to come), or care had been taken over by other specialists. The baseline characteristics of the dropouts are shown in Table 2.2.

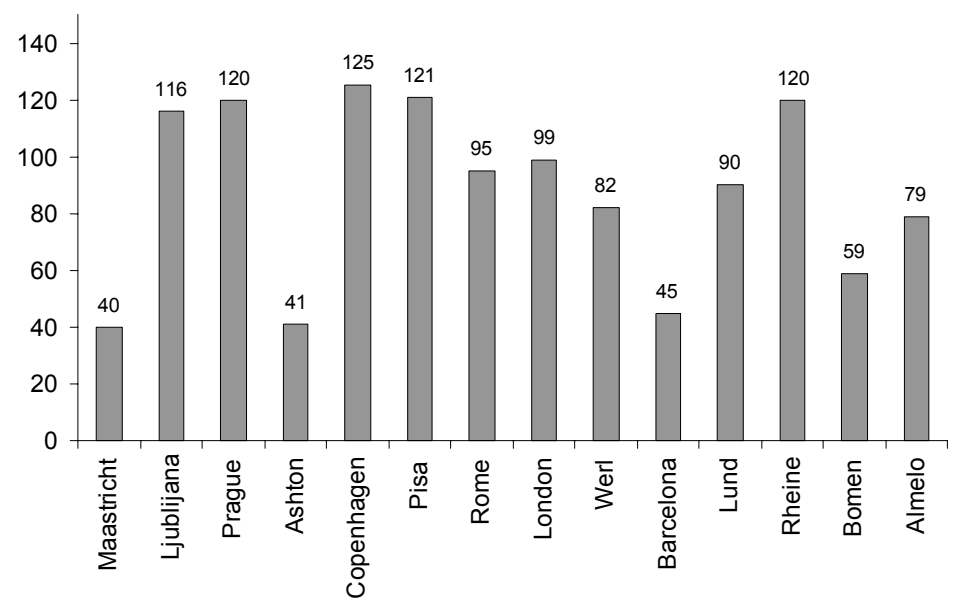

Figure 2.2 Number of included patients per centre.

Table 2.1 General patient characteristics.

\begin{tabular}{lc}
\hline Characteristic $^{\mathrm{a}}$ & $\%$ \\
\hline Age, years & \\
Male gender & $65 \pm 12$ \\
Glycosylated hemoglobin $>8.4 \%$ & 64 \\
Duration of diabetes $>10$ years & 49 \\
Disabling co-morbidity & 70 \\
\hline
\end{tabular}

${ }^{\text {a }}$ Mean \pm SD. 
Table 2.2 General patient characteristics of dropouts.

\begin{tabular}{|c|c|}
\hline Characteristic & $\%$ \\
\hline Age, years $^{a}$ & $68 \pm 12$ \\
\hline Male gender & 59 \\
\hline Glycosylated hemoglobin $>8.4 \%$ & 33 \\
\hline Duration of diabetes $>10$ years & 75 \\
\hline Disabling co-morbidity & 32 \\
\hline
\end{tabular}

${ }^{\text {a }}$ Mean \pm SD.

\section{Discussion}

In this article, we have described the design of a large, prospective data collection study in the field of diabetic foot disease. This study will provide us with a large volume of new and relevant data on patients with diabetic foot ulcers in Europe. However, it has a number of limitations: the study is not an epidemiological study reporting on the characteristics of all incident ulcers in certain European regions. Although very interesting, such a study would require screening of many thousands of patients in primary care and is therefore probably not feasible. Second, the number of items on which data were collected was limited because data should reflect daily clinical practice and therefore had to be obtained during daily clinical practice. Data collection was focused on those characteristics that were considered to be related to outcomes. Also, our cohort does not fully reflect the total population attending the participating clinics since we excluded patients with a previous ulcer within a period of 12 months.

In conclusion, "Optimal Organization of Health Care in Diabetic Foot Disease" is one of the first large multicentre studies in the field of diabetic foot disease on clinical presentation, clinical outcome, quality of life, resource utilization, and health care organization and their interrelationships. The first reports of this study will be in spring 2007. These data should provide us with new insights that enable us to improve care for these patients and guide the development of new studies in this area. 


\section{References}

1. Wild S, Roglic G, Green A, Sicree R, King H. Global prevalence of diabetes: estimates for the year 2000 and projections for 2030. Diabetes Care 2004;27:1047-1053

2. Apelqvist J, Bakker K, van Houtum WH, Nabuurs-Franssen MH, Schaper NC. International Consensus on the Diabetic Foot. Schaper NC, Maastricht 1999

3. Apelqvist $\mathrm{J}$, Larsson $\mathrm{J}$. What is the most effective way to reduce incidence of amputation in the diabetic foot? Diabetes Metab Res Rev 2000;16 S1:S75-83

4. Brod M. Quality of life issues in patients with diabetes and lower extremity ulcers: patients and care givers. Qual Life Res 1998;7:365-372

5. Nabuurs-Franssen MH, Huijberts MS, Nieuwenhuijzen Kruseman AC, Willems J, Schaper NC. Health-related quality of life of diabetic foot ulcer patients and their caregivers. Diabetologia 2005;48:1906-1910

6. Ragnarson Tennvall G, Apelqvist J. Health-related quality of life in patients with diabetes mellitus and foot ulcers. J Diabetes Complications 2000;14:235-241

7. Larsson J, Agardh CD, Apelqvist J, Stenstrom A. Long-term prognosis after healed amputation in patients with diabetes. Clin Orthop Relat Res 1998:149-158

8. Ragnarson Tennvall G, Apelqvist J. Health-economic consequences of diabetic foot lesions. Clin Infect Dis 2004;39 S2:S132-139

9. Apelqvist J, Ragnarson-Tennvall G, Larsson J, Persson U. Long-term costs for foot ulcers in diabetic patients in a multidisciplinary setting. Foot Ankle Int 1995;16:388-394

10. Boulton AJ. The diabetic foot: from art to science. The 18th Camillo Golgi lecture. Diabetologia 2004;47:1343-1353

11. Cavanagh PR, Lipsky BA, Bradbury AW, Botek G. Treatment for diabetic foot ulcers. Lancet 2005;366:1725-1735

12. Frykberg RG. An evidence-based approach to diabetic foot infections. Am J Surg 2003;186: 44S-54S; discussion 61S-64S

13. Reiber GE, Vileikyte L, Boyko EJ, del Aguila M, Smith DG, Lavery LA, Boulton AJ. Causal pathways for incident lower-extremity ulcers in patients with diabetes from two settings. Diabetes Care 1999;22:157-162

14. Boulton AJ. The pathogenesis of diabetic foot problems: an overview. Diabet Med 1996;13 S1:S12-16

15. Ziegler D. Diagnosis and management of diabetic peripheral neuropathy. Diabet Med 1996;13 S1:S34-38

16. Ahroni JH, Boyko EJ, Forsberg RC. Clinical correlates of plantar pressure among diabetic veterans. Diabetes Care 1999;22:965-972

17. Fernando DJ, Masson EA, Veves A, Boulton AJ. Relationship of limited joint mobility to abnormal foot pressures and diabetic foot ulceration. Diabetes Care 1991;14:8-11

18. Murray HJ, Young MJ, Hollis S, Boulton AJ. The association between callus formation, high pressures and neuropathy in diabetic foot ulceration. Diabet Med 1996;13:979-982

19. Schaper NC, Apelqvist J, Bakker K. The international consensus and practical guidelines on the management and prevention of the diabetic foot. Curr Diab Rep 2003;3:475-479

20. Beks PJ, Mackaay AJ, de Neeling JN, de Vries H, Bouter LM, Heine RJ. Peripheral arterial disease in relation to glycaemic level in an elderly Caucasian population: the Hoorn study. Diabetologia 1995;38:86-96

21. Beach KW, Bedford GR, Bergelin RO, Martin DC, Vandenberghe N, Zaccardi M, Strandness DE Jr. Progression of lower-extremity arterial occlusive disease in type II diabetes mellitus. Diabetes Care 1988;11:464-472

22. Conrad MC. Large and small artery occlusion in diabetics and nondiabetics with severe vascular disease. Circulation 1967;36:83-91

23. Faglia E, Favales F, Quarantiello A, Calia P, Clelia P, Brambilla G, Rampoldi A, Morabito A. Angiographic evaluation of peripheral arterial occlusive disease and its role as a prognostic determinant for major amputation in diabetic subjects with foot ulcers. Diabetes Care $1998 ; 21: 625-630$ 
24. Jude EB, Oyibo SO, Chalmers N, Boulton AJ. Peripheral arterial disease in diabetic and nondiabetic patients: a comparison of severity and outcome. Diabetes Care 2001;24: 1433-1437

25. McDaniel MD, Cronenwett JL. Basic data related to the natural history of intermittent claudication. Ann Vasc Surg 1989;3:273-277

26. Vigna GB, Fellin R. Dyslipidemia in peripheral vascular disease. Curr Opin Lipidol 1996;7: 254-259

27. Clausell N, Kalil P, Biolo A, Molossi S, Azevedo M. Increased expression of tumor necrosis factor-alpha in diabetic macrovasculopathy. Cardiovasc Pathol 1999;8:145-151

28. O'Neal DN, Lewicki J, Ansari MZ, Matthews PG, Best JD. Lipid levels and peripheral vascular disease in diabetic and non-diabetic subjects. Atherosclerosis 1998;136:1-8

29. Pedersen TR, Kjekshus J, Pyörälä K, Olsson AG, Cook TJ, Musliner TA, Tobert JA, Haghfelt $T$. Effect of simvastatin on ischemic signs and symptoms in the Scandinavian simvastatin survival study (4S). Am J Cardiol 1998;81:333-335

30. Valentine RJ, Grayburn PA, Vega GL, Grundy SM. Lp(a) lipoprotein is an independent, discriminating risk factor for premature peripheral atherosclerosis among white men. Arch Intern Med 1994;154:801-806

31. Delamaire M, Maugendre D, Moreno M, Le Goff MC, Allannic H, Genetet B. Impaired leucocyte functions in diabetic patients. Diabet Med 1997;14:29-34

32. Mowat A, Baum J. Chemotaxis of polymorphonuclear leukocytes from patients with diabetes mellitus. N Engl J Med 1971;284:621-627

33. Davidson NJ, Sowden JM, Fletcher J. Defective phagocytosis in insulin controlled diabetics: evidence for a reaction between glucose and opsonising proteins. J Clin Pathol 1984;37: 783-786

34. Repine JE, Clawson CC, Goetz FC. Bactericidal function of neutrophils from patients with acute bacterial infections and from diabetics. J Infect Dis 1980;142:869-875

35. Eneroth M, Apelqvist J, Stenstrom A. Clinical characteristics and outcome in 223 diabetic patients with deep foot infections. Foot Ankle Int 1997;18:716-722

36. Lipsky BA, Berendt AR, Deery HG, Embil JM, Joseph WS, Karchmer AW, LeFrock JL, Lew DP, Mader JT, Norden C, Tan JS; Infectious Diseases Society of America. Diagnosis and treatment of diabetic foot infections. Clin Infect Dis 2004;39:885-910

37. Rauwerda JA. Foot debridement: anatomic knowledge is mandatory. Diabetes Metab Res Rev 2000;16 S1:S23-26

38. Lipsky BA. A report from the international consensus on diagnosing and treating the infected diabetic foot. Diabetes Metab Res Rev 2004;20 S1:S68-77

39. Lipsky BA, Armstrong DG, Citron DM, Tice AD, Morgenstern DE, Abramson MA. Ertapenem versus piperacillin/tazobactam for diabetic foot infections (SIDESTEP): prospective, randomised, controlled, double-blinded, multicentre trial. Lancet 2005;366:1695-1703

40. Margolis DJ, Allen-Taylor L, Hoffstad O, Berlin JA. Diabetic neuropathic foot ulcers: the association of wound size, wound duration, and wound grade on healing. Diabetes Care 2002;25:1835-1839

41. Armstrong DG, Lavery LA, Harkless LB. Validation of a diabetic wound classification system. The contribution of depth, infection, and ischemia to risk of amputation. Diabetes Care 1998;21:855-859 
32 


\section{Chapter 3}

High prevalence of ischemia, infection and serious co-morbidity in patients with diabetic foot disease in Europe.

Baseline results from the Eurodiale study

Prompers L, Huijberts M, Apelqvist J, Jude E, Piaggesi A, Bakker K, Edmonds M, Holstein P, Jirkovska A, Mauricio D, Ragnarson Tennvall G, Reike H, Spraul M, Uccioli L, Urbancic V, van Acker K, van Baal J, van Merode F, Schaper N.

Diabetologia 2007;50:18-25 


\section{Abstract}

Aims/hypothesis

Large clinical studies describing the typical clinical presentation of diabetic foot ulcers are limited and most studies were performed in single centres with the possibility of selection of specific subgroups. The aim of this study was to investigate the characteristics of diabetic patients with a foot ulcer in 14 European hospitals in ten countries.

\section{Methods}

The study population included 1,229 consecutive patients presenting with a new foot ulcer between 1 September 2003 and 1 October 2004. Standardised data on patient characteristics, as well as foot and ulcer characteristics, were obtained. Foot disease was categorised into four stages according to the presence or absence of peripheral arterial disease (PAD) and infection: $A$ : PAD -, infection -; B: PAD -, infection +; C: PAD +, infection -; D: PAD +, infection + .

\section{Results}

PAD was diagnosed in $49 \%$ of the subjects, infection in $58 \%$. The majority of ulcers $(52 \%)$ were located on the non-plantar surface of the foot. With regard to severity, $24 \%$ had stage $A, 27 \%$ had stage $B, 18 \%$ had stage $C$ and $31 \%$ had stage $D$ foot disease. Patients in the latter group had a distinct profile: they were older, had more non-plantar ulcers, greater tissue loss and more serious co-morbidity.

\section{Conclusions/interpretation}

According to our results in this European cohort, the severity of diabetic foot ulcers at presentation is greater than previously reported, as one-third had both PAD and infection. Non-plantar foot ulcers were more common than plantar ulcers, especially in patients with severe disease, and serious co-morbidity increased significantly with increasing severity of foot disease. Further research is needed to obtain insight into the clinical outcome of these patients. 


\section{Introduction}

One in every seven individuals with diabetes will suffer from a foot ulcer during their lifetime ${ }^{1,2}$; many of these ulcers will need intensive treatment and hospitalisation, healing often takes months, and some patients will eventually lose their leg. Given the high costs associated with these ulcers, this disease is not only a major burden to the patient but also to the health care system ${ }^{3}$, and there is growing awareness that more attention should be given to this condition ${ }^{4}$. The development of a foot ulcer usually involves several mechanisms, such as neuropathy, increased biomechanical stress, external trauma and peripheral arterial disease (PAD) $)^{5}$. Moreover, these ulcers are often complicated by infection ${ }^{6}$. Thus, different presentations of foot ulcers can be encountered in clinical practice, and management strategies, outcome and resource utilisation are strongly influenced by characteristics of these, such as the presence of PAD, the presence of infection and, probably, the presence of co-morbidity ${ }^{1,7}$. The number of large studies reporting on patient and ulcer characteristics is limited, but significant differences in the underlying pathologies and patient characteristics have been reported ${ }^{1,8-10}$. These differences might be related to factors such as race and variation in demographics, but it is also likely that the characteristics of the local healthcare organisation will determine the type of patients that are reported on, owing to differences in referral. In many centres, patients with neuropathic or mildly neuroischemic ulcers are treated in foot clinics, while patients with severe ischemia and deep foot infections are admitted to surgical wards. From several studies there emerges a 'classic' picture of a patient with a neuropathic ulcer on the plantar surface of the foot ${ }^{1,8,11,12}$; with optimal therapy $>80 \%$ of these 'uncomplicated' ulcers can heal within three months ${ }^{13-15}$. One might therefore question whether some studies provide an image of diabetic foot disease that is biased towards the least complicated foot ulcers or a specific subset of patients.

The European Study Group on Diabetes and the Lower Extremity (Eurodiale) is a collaborative network of 14 European centres, originally created to stimulate multidisciplinary research in the field of diabetic foot disease. One of the main aims of the Eurodiale group is to obtain data on clinical outcome in patients with different ulcer phenotypes and disease severity to provide international reference data for healing rate and healing time, as well as data on adverse outcomes such as non-healing, amputation and death. In addition, the identification of the main determinants of outcome was an important objective of this study.

Therefore this multi-disciplinary group, comprising diabetologists, vascular surgeons and orthopaedic surgeons, initiated a prospective data collection study, in which baseline and 12-month follow-up data on all patients treated in 
these centres for a new foot ulcer were collected. The study was designed in such a way that data collection was possible during daily practice, in order to recruit a cohort as unselected as possible. This report provides an overview of the baseline characteristics of the Eurodiale cohort to present a picture of the severity of this disease in the 'average' European patient with a diabetic foot ulcer.

\section{Subjects and methods}

\section{Study design}

All consecutive diabetic patients presenting with a new foot ulcer between 1 September 2003 and 1 October 2004 were asked to participate in the study; 1,229 patients attending 1 of 14 diabetic foot centres in ten European countries were included and followed until healing or major amputation or for the maximum period of one year. Follow-up visits were performed every four weeks. At baseline and during all follow-up visits, data were recorded on standardised case record forms. The baseline and follow-up forms were designed by the Eurodiale group during a 1-year preparatory phase and were tested in a pilot study. In total, 80 items were to be collected at baseline to describe the most important individual and disease-specific factors that might influence management strategies and outcome. All personnel involved in the data collection were trained on several occasions (including site visits) in the use of the case record form and the techniques required to obtain the data. All case record forms were sent to the primary study centre where they were checked by data managers. If there were missing data or inconsistencies, the participating centre was contacted to obtain additional information. Subsequently, the forms were scanned and transformed into ASCII files.

A foot ulcer was defined as a full-thickness lesion below the ankle. Exclusion criteria were treatment for an ulcer on the same foot during the 12 months before inclusion and a life expectancy shorter than one year. Both patients presenting with a foot ulcer at the outpatient clinic and those admitted to hospital were recruited, irrespective of the specialist primarily responsible for the patient's care. The mean number of patients per centre was 88 (range 40-126). Thirty-seven per cent of the included patients were referred by a medical specialist; the others were referred by their general practitioner or were self-referrals. The local ethics committees of the 14 hospitals approved the study protocol and all patients gave written informed consent. 


\section{Patient and foot characteristics}

The patient characteristics recorded included co-morbidity, living conditions and previous management. Disabling co-morbidity was defined as the presence of severe visual impairment (defined as the inability to read a newspaper after correction), end-stage renal disease (defined as renal replacement therapy), heart failure and/or angina pectoris New York Heart Association (NYHA) classification III or IV, and/or the inability to stand or walk without help. Various techniques and definitions can be used to describe the underlying pathology of a foot ulcer to assess and classify its severity. In this study all patients underwent a standardised examination according to the PEDIS system, which classifies foot ulcers according to five categories: perfusion, extent, depth, infection and sensation ${ }^{16,17}$. This system was developed by the International Consensus on the Diabetic Foot for the classification of patients for clinical research purposes. Perfusion assessment followed PEDIS guidelines and included evaluation of the presence of pedal pulses and measurement of the ankle-brachial pressure index (ABPI) using a handheld Doppler device. The presence of PAD was defined as an ABPI of $<0.9$ and/or two absent foot pulses ${ }^{16}$. In addition, we graded an ABPI of $<0.5$ as severe limb ischemia. Extent was determined by multiplying the largest diameter by the second largest diameter perpendicular to the first ${ }^{16}$. Depth was described as superficial or deep: a superficial ulcer was a full-thickness lesion of the skin not extending through the subcutis, and a deep ulcer was a lesion of the skin extending through the subcutis. Infection was diagnosed if two or more of the following signs were present: frank purulence, local warmth, erythema, lymphangitis, oedema, pain, fever and foul smell. Evaluation of sensation (neuropathy) included pressure sensation (10 g monofilament on plantar aspect of hallux, metatarsophalangeal joint 1 and 5), tactile sensation (cotton wisp on the dorsum of the foot), vibration sensation ( $128 \mathrm{~Hz}$ tuning fork on the dorsum of the hallux) and blunt/sharp discrimination (dorsum of the foot) 16 . Neuropathy was diagnosed if the results of two or more of the aforementioned tests were abnormal ${ }^{16}$. In addition, the location of the ulcer was described (six predefined areas). In all patients, serum $\mathrm{HbA}_{1 c}$ and serum creatinine levels were determined at each participating hospital.

\section{Classification of foot disease}

The presence of PAD and infection in patients with diabetic foot ulcers are major factors contributing to clinical outcome in terms of healing rates, healing time and amputation ${ }^{8}$. Foot ulcers were therefore categorised into four stages according to presence or absence of infection and PAD (Table 3.1); these stages are similar to those of the University of Texas system ${ }^{8}$. Using this 
classification, healing rates of $90 \%$ in stage $A, 89 \%$ in stage $B, 69 \%$ in stage $C$ and $36 \%$ in stage $\mathrm{D}$ were reported ${ }^{13}$.

Table 3.1 Classification of foot disease.

\begin{tabular}{lccc}
\hline Stage & Definition & Number of patients & Percentage of study population \\
\hline A & PAD -, infection - & 270 & 24 \\
B & PAD -, infection + & 305 & 27 \\
C & PAD +, infection - & 205 & 18 \\
D & PAD +, infection + & 347 & 31 \\
\hline
\end{tabular}

\section{Statistical analysis}

Statistical analysis was performed using the SPSS statistical package, version 11.0 (SPSS, Chicago, IL, USA). As most data were scored as categories, the data are expressed as frequencies. Comparisons between groups were made using the $\chi_{2}$ test; statistical significance was defined as a $p$ value of $<0.05$.

\section{Results}

\section{Patient characteristics}

At the time of study entry, $27 \%$ of all patients were admitted to the hospital. Sixty-three per cent of the patients were either previously managed in primary care or did not receive any treatment before inclusion. General patient characteristics (Table 3.2) were similar in all centres. Disabling co-morbidity was present in $32 \%$ of the patients: severe visual impairment in $15 \%$, endstage renal disease in $6 \%$, heart failure and/or angina pectoris NYHA III/IV in $11 \%$, and the inability to stand or walk without help in $10 \%$ of all patients. Sixty per cent of the patients were not selfcaring but had a partner or relative who was involved in daily personal care; $18 \%$ of the patients were unemployed, $19 \%$ were employed and $64 \%$ were retired at study entry.

Table 3.2 General characteristics of the patients.

\begin{tabular}{lc}
\hline Characteristic & $\%$ \\
\hline Age, years & a \\
Male gender & $65 \pm 12$ \\
Glycosylated hemoglobin $>8.4 \%$ & 64 \\
Duration of diabetes $>10$ years & 49 \\
Disabling co-morbidity & 70 \\
\hline
\end{tabular}




\section{Ulcer and foot characteristics}

Among this cohort, PAD was present in $49 \%$; however this value is possibly an underestimation as $32 \%$ of the ABPIs were $>1.2$ and were therefore unreliable. PAD occurred more frequently in older patients (in $71 \%$ of patients aged $>70$ years) and in patients with disabling co-morbidity $(60 \%)$. Severe limb ischemia, defined as an ABPI of $<0.5$, was present in 113 patients ( $12 \%$ of all patients). Diabetic neuropathy was diagnosed in $86 \%$; other neurological disorders resulting in loss of sensory or motor function (e.g. cerebrovascular accident) were present in $7 \%$.

\section{Infection}

At the time of examination, $58 \%$ of the ulcers were infected; however, of the patients admitted to hospital, $82 \%$ had evidence of infection. In patients with PAD, infection was diagnosed more frequently (63 vs. $53 \%, p<0.05$ ).

\section{Location, size, depth and duration}

Data on ulcer location are shown in Figure 3.1. More than half of the ulcers $(52 \%)$ were non-plantar ulcers. The most frequent ulcer site was the dorsal or interdigital area of the toes (32\%). The classic plantar forefoot or midfoot ulcer was present in $22 \%$ of the patients. Almost half of the patients $(45 \%)$ had deep ulcers that extended into tissue below the subcutis (e.g. tendons, muscle or bone). Ulcer size was between 1 and $5 \mathrm{~cm}^{2}$ in the majority of the patients $(52 \%)$, and was $>5 \mathrm{~cm}^{2}$ in $11 \%$. The duration of the ulcer at study entry was shorter than 1 week in $16 \%$ of the patients, between one week and three months in $57 \%$, and $>3$ months in $27 \%$.

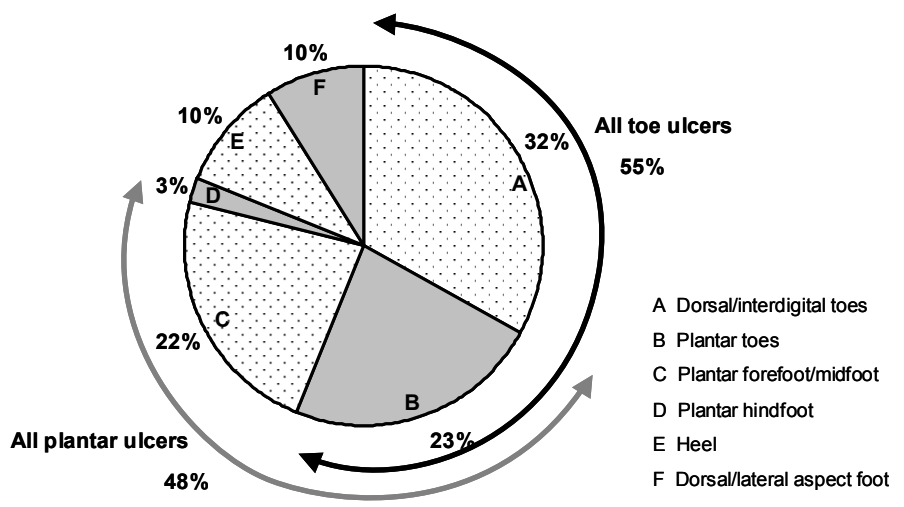

Figure 3.1 Data on ulcer location. 


\section{Patient and ulcer characteristics in relation to severity of disease}

Data on disease classification are shown in Table 3.1 and Figure 3.2. Both infection and PAD were present in $31 \%$ of the patients (stage D). Ulcers in these patients were more often deep (64 vs. $20 \%$ in stage $A ; p<0.001)$ and $>5$ $\mathrm{cm}_{2}$ (20 vs. $4 \%$ in stage $\left.A, p<0.001\right)$. Stage $D$ ulcers were also more often nonplantar (65 vs. $36 \%$ in stage $A, p<0.001$; Figure $3.2 a$ ). Increasing disease severity was associated with age $(56 \%$ in stage $D$ vs. $22 \%$ in stage $A$ were aged $>70$ years, $p<0.001$; Figure $3.2 \mathrm{~b}$ ) and the prevalence of disabling comorbidity ( $38 \%$ in stage $D$ vs. $23 \%$ in stage $A, p<0.001$; Figure $3.2 c$ ). The same pattern was observed for each co-morbidity; Figure 3.2d shows the relationship between disease stage and visual impairment. The distribution of patients from stage $A$ to $D$ was similar for the group of referrals from primary care and the group referred by other specialists.
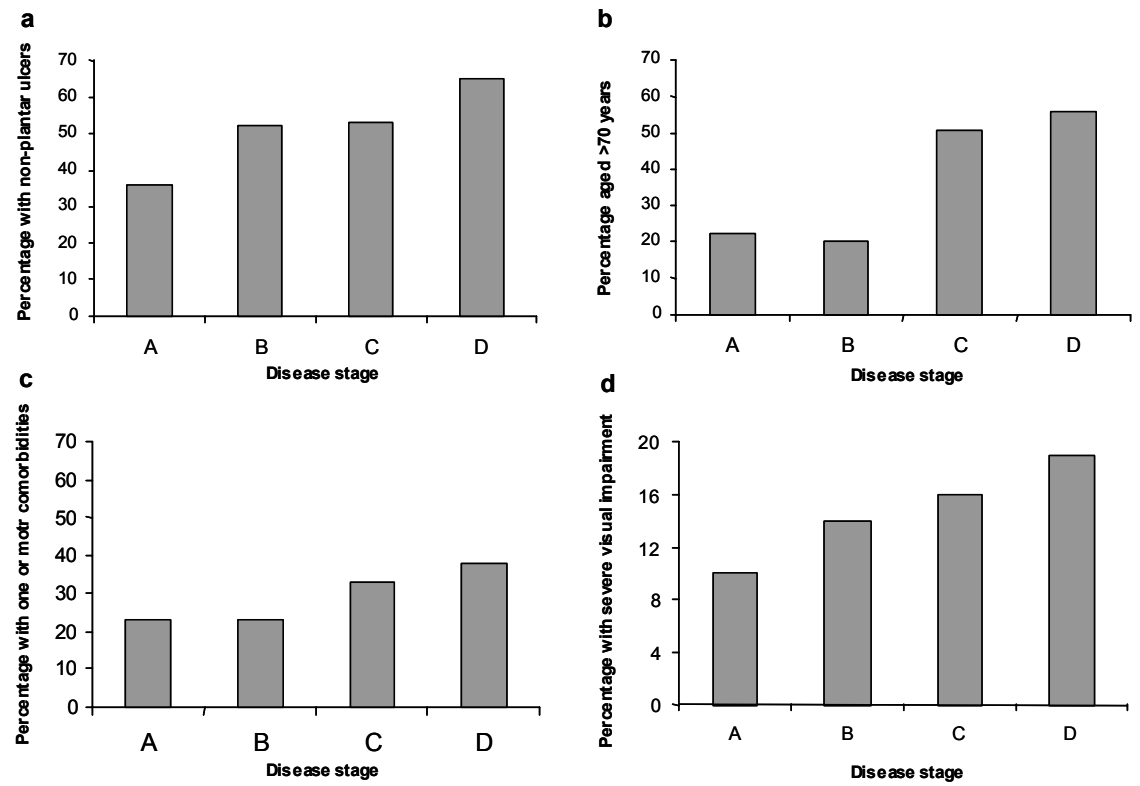

Figure 3.2 Disease stage (A: PAD -, infection -; B: PAD -, infection +; C: PAD +, infection -; D: $P A D+$, infection + ) vs. the following ulcer and patient characteristics: a percentage with non-plantar ulcers, b percentage aged $>70$ years, c percentage with one or more co-morbidities, d percentage with severe visual impairment. 


\section{Discussion}

In this paper data are presented on disease severity and the relationship with patient characteristics in a cross-section of patients treated in clinics throughout Europe interested in the diabetic foot. Data were obtained in 1,229 diabetic patients with a new ulcer who were treated in 14 participating hospitals. One of the strengths of this study is that it reflects daily clinical practice. The main findings are that a large number of patients have severe disease (both infection and PAD were present in one-third of the patients); non-plantar foot ulcers are more common than plantar ulcers, especially in patients with severe disease; and serious co-morbidity increases significantly with increasing severity of foot disease.

PAD and the presence of infection are well-known prognostic factors in diabetic foot disease ${ }^{1}$, but how often do we encounter these problems in patients with foot ulcers? Knowledge of the frequencies of the different ulcer phenotypes is essential to predict outcome, to determine management strategies and to allocate resources. In patients with diabetic foot ulcers the prevalence of PAD varies substantially between studies; indeed, in three studies that included up to 360 patients the reported prevalence ranged from 10 to $60 \%, 8,-21$. In our study, PAD was present in $49 \%$ of patients, but varied from 22 to $73 \%$ in the different centres. This variation is difficult to explain and could be related to differences in the prevalence of PAD, but is more likely due to differences in health care organisation resulting in different referral patterns. These differences could also (in part) explain the differences in PAD prevalence in the aforementioned studies. Although our data indicate that PAD is common in foot ulcer patients, the degree of peripheral ischemia can vary substantially between patients and, unfortunately, physical examination is of limited value ${ }^{22}$. In non-diabetic patients, measurement of the ABPI is the cornerstone of the evaluation of $P A D^{23}$. However, in diabetic patients, non-compressibility of the lower leg arteries can occur as a result of media calcification (Mönckeberg's sclerosis), which produces a falsely elevated ABPI. Indeed, in our study, noncompressible lower leg arteries (defined as an ABPI of $>1.2$ ) were observed in $32 \%$ of the patients. As ABPI values below 0.9 are clearly indicative of PAD both in non-diabetic and diabetic patients, we are confident that these patients were correctly categorised as having PAD. However, the use of a more sensitive instrument would probably have resulted in an even higher prevalence of PAD in our patients with an ABPI of $>0.9$. Alternative techniques for diagnosis of $P A D$, such as systolic toe pressure measurements or duplex scanning of the lower leg, were not available at all participating centres. Transcutaneous oxygen pressure can be used to predict the chance of healing of ischemic foot ulcers ${ }^{23,24}$; however, measurements are affected by the presence of neuropathy, infection and oedema ${ }^{25}$. Based on these 
considerations the combination of palpation of pulses and Doppler pressure measurement was chosen, as formulated by the International Consensus on the Diabetic Foot in their report on classification of foot ulcers for research purposes ${ }^{16}$. We also found also a relatively high prevalence of infection. In this study, $58 \%$ of all ulcers were infected at presentation according to predefined criteria; infection rates of $35-50 \%$ were reported in the majority of earlier studies $^{8,18,19}$.

In previous reports the combination of PAD and infection was associated with the poorest outcome. In the validation study of the University of Texas wound classification system ${ }^{8}$, patients with the combination of infection and ischemia were 90 times more likely to undergo a midfoot or higher amputation than those with less advanced wound stages. In the total contact cast study of NabuursFranssen et al. ${ }^{13}$, the healing rate of patients with mild to moderate ischemia and infection was only $36 \%$, compared with a rate of $90 \%$ in patients with neuropathy with or without infection. Not many studies on patients with a foot ulcer report on the relative proportion of the study population with a high-risk profile. In three earlier studies these unfavourable disease characteristics were present in $5-15 \%$ of patients, whereas the proportion of our cohort with this profile was much higher $(31 \%)^{8,18,19}$.

Our results clearly indicate that the ulcer and patient characteristics of this large group of patients with PAD and infection are different from those of patients with neither PAD nor infection. The ulcers in the former patients are mainly non-plantar (65\%) and are associated with more extensive tissue loss as they were also deeper and larger. It is evident that these patients are older and more frail, since serious co-morbidity also clusters in this group.

Our findings have a number of implications. With regard to evidence-based management of diabetic foot ulcers, we might conclude that there is little evidence on how to treat the patients with the most severe disease, who make up a significant proportion of the patients seen in the foot clinic. Although relatively high rates of non-plantar foot ulceration $(40-50 \%)$ have previously been observed ${ }^{1,26}$, earlier studies and guidelines focused on plantar foot ulceration in neuropathic patients. Examples include plantar pressure measurements ${ }^{12}$, insoles for the prevention of plantar forefoot and midfoot ulcers $^{27}$, and total contact casting ${ }^{14}$. There are very few studies on the management of nonplantar ulcers, despite the fact that healing rates might be lower in dorsal compared with plantar ulcers ${ }^{28}$. Studies on the treatment of PAD in diabetic foot disease are also scarce, and many questions remain to be answered. It is unclear at what degree of peripheral ischemia intervention is cost-effective and which procedure -bypass or endovascular interventionshould be performed ${ }^{29,30}$. Treatment of infection in patients with PAD is another topic that has gained little attention. It has been shown that penetration of antibiotics is poorer in patients with $P A D^{31}$, but in several important trials on the 
treatment of infection in diabetic foot disease PAD was present in only a minority of patients ${ }^{32,33}$. The high number of patients with severe foot disease will also have implications for healthcare costs in view of the expected poor healing, the required diagnostic and interventional procedures, the use of antibiotics and the need for hospital admissions. Moreover, with regard to treatment, given the presence of significant co-morbidities, a comprehensive, multidisciplinary approach is required. One may propose that allocation of resources should be adjusted to the relative proportion of patients with less severe (no PAD and no infection) vs. severe disease (PAD plus infection). This study also shows that the patients with the poorest general health status have the most severe foot disease, and will need the most intensive therapy. This implies that the burden of disease is highest in those who are least able to cope with it. This should prompt caregivers to adapt management strategies to the specific characteristics of this group.

It is evident that this study has several limitations. It is a hospital-based observational study evaluating consecutive patients who were treated in European centres interested in diabetic foot care. The Eurodiale cohort included patients referred from a primary care setting or by other specialists, as well as patients not specifically referred. One-third of the patients were referred by other specialists, either from the same hospital or from other hospitals (tertiary referrals). These latter patients might therefore have had more severe disease, although in terms of ulcer stages, no differences were observed between patients who were referred by other specialists and those who were not. In addition, studies with long-term follow-up indicate that diabetic foot ulceration is a recurrent disease ${ }^{34,35}$. Since we excluded patients with a previous ulcer within the twelve months prior to presentation, our cohort does not properly reflect the total population attending the participating clinics. Furthermore, since the study was embedded in daily clinical practice, limitations had to be set as to the number and type of data to be collected. The dataset does not give a complete description of all characteristics of these patients and, although based on current international guidelines, more sophisticated tools could have been used to assess certain pathologies.

In conclusion, these baseline data from the Eurodiale cohort, reflecting the average European patient with a diabetic foot ulcer, contain an important message: many patients with diabetic foot ulcers are severely ill, and this is reflected by the severe underlying pathology and the presence of disabling comorbidity. Follow-up data on these patients, which are expected in the coming year, could give us more insight into the implications of the severity of this disease for clinical outcome, resource utilization and quality of life. 


\section{References}

1. Reiber GE, Vileikyte L, Boyko EJ, del Aguila M, Smith DG, Lavery LA, Boulton AJ. Causal pathways for incident lower-extremity ulcers in patients with diabetes from two settings. Diabetes Care 1999;22:157-162

2. Reiber GE, Lipsky BA, Gibbons GW. The burden of diabetic foot ulcers. Am J Surg 1998;176:5S-10S

3. Ragnarson Tennvall G, Apelqvist J. Health-economic consequences of diabetic foot lesions. Clin Infect Dis 2004;39(S2): S132-S139

4. Jeffcoate WJ, Harding KG. Diabetic foot ulcers. Lancet 2003;361:1545-1551

5. Boulton AJ. The diabetic foot: from art to science. The $18^{\text {th }}$ Camillo Golgi lecture. Diabetologia 2004;47:1343-1353

6. Frykberg RG. An evidence-based approach to diabetic foot infections. Am J Surg 2003; 186:44S-54S; discussion 61S-64S

7. Apelqvist J, Agardh CD. The association between clinical risk factors and outcome of diabetic foot ulcers. Diabetes Res Clin Pract 1992;18:43-53

8. Armstrong DG, Lavery LA, Harkless LB. Validation of a diabetic wound classification system. The contribution of depth, infection, and ischemia to risk of amputation. Diabetes Care 1998;21:855-859

9. Ramsey SD, Newton K, Blough D, McCulloch DK, Sandhu N, Reiber GE, Wagner EH. Incidence, outcomes, and cost of foot ulcers in patients with diabetes. Diabetes Care 1999; 22:382-387

10. Margolis DJ, Allen-Taylor L, Hoffstad O, Berlin JA. Diabetic neuropathic foot ulcers: the association of wound size, wound duration, and wound grade on healing. Diabetes Care 2002;25:1835-1839

11. Mueller MJ, Sinacore DR, Hastings MK, Strube MJ, Johnson JE. Effect of Achilles tendon lengthening on neuropathic plantar ulcers. A randomized clinical trial. J Bone Joint Surg Am 2003;85-A:1436-1445

12. Lavery LA, Armstrong DG, Wunderlich RP, Tredwell J, Boulton AJ. Predictive value of foot pressure assessment as part of a population-based diabetes disease management program. Diabetes Care 2003;26:1069-1073

13. Nabuurs-Franssen MH, Sleegers R, Huijberts MS, Wijnen W, Sanders AP, Walenkamp G, Schaper NC. Total contact casting of the diabetic foot in daily practice: a prospective followup study. Diabetes Care 2005;28:243-247

14. Mueller MJ, Diamond JE, Sinacore DR, Delitto A, Blair VP 3rd, Drury DA, Rose SJ. Total contact casting in treatment of diabetic plantar ulcers. Controlled clinical trial. Diabetes Care 1989;12:384-388

15. Armstrong DG, Nguyen HC, Lavery LA, van Schie CH, Boulton AJ, Harkless LB. Off-loading the diabetic foot wound: a randomized clinical trial. Diabetes Care 2001;24:1019-1022

16. Schaper NC. Diabetic foot ulcer classification system for research purposes: a progress report on criteria for including patients in research studies. Diabetes Metab Res Rev 2004;20(S1): S90-S95

17. Boulton AJ, Gries FA, Jervell JA. Guidelines for the diagnosis and outpatient management of diabetic peripheral neuropathy. Diabet Med 1998;15:508-514

18. Oyibo SO, Jude EB, Tarawneh I, Nguyen HC, Armstrong DG, Harkless LB, Boulton AJ. The effects of ulcer size and site, patient's age, sex and type and duration of diabetes on the outcome of diabetic foot ulcers. Diabet Med 2001;18:133-138

19. Oyibo SO, Jude EB, Tarawneh I, Nguyen HC, Harkless LB, Boulton AJ. A comparison of two diabetic foot ulcer classification systems: the Wagner and the University of Texas wound classification systems. Diabetes Care 2001;24:84-88

20. Moulik PK, Mtonga R, Gill GV. Amputation and mortality in new-onset diabetic foot ulcers stratified by etiology. Diabetes Care 2003;26:491-494

21. Apelqvist J, Larsson J, Agardh CD. The importance of peripheral pulses, peripheral oedema and local pain for the outcome of diabetic foot ulcers. Diabet Med 1990;7:590-594 
22. Schaper NC, Nabuurs-Franssen $\mathrm{MH}$. The diabetic foot: pathogenesis and clinical evaluation. Semin Vasc Med 2002;2:221-228

23. Dormandy JA, Rutherford RB. Management of peripheral arterial disease (PAD). TASC Working Group. TransAtlantic Inter- Society Concensus (TASC). J Vasc Surg 200;31: S1-S296

24. Cavanagh PR, Lipsky BA, Bradbury AW, Botek G. Treatment for diabetic foot ulcers. Lancet 2005;366:1725-1735

25. Boyko EJ, Ahroni JH, Stensel VL, Smith DG, Davignon DR, Pecoraro RE. Predictors of transcutaneous oxygen tension in the lower limbs of diabetic subjects. Diabet Med 1996; 13:549-554

26. Larsen $\mathrm{K}$, Holstein $\mathrm{P}$, Deckert T. Limb salvage in diabetics with foot ulcers. Prosthet Orthot Int 1989;13:100-103

27. Viswanathan V, Madhavan S, Gnanasundaram S, Gopalakrishna G, Das BN, Rajasekar S, Ramachandran A. Effectiveness of different types of footwear insoles for the diabetic neuropathic foot: a follow-up study. Diabetes Care 2004;27:474-477

28. Caravaggi C, De Giglio R, Pritelli C, Sommaria M, Dalla Noce S, Faglia E, Mantero M, Clerici G, Fratino P, Dalla Paola L, Mariani G, Mingardi R, Morabito A. HYAFF 11-based autologous dermal and epidermal grafts in the treatment of noninfected diabetic plantar and dorsal foot ulcers: a prospective, multicenter, controlled, randomized clinical trial. Diabetes Care 2003;26:2853-2859

29. Faglia E, Dalla Paola L, Clerici G, Clerissi J, Graziani L, Fusaro M, Gabrielli L, Losa S, Stella A, Gargiulo M, Mantero M, Caminiti M, Ninkovic S, Curci V, Morabito A. Peripheral angioplasty as the first-choice revascularization procedure in diabetic patients with critical limb ischemia: prospective study of 993 consecutive patients hospitalized and followed between 1999 and 2003. Eur J Vasc Endovasc Surg 2005;29:620-627

30. Adam DJ, Beard JD, Cleveland T, Bell J, Bradbury AW, Forbes JF, Fowkes FG, Gillepsie I, Ruckley CV, Raab G, Storkey H; BASIL trial participants. Bypass versus angioplasty in severe ischaemia of the leg (BASIL): multicentre, randomised controlled trial. Lancet 2005;366:1925-1934

31. Raymakers JT, Houben AJ, van der Heyden JJ, Tordoir JH, Kitslaar PJ, Schaper NC (2001) The effect of diabetes and severe ischaemia on the penetration of ceftazidime into tissues of the limb. Diabet Med 18:229-234

32. Harkless L, Boghossian J, Pollak R, Caputo W, Dana A, Gray S, Wu D. An open-label, randomized study comparing efficacy and safety of intravenous piperacillin/tazobactam and ampicillin/sulbactam for infected diabetic foot ulcers. Surg Infect (Larchmt) 2005;6:27-40

33. Lipsky BA, Armstrong DG, Citron DM, Tice AD, Morgenstern DE, Abramson MA. Ertapenem versus piperacillin/tazobactam for diabetic foot infections (SIDESTEP): prospective, randomised, controlled, double-blinded, multicentre trial. Lancet 2005;366:1695-1703

34. Abbott CA, Carrington AL, Ashe H, Bath S, Every LC, Griffiths J, Hann AW, Hussein A, Jackson N, Johnson KE, Ryder CH, Torkington R, Van Ross ER, Whalley AM, Widdows P, Williamson S, Boulton AJ; North-West Diabetes Foot Care Study. The North-West Diabetes Foot Care Study: incidence of, and risk factors for, new diabetic foot ulceration in a community-based patient cohort. Diabet Med 2002;19:377-384

35. Litzelman DK, Marriott DJ, Vinicor F. Independent physiological predictors of foot lesions in patients with NIDDM. Diabetes Care 1997;20:1273-1278 
46 


\section{Chapter 4}

Prediction of outcome in individuals with diabetic foot ulcers: focus on the differences between individuals with and without peripheral arterial disease

The Eurodiale study

Prompers L, Schaper N, Apelqvist J, Edmonds M, Jude E, Mauricio D, Uccioli K, Urbanic V, Bakker K, Holstein P, Jirkovska A, Piaggesi A, Ragnarson Tennvall G, Reike H, Spraul M, van Acker K, van Baal J, van Merode F, Ferreira I, Huijberts M

Diabetologia, 2008, accepted for publication 


\section{Abstract}

Aims/hypothesis

Outcome data on individuals with diabetic foot ulcers are scarce, especially in those with peripheral arterial disease (PAD). We therefore examined the clinical characteristics that best predict poor outcome in a large population of diabetic foot ulcer patients and examined whether such predictors differ between patients with and without PAD.

\section{Methods}

Analyses were conducted within the Eurodiale Study, a prospective cohort study of 1088 diabetic foot ulcer patients across 14 centres in Europe. Multiple logistic regression modelling was used to identify independent predictors of outcome (i.e. non-healing of the foot-ulcer).

Results

After 1 year of follow-up, $23 \%$ of the patients had not healed. Independent baseline predictors of non-healing in the whole study population were older age, male sex, heart failure, the inability to stand or walk without help, end-stage renal disease, larger ulcer size, peripheral neuropathy and PAD. When analyses were performed according to PAD status, infection emerged as a specific predictor of non-healing in PAD patients only.

Conclusions/interpretation

Predictors of healing differ between patients with and without PAD, suggesting that diabetic foot ulcers with or without concomitant PAD should be defined as two separate disease-states. The observed negative impact of infection on healing that was confined to patients with PAD needs further investigation. 


\section{Introduction}

Diabetic foot ulcers are a common and much feared complication of diabetes, with recent studies suggesting that the lifetime risk of developing a foot ulcer in diabetic patients may be as high as $25 \%{ }^{1}$. Foot ulceration requires long and intensive treatment, has important effects on quality of life of both patients and care-givers $^{2}$ and is associated with major healthcare costs ${ }^{3-5}$. Although in recent years much effort has been put into the development of international guidelines in order to stimulate the delivery of uniform and structured care ${ }^{6}$, prospective data on outcomes and predictors of outcome in patients with diabetic foot ulcers are limited.

The population of diabetic patients who present with foot ulceration is heterogeneous: although most patients have peripheral polyneuropathy, there are several other characteristics that may vary between patients, such as the presence of peripheral arterial disease (PAD), infection and co-morbidities. PAD is present in approximately one-half of all patients with foot ulcers ${ }^{7}$ and is considered an important predictor of outcome ${ }^{8,9}$. Therefore, outcome data on this important subgroup of patients with diabetic foot disease are needed. Such a requirement is underlined by the fact that although diabetic foot ulcers are usually reported and analysed as one clinical entity, marked differences in patient, foot and ulcer characteristics can exist between patients with and without $\mathrm{PAD}^{7}$. These observations raise the question of whether predictors of outcome in patients with and without PAD may differ.

The aim of the present study was therefore: (1) to obtain prospective data on outcome of individuals presenting with a new diabetic foot ulcer, including both patients with and without PAD; (2) to assess clinical characteristics that best predict poor outcome (i.e. non-healing of the foot ulcer) from this large set of patients; and (3) to examine whether such predictors differ between patients with and without PAD.

\section{Methods}

\section{Study design and population}

The Eurodiale consortium is an international collaborative network that was created to stimulate further research in the field of diabetic foot disease. Its main objective was to assess outcome and the major predictors of clinical outcome in a large sample of European patients with diabetic foot ulcers. The design and rationale of this study have been described in detail elsewhere ${ }^{10}$. Briefly, between September $1^{\text {st }}, 2003$, and October $1^{\text {st }}, 2004,1232$ patients with a new foot ulcer were included in 14 diabetic foot centres in ten European 
countries. The mean (range) number of included patients per centre was 88 (40-125). All participating centres have a longstanding expertise in the field of diabetic foot disease. Patients included were those presenting for the first time with a new foot ulcer within a period of 12 months, either at the outpatient or inpatient clinics of participating centres. Excluded patients were those who had been treated at the participating centres for an ulcer on the ipsilateral foot during the previous 12 months and those with a life expectancy of less than one year. Participants attended follow-up visits on a monthly basis. At baseline and during all follow-up visits, data were collected and recorded on standardised case record forms. This was done by dedicated investigators in each centre who were trained during plenary meetings and on-site visits. Recorded data included demographics, data on co-morbidities, foot and ulcer characteristics, as well as management. The local ethics committees of the 14 hospitals approved the study protocol and all patients gave written informed consent.

\section{Management of diabetic foot ulcer}

All patients were treated according to protocols based on the International Consensus on the Diabetic Foot ${ }^{11}$, which include offloading, diagnosis and treatment of infection, assessment of vascular status, treatment of PAD and regular wound debridement.

\section{Potential predictive factors}

Potential determinants of healing were chosen on the basis of (1) current literature; (2) expert opinion after extensive discussions during EURODIALE meetings; and (3) suitability for use in daily clinical practice. In addition to sex, age at baseline and duration of diabetes, several disease-specific characteristics and co-morbidities were investigated ${ }^{10}$.

\section{Ulcer characteristics}

All patients underwent a standardised examination according to the PEDIS system. This was developed by the International Consensus on the Diabetic Foot to enable classification of patients for clinical research purposes ${ }^{11,12}$ and classifies foot ulcers according to five categories: perfusion, extent, depth, infection and sensation.

Perfusion assessment included evaluation of the presence of pedal pulses and measurement of the ankle-brachial pressure index (ABPI) using a handheld Doppler device; PAD was considered to be present if ABPI was $<0.9$ and/or two foot pulses were absent. 
Extent (i.e. size) was determined by multiplying the largest by the second largest diameter perpendicular to the first and divided into three categories: $<1 \mathrm{~cm}^{2}, 1-5 \mathrm{~cm}^{2}$ and $>5 \mathrm{~cm}^{2}$.

Depth was described as either deep or superficial if a full thickness lesion of the skin was or was not extending through the subcutis, respectively.

Infection was diagnosed if two or more of the following signs were present: frank purulence, local warmth, erythema, lymphangitis, oedema, pain, fever and foul smell. The term infection covers both soft tissue infection and bone infection.

Evaluation of sensation (peripheral neuropathy [PNP]) included pressure sensation (10 g monofilament on plantar aspect of hallux, metatarsophalangeal joints 1 and 5), tactile sensation (cotton wisp on dorsum of foot), vibration sensation (128 Hz tuning fork on dorsum of the hallux) and blunt/sharp discrimination (dorsum of foot). PNP was diagnosed if the results of two or more of the aforementioned tests were abnormal.

In addition, the location of the ulcer was divided into plantar (on the plantar toes, plantar mid- or forefoot and plantar hind foot) and non-plantar (on the dorsal or interdigital part of the toes, on the dorsal or lateral aspect of the foot and heel ulcers). Ulcer duration was divided in three categories: $<1$ week, between 1 week and 3 months, and $>3$ months.

\section{Co-morbidities}

The following disabling co-morbidities were assessed: presence of severe visual impairment (defined as the inability to read a newspaper after correction), end-stage renal disease (ESRD) (defined as dependency on haemodialysis or peritoneal dialysis or a previous renal transplant procedure), heart failure (New York Heart Association [NYHA] classification III or IV), any neurological disorder (excluding diabetic polyneuropathy) resulting in loss of motor or sensory function (e.g. stroke) and inability to stand or walk without help.

\section{Study main outcome}

Main outcome was complete healing (with or without minor amputation) of the foot, within the maximum follow-up period of 1 year. Healing was defined as healing (intact skin) of the whole foot at two consecutive visits. If more than one ulcer was present, the foot was defined as healed once all ulcers were healed. Outcome information was not obtained in 144 patients $(11.7 \%$ of the patients included) who dropped out of the study and were therefore excluded from the analyses. Reasons for dropout were non-compliance $(n=24)$, inability to follow the patient (lack of transportation, no social support, too sick to attend) $(n=25)$ or if care had been taken over by other specialists $(n=29)$; in 66 patients the 
reason for dropout could not be discovered. At baseline these participants were slightly older and had a higher incidence of heart failure, deeper ulcers and ulcers of longer duration than those included in the analyses $(n=1088)$ (Table 4.1).

Table 4.1 Baseline characteristics between subjects included and those excluded (drop-outs) from the present study.

\begin{tabular}{|c|c|c|c|}
\hline Variable & $\begin{array}{l}\text { Included } \\
(n=1088)\end{array}$ & $\begin{array}{c}\text { Drop-outs } \\
(\mathrm{n}=144)\end{array}$ & $\mathrm{p}$-value \\
\hline Age, years & $64.7 \pm 12.5$ & $68.0 \pm 11.6$ & 0.003 \\
\hline Male gender, $n(\%)^{\mathrm{a}}$ & $703(64.6)$ & $85(59.0)$ & 0.189 \\
\hline Duration of diabetes, $n(\%)^{a}$ & & & 0.418 \\
\hline$<5$ years & $148(14.1)$ & $19(13.5)$ & \\
\hline $5-10$ years & $169(16.1)$ & $17(12.1)$ & \\
\hline$>10$ years & $731(69.8)$ & 105 (74.5) & \\
\hline Deep ulcer, $n(\%)^{\mathrm{a}}$ & $476(43.8)$ & $80(55.6)$ & 0.007 \\
\hline Size of ulcer, $n(\%)^{\mathrm{a}}$ & & & 0.843 \\
\hline$<1 \mathrm{~cm}^{2}$ & $403(37.2)$ & $50(35.0)$ & \\
\hline $1-5 \mathrm{~cm}^{2}$ & $563(52.0)$ & $76(53.1)$ & \\
\hline$>5 \mathrm{~cm}^{2}$ & $117(10.8)$ & $17(11.9)$ & \\
\hline Duration of ulcer, $n(\%)^{a}$ & & & $<0.001$ \\
\hline$<1$ week & $184(17.0)$ & $10(7.0)$ & \\
\hline 1 week - 3 months & $627(58.1)$ & $68(47.6)$ & \\
\hline$>3$ months & 269 (24.9) & $65(45.5)$ & \\
\hline Plantar location, $n(\%)^{\mathrm{a}}$ & $493(48.2)$ & $62(46.3)$ & 0.675 \\
\hline Pretibial oedema, $n(\%)^{\mathrm{a}}$ & $197(18.2)$ & $29(20.3)$ & 0.538 \\
\hline Heart failure NYHA III-IV, $n(\%)^{\mathrm{a}}$ & $117(10.9)$ & $23(16.1)$ & 0.065 \\
\hline Neurological disorder, $n(\%)^{\mathrm{a}}$ & $70(6.5)$ & $9(6.3)$ & 0.918 \\
\hline Inability to stand or walk without help, $n(\%)^{a}$ & $107(9.9)$ & $15(10.4)$ & 0.843 \\
\hline Visual impairment, $n(\%)^{\mathrm{a}}$ & $164(15.3)$ & $19(13.2)$ & 0.507 \\
\hline End Stage Renal Disease, $n(\%)^{a}$ & $63(5.8)$ & $7(4.9)$ & 0.639 \\
\hline Polyneuropathy, $n(\%)^{a}$ & $826(78.5)$ & $105(76.1)$ & 0.515 \\
\hline Infection, $n(\%)^{\mathrm{a}}$ & $591(57.2)$ & $82(61.2)$ & 0.380 \\
\hline Peripheral arterial disease, $n(\%)^{a}$ & $505(47.5)$ & $78(56.1)$ & 0.056 \\
\hline
\end{tabular}

Unless otherwise stated, data are mean values $\pm S D$. ${ }^{a}$ Percentages may not sum to 100 due to missing information.

\section{Statistical analyses}

All statistical analyses were carried using the STATA software package version 9.2 (STATA, College Station, TX, USA). Comparisons between groups' characteristics were made with $X^{2}$ tests (frequency data) or Student's $t$ test (continuous data).

\section{Multiple imputation of missing values of predictor variables}

Values for one $(n=188)$, two $(n=35)$ or three $(n=13)$ predictor variables were not available for 236 participants; the number of missing values per predictor 
ranged from 0 to $6 \%$. In order to decrease bias and increase power of the analyses ${ }^{13}$, we used multiple imputation chained equations (procedure 'ICE' in STATA) to impute those missing values ( $1.7 \%$ of all required values) rather than performing complete case analyse ${ }^{14,15}$. With ICE the imputation model of a single variable uses all the other variables as predictors by appropriate regression models (i.e. linear, logistic or multinomial if imputed variable is continuous, dichotomous or categorical). We generated five imputed datasets that were used to fit the regression models of interest (in each dataset and in the final, i.e. the combined dataset). Parameter estimates and standard errors were combined across the five replicates according to the procedure described by Rubin ${ }^{16}$ and Carlin et al. ${ }^{17}$ (procedure 'micombine' in STATA).

\section{Development of predictive models}

First, univariable logistic regression analyses were performed for all potential predictor variables with the outcome of interest (non-healing), with values presented as univariable odds ratios (ORs) along with the respective $95 \% \mathrm{Cl}$. Second, all potential predictors were entered simultaneously in a multivariable logistic regression model that was reduced to a most parsimonious model using a backward selection method based on Akaike's Information Criterion. These models yielded a set of variables that best predict (and can be regarded as independent predictors of) outcome.

\section{Results}

\section{Clinical outcome}

Within the 1 year follow-up, $77 \%$ of the 1088 patients healed, $12 \%$ were still undergoing treatment, $5 \%$ underwent a major (i.e. above the ankle level) amputation and $6 \%$ died (before healing of the foot ulcer). Among the patients who healed, $17 \%$ underwent a minor amputation; this rate was similar to that in those patients who did not heal $(20 \%, p=0.425)$.

When stratifying patients according to the presence or absence of PAD, significantly $(p<0.001)$ worse healing rates were observed in patients with than in those without PAD ( 69 vs $84 \%$, respectively). Major amputation and mortality rates were also higher in patients with ( 8 and $9 \%$, respectively) than in patients without PAD ( 2 and $3 \%$ respectively) $(p<0.001)$. Baseline characteristics of patients with PAD compared with those without PAD are provided in Table 4.2. 
Table 4.2 Patients's baseline characteristics according to their PAD status.

\begin{tabular}{|c|c|c|c|}
\hline Variable & $\begin{array}{l}\text { Patients with PAD } \\
\quad(n=505)\end{array}$ & $\begin{array}{l}\text { Patients without } \\
\text { PAD }(n=558)\end{array}$ & $p$-value \\
\hline Age, years & $69.1 \pm 11.2$ & $60.5 \pm 12.3$ & $<0.001$ \\
\hline Male gender, $n(\%)^{\mathrm{a}}$ & $321(65.6)$ & $366(63.6)$ & 0.490 \\
\hline Duration of diabetes, $n(\%)^{\mathrm{a}}$ & & & 0.265 \\
\hline$<5$ years & $63(12.9)$ & $80(14.9)$ & \\
\hline $5-10$ years & $72(14.7)$ & $93(17.4)$ & \\
\hline$>10$ years & $354(72.4)$ & $363(67.7)$ & \\
\hline Deep ulcer, $n(\%)^{\mathrm{a}}$ & $266(52.7)$ & $200(35.8)$ & $<0.001$ \\
\hline Size of ulcer, $n(\%)^{\text {a }}$ & & & 0.002 \\
\hline$<1 \mathrm{~cm}^{2}$ & $173(34.4)$ & $219(39.5)$ & \\
\hline $1-5 \mathrm{~cm}^{2}$ & $259(51.5)$ & $294(53.0)$ & \\
\hline$>5 \mathrm{~cm}^{2}$ & $71(14.2)$ & $42(7.5)$ & \\
\hline Duration of ulcer, $n(\%)^{\mathrm{a}}$ & & & $<0.001$ \\
\hline$<1$ week & $58(11.5)$ & $120(21.7)$ & \\
\hline 1 week -3 months & $296(58.0)$ & $318(57.5)$ & \\
\hline$>3$ months & $148(29.5)$ & $115(20.8)$ & \\
\hline Plantar location, $n(\%)^{\mathrm{a}}$ & $197(40.9)$ & $284(55.0)$ & $<0.001$ \\
\hline Pretibial oedema, $n(\%)^{\mathrm{a}}$ & $111(22.0)$ & $83(14.9)$ & 0.002 \\
\hline Heart failure NYHA III-IV, $n(\%)^{a}$ & $64(12.7)$ & $47(8.5)$ & 0.027 \\
\hline Neurological disorder, $n(\%)^{\mathrm{a}}$ & $40(8.0)$ & $27(4.9)$ & 0.039 \\
\hline Inability to stand or walk without help, $n(\%)^{a}$ & 65 (12.9) & $36(6.5)$ & $<0.001$ \\
\hline Visual impairment, $n(\%)^{\mathrm{a}}$ & 89 (17.9) & $66(12.0)$ & 0.007 \\
\hline End Stage Renal Disease, $n(\%)^{\mathrm{a}}$ & $35(7.0)$ & $25(4.5)$ & 0.082 \\
\hline Polyneuropathy, $n(\%)^{\text {a }}$ & $383(77.2)$ & $424(79.3)$ & 0.429 \\
\hline Infection, $n(\%)^{\mathrm{a}}$ & $293(60.9)$ & $282(53.4)$ & 0.016 \\
\hline
\end{tabular}

Unless otherwise stated, data are mean values $\pm S D{ }^{\text {a }}$ Percentages may not sum to 100 due to missing information.

\section{Predictors of healing}

Table 4.3 shows the univariable associations of the potential predictors of nonhealing in the overall population and Table 4 presents the variables retained in the predictive models after backward selection in the combined imputed datasets. The estimates were similar to those obtained in the complete cases dataset $(n=854)$ indicating that missing values were non-selective (data not shown). These include the following eight characteristics, all of which predict lower probabilities of healing: older age, male sex, larger ulcer size, heart failure, inability to stand or walk without help, ESRD, PNP and PAD. These variables were consistently identified in all five imputed datasets.

Since we hypothesised that, from an aetiological point of view, predictors of non-healing would differ between patients with and those without PAD, predictive models were also fitted for these two groups separately (Table 4.4). In patients with PAD almost all of the predictors identified in the whole study population, with the exception of PNP, were again found to be independent predictors of healing. In addition, the presence of infection emerged as an 
additional independent predictor of non-healing. In patients without PAD, older age, larger ulcer size, inability to stand or walk without help, ESRD, PNP and, in addition, longer ulcer duration were independent predictors of poorer healing.

The observed interaction between infection and PAD status partly supports the classification of foot ulcer disease into four stages as suggested by Armstrong et al. (University of Texas classification system) ${ }^{9}$. Accordingly, upon analysis of the odds of non-healing per PAD $\times$ infection status, it was only in those patients with both PAD and infection that the odds of non-healing were markedly increased compared with those without PAD nor infection: OR 2.82, Cl 1.884.22, $\mathrm{p}<0.001$ in unadjusted analyses (Figure 4.1) vs OR 1.87, Cl 1.20-2.91, $p<0.001$ after adjustments for the other variables included in the predictive model.

Table 4.3 Association of each potential predictor with non-healing in the overall population $(n=1088)$.

\begin{tabular}{|c|c|c|c|}
\hline \multirow[t]{2}{*}{ Predictor variables } & \multicolumn{3}{|c|}{ Outcome: Healing } \\
\hline & OR & $95 \% \mathrm{Cl}$ & $p$-value \\
\hline Age, per 10 years increase & 1.32 & $1.17 ; 1.49$ & $<0.001$ \\
\hline Gender, men vs. women & 1.50 & $1.07 ; 1.97$ & 0.018 \\
\hline Duration of diabetes & & & 0.712 \\
\hline $5-10$ years vs. $<5$ years $^{\text {a }}$ & 0.96 & $0.56 ; 1.65$ & \\
\hline$>10$ years vs. $<5$ years $^{\text {a }}$ & 1.05 & $0.69 ; 1.60$ & \\
\hline Depth of ulcer, deep vs. superficial & 1.66 & $1.25 ; 2.20$ & $<0.001$ \\
\hline Size of ulcer & & & $<0.001$ \\
\hline $1-5 \mathrm{~cm}^{2}$ vs. $<1 \mathrm{~cm}^{2 a}$ & 2.25 & $1.60 ; 3.17$ & \\
\hline$>5 \mathrm{~cm}^{2}$ vs. $<1 \mathrm{~cm}^{2 \mathrm{a}}$ & 4.22 & $2.64 ; 6.72$ & \\
\hline Duration of ulcer & & & $<0.001$ \\
\hline 1 week to 3 months vs. $<1$ week $^{a}$ & 1.81 & $1.15 ; 2.85$ & \\
\hline$>3$ months vs. $<1$ week $^{a}$ & 2.61 & $1.60 ; 4.27$ & \\
\hline Location, plantar vs. non-plantar & 0.73 & $0.55 ; 0.98$ & 0.035 \\
\hline Pretibial oedema, yes vs. no & 1.79 & $1.27 ; 2.51$ & 0.001 \\
\hline Heart failure (NYHA III-IV), yes vs. no & 2.03 & $1.35 ; 3.05$ & 0.001 \\
\hline Neurological disorder, yes vs. no & 1.44 & $0.85 ; 2.46$ & 0.176 \\
\hline Inability to stand or walk without help, yes vs. no & 2.50 & $1.62 ; 3.79$ & $<0.001$ \\
\hline Visual impairment, yes vs. no & 1.36 & $0.94 ; 1.98$ & 0.105 \\
\hline End stage renal disease, yes vs. no & 2.20 & $1.30 ; 3.73$ & 0.004 \\
\hline Polyneuropathy, yes vs. no & 1.41 & $0.98 ; 2.04$ & 0.065 \\
\hline Soft tissue infection, yes vs. no & 1.47 & $1.09 ; 2.00$ & 0.012 \\
\hline Peripheral arterial disease, yes vs. no & 2.31 & $1.72 ; 3.10$ & $<0.001$ \\
\hline
\end{tabular}

${ }^{a}$ reference category. 
Table 4.4 Multivariable models with independent predictors of non-healing in the whole study population, and in patients with and without PAD.

\begin{tabular}{|c|c|c|c|c|c|c|c|c|c|}
\hline \multirow{2}{*}{ Variable } & \multicolumn{3}{|c|}{ All patients } & \multicolumn{3}{|c|}{ Patients with PAD } & \multicolumn{3}{|c|}{ Patients without PAD } \\
\hline & OR & $95 \% \mathrm{Cl}$ & p-value & OR & $95 \% \mathrm{Cl}$ & $p$-value & OR & $95 \% \mathrm{Cl}$ & p-value \\
\hline Age, per 10 years increase & 1.28 & $1.11 ; 1.47$ & 0.001 & 1.42 & $0.17 ; 1.73$ & $<0.001$ & 1.55 & $0.91 ; 2.63$ & 0.105 \\
\hline Gender, men vs. women & 1.72 & $1.23 ; 2.40$ & 0.002 & 1.97 & $1.25 ; 3.11$ & 0.003 & - & - & - \\
\hline Size of ulcer & & & $<0.001$ & & & $<0.001$ & & & 0.008 \\
\hline $1-5 \mathrm{~cm}^{2}$ vs. $<1 \mathrm{~cm}^{2 a}$ & 2.26 & $1.58 ; 3.22$ & & 3.22 & $1.95 ; 5.32$ & & 1.25 & $0.74 ; 2.12$ & \\
\hline$>5 \mathrm{~cm}^{2}$ vs. $<1 \mathrm{~cm}^{2 a}$ & 3.88 & $2.37 ; 6.34$ & & 3.84 & $1.97 ; 7.48$ & & 3.48 & $1.62 ; 7.46$ & \\
\hline Duration of ulcer & & & - & & & - & & & 0.086 \\
\hline $\begin{array}{l}1 \text { week to } 3 \text { months vs. } \\
<1 \text { week }^{\text {a }}\end{array}$ & - & - & & - & - & & 2.14 & $1.05 ; 4.36$ & \\
\hline$>3$ months vs. $<1$ week * & - & - & & - & - & & 2.18 & $0.98 ; 4.84$ & \\
\hline $\begin{array}{l}\text { Heart failure (NYHA III-IV), } \\
\text { yes vs. no }\end{array}$ & 1.55 & $0.99 ; 2.43$ & 0.054 & 1.54 & $0.87 ; 2.74$ & 0.141 & - & - & - \\
\hline $\begin{array}{l}\text { Inability to stand or walk } \\
\text { without help, yes vs. no }\end{array}$ & 2.00 & $1.27 ; 3.14$ & 0.003 & 2.36 & $1.34 ; 4.17$ & 0.003 & 1.91 & $0.86 ; 4.24$ & 0.112 \\
\hline $\begin{array}{l}\text { End stage renal disease, } \\
\text { yes vs. no }\end{array}$ & 2.51 & $1.41 ; 4.48$ & 0.002 & 3.04 & $1.38 ; 6.70$ & 0.006 & 2.00 & $0.76 ; 5.25$ & 0.161 \\
\hline Polyneuropathy, yes vs. no & 1.42 & $0.96 ; 2.08$ & 0.078 & - & - & - & 1.70 & $0.89 ; 3.25$ & 0.108 \\
\hline $\begin{array}{l}\text { Soft tissue infection, yes vs. } \\
\text { no }\end{array}$ & - & - & - & 1.63 & $1.03 ; 2.58$ & 0.036 & - & - & - \\
\hline $\begin{array}{l}\text { Peripheral arterial disease, } \\
\text { yes vs. no }\end{array}$ & 1.71 & $1.23 ; 2.37$ & 0.001 & & $\mathrm{~N} / \mathrm{A}$ & & & $\mathrm{N} / \mathrm{A}$ & \\
\hline
\end{tabular}

\footnotetext{
${ }^{a}$ reference category; N/A, not applicable.
}

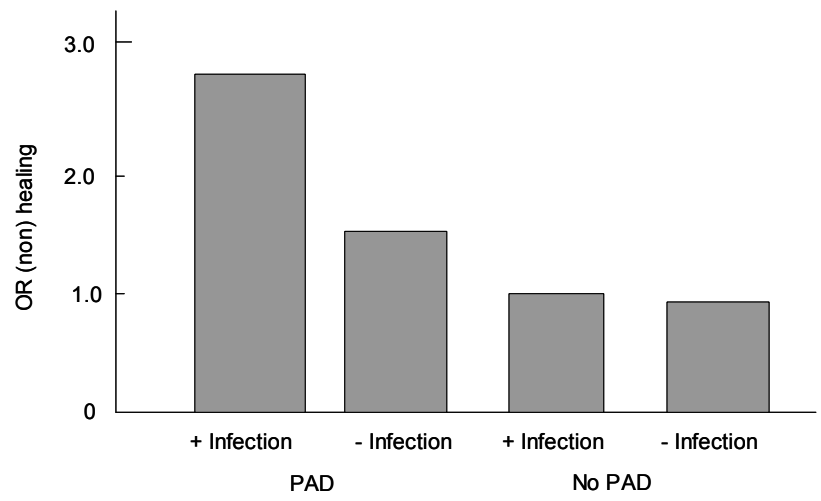

Figure 4.1 ORs of healing per PAD and infection status. 


\section{Discussion}

The Eurodiale study is one of the few large prospective, international studies on outcome and determinants of outcome in diabetic foot disease. Despite the severity of the underlying disease and the important co-morbidity ${ }^{7}$, clinical outcome of this population within 1 year follow-up can be considered favourable. In our cohort, $77 \%$ of the patients healed (with or without a minor amputation), 5\% underwent a major amputation and 6\% died. However, healing rates in patients with PAD were considerably worse. In addition, predictors of healing also differed between the groups with and without PAD. The presence of infection, which is generally regarded as an important predictor of healing, was only predictive in individuals with PAD.

With regard to the overall outcome in our cohort, two recent studies found relatively comparable outcomes. Jeffcoate et al. reported healing (excluding minor amputations) rates of $66 \%$ and an amputation rate of $5 \%$ with a similar prevalence of $P A D^{18}$. In a German cohort, Beckert et al. found healing rates between 57 and $93 \%$ and major amputation rates of $3 \%{ }^{19}$, although the data as presented in that report cannot be easily compared because of their unique classification system. Oyibo et al. also found similar rates of major amputation in their cohort $(5 \%)^{20}$.

Our study shows that the combination of PAD and infection has a major impact on healing rates (Fig. 1); this significant interaction between PAD and infection is, in our opinion, one of the major findings of this study. In the patients without PAD we did not observe an association between infection and non-healing, which suggests that in these patients current antibiotic regimens and surgical techniques seem adequate to save a limb with adequate perfusion. However, within the total population of individuals with diabetic foot disease in developed countries, the group of infected and ischaemic ulcers accounted for almost one-third of all patients in our earlier report ${ }^{7}$. In a recent study, a significant relation between PAD, infection and poor outcome was also observed: in that study's large cohort of outpatients with type 2 diabetes, PAD was an independent predictor of infection-related mortality ${ }^{21}$. Unfortunately, there is very little insight into the pathophysiology and treatment of infection in individuals with PAD. Currently it is not clear why infection is more prevalent and more difficult to treat in individuals with PAD. Remarkably, very few patients with PAD were included in most of the randomised trials on antibiotic therapy in diabetic foot infections ${ }^{22,23}$. It has previously been demonstrated that lower limb tissue levels of antibiotics can be markedly decreased as a result of impaired perfusion in $P A D^{24}$. It is open to speculation whether aggressive revascularisation will improve control of infection in these patients.

Although some earlier studies have examined the impact of co-morbidities on ulcer healing ${ }^{25}$, no studies, to our knowledge, have systematically assessed in 
a multivariable analysis the effects on ulcer healing of patient characteristics including co-morbidities, as well as foot and ulcer characteristics at baseline. In our study, older age, ulcer size and several co-morbidities were independent predictors of non-healing in patients with and without PAD. Recently a number of larger studies reported data on determinants of outcome in diabetic foot disease such as the single-centre study by Beckert in Germany and the UK multi-centre study initiated by Jeffcoate ${ }^{19,26}$. The former focused on woundbased characteristics and also found that the presence of PAD (defined as absence of pedal pulses) was an independent predictor of outcome (healing), while infection was not. In the recent UK multi-centre study, ulcer area was a strong predictor of outcome, as was the presence of PAD; co-morbidities were not taken into account in the regression analyses. Surprisingly, depth of the ulcer was not associated with outcome in our multivariable model, a finding also shown by Ince et al. ${ }^{26}$. In a retrospective study, Miyajima et al. reported on patient characteristics that determined major lower extremity amputation and found that haemodialysis was an independent predictor of major amputation; in this study wound characteristics were not part of the regression analyses ${ }^{27}$. The poor prognosis of foot ulcers for individuals in our study with ESRD is in line with earlier reports, in which amputation rates of $57 \%$ in individuals on haemodialysis were observed ${ }^{25}$. Although in our study ESRD was a predictor of non-healing in patients with and without PAD, it seemed to have a particular negative effect in the latter patient group. PAD is frequently diagnosed and associated with adverse outcomes in haemodialysis patients ${ }^{28}$. PAD in ESRD patients is more severe and is accompanied by diffuse vascular calcifications, involvement of both distal infrapopliteal and foot arteries, and by impaired microcirculatory perfusion ${ }^{29-31}$. The severity of PAD in ESRD may explain the importance of ESRD in our healing models; additional mechanisms are probably impaired host defences in chronic renal failure and uraemia, or the presence of more resistant micro-organisms ${ }^{32,33}$.

The outcome of patients without PAD in our study was relatively favourable: $84 \%$ of the patients healed with or without minor amputation, $2 \%$ underwent a major amputation and 3\% died. In our multivariate models, loss of sensation was associated with a poorer outcome in these patients, suggesting that loss of protective sensation is not only a key factor in the development of an ulcer, but also affects its outcome. This may be related to the preserved mechanism of offloading the ulcer in individuals with intact protective sensation. However, neuropathy may also have direct effects on wound healing. Although data on the effect of neuropathy on wound healing in humans are scarce, some animal studies suggest that denervation may contribute to impaired wound healing in diabetes $^{34,35}$. A large dataset on individuals with neuropathic ulcers comes from retrospective database analyses in which healing rates of $47 \%$ were observed $^{36}$. Although this study reported on healing at 20 weeks (whereas the 
current one examined healing rates at one year), the different results compared with our study are striking and may be related to an increased awareness of the importance of adequate offloading, as a result of publication of international guidelines and reports on casting techniques ${ }^{37-39}$.

There are several limitations to our study. Individuals who were lost to follow-up were excluded from the analyses as healing status could not be obtained; these individuals were slightly older and had a greater incidence of heart failure, deep ulcers or ulcers with a longer duration and PAD at baseline. In addition, we excluded patients who had had a previous ulcer within 12 months prior to presentation (i.e. we probably excluded patients with recurrent ulcers). Also we excluded patients with a life expectancy shorter than 1 year because of anticipated problems with follow-up. The estimates obtained in our models may therefore have underestimated the probability of non-healing in patients with a recurrent foot ulcer, although in one earlier study healing rate of neuropathic foot ulcers did not decrease in patients with multiple recurrences ${ }^{40}$. Since our study was embedded in daily clinical practice, limitations had to be set with regard to the number and type of data collected. It was therefore not possible to record more characteristics of these patients such as medication and extensive documentation of all complications. Moreover, to facilitate data collection, some continuous data (e.g. ulcer size) had to be transformed into a limited set of categories. Nevertheless, the set of potential predictors used in the present study do cover relevant patient and disease-specific aspects that can be easily assessed and used for patient risk estimation in clinical practice. Finally, our predictive model is based on outcomes that can be obtained in developed countries with access to the necessary resources such as antibiotic treatment and revascularisation; our results, therefore, are most relevant for diabetic foot ulcer patients in developed countries.

In conclusion, the results of this study have several implications. Both ulcer characteristics and several patient-related characteristics affected the outcome of diabetic foot ulcers. Therefore, a holistic approach by healthcare professionals who are familiar with the treatment of complicated diabetic patients is essential in order to identify the high-risk patient and start appropriate treatment. We found that patients with and without PAD differ in clinical characteristics, outcome and predictors of outcome. Taking into account these findings and the different pathophysiology and treatment of PAD and non-PAD ulcers, we feel that that diabetic foot ulcer with and without PAD should be defined as two separate disease states. The prevalent combination of PAD and infection is a unique entity; an important challenge lies in the development of evidence-based strategies to improve the poor outcome of these patients. Both studies comparing different antibiotic regimens in PAD, and studies evaluating the effects of early revascularisation on control of infection are urgently needed. 


\section{References}

1. Singh N, Armstrong DG, Lipsky BA (2005) Preventing foot ulcers in patients with diabetes. Jama 2005;293:217-228

2. Nabuurs-Franssen MH, Huijberts MS, Nieuwenhuijzen Kruseman AC, Willems J, Schaper NC. Health-related quality of life of diabetic foot ulcer patients and their caregivers. Diabetologia 2005;48:1906-1910

3. Apelqvist J, Ragnarson-Tennvall G, Larsson J, Persson U. Long-term costs for foot ulcers in diabetic patients in a multidisciplinary setting. Foot Ankle Int 1995;16:388-394

4. Apelqvist J, Ragnarson-Tennvall G, Persson U, Larsson J. Diabetic foot ulcers in a multidisciplinary setting. An economic analysis of primary healing and healing with amputation. J Intern Med 1994;235:463-471

5. Ragnarson Tennvall G, Apelqvist J. Health-economic consequences of diabetic foot lesions. Clin Infect Dis 2004;39 S2:S132-139

6. Apelqvist J, Bakker K, van Houtum WH, Nabuurs-Franssen MH, Schaper NC. International consensus and practical guidelines on the management and the prevention of the diabetic foot. International Working Group on the Diabetic Foot. Diabetes Metab Res Rev 2000;16 S1:S84-92

7. Prompers L, Huijberts M, Apelqvist J, Jude E, Piaggesi A, Bakker K, Edmonds M, Holstein P, Jirkovska A, Mauricio D, Ragnarson Tennvall G, Reike H, Spraul M, Uccioli L, Urbancic V, Van Acker K, van Baal J, van Merode F, Schaper N. High prevalence of ischaemia, infection and serious comorbidity in patients with diabetic foot disease in Europe. Baseline results from the Eurodiale study. Diabetologia 2007;50:18-25

8. Boulton AJ. The pathogenesis of diabetic foot problems: an overview. Diabet Med 1996;13 S1: S12-16

9. Armstrong DG, Lavery LA, Harkless LB. Validation of a diabetic wound classification system. The contribution of depth, infection, and ischemia to risk of amputation. Diabetes Care 1998;21:855-859

10. Prompers L, Huijberts M, Apelqvist J, Jude E, Piaggesi A, Bakker K, Edmonds M, Holstein P, Jirkovska A, Mauricio D, Tennvall GR, Reike H, Spraul M, Uccioli L, Urbancic V, Van Acker K, Van Baal J, Van Merode F, Schaper N.Optimal organisation of health care in diabetic foot disease. Introduction to the Eurodiale study. Int J Low Extrem Wounds 2007;6:11-17

11. Schaper NC, Apelqvist J, Bakker K. The international consensus and practical guidelines on the management and prevention of the diabetic foot. Curr Diab Rep 2003;3:475-479

12. Schaper NC. Diabetic foot ulcer classification system for research purposes: a progress report on criteria for including patients in research studies. Diabetes Metab Res Rev 2004;20 S1:S90-95

13. Little R. Regression with missing X's: a review. J Am Stat Assoc 1992;87:1227-1237

14. Royston P. Multiple imputation of missing values: update of ice. Stata Journal $2005 ; 5$ : 527-536

15. van Buuren S, Boshuizen HC, Knook DL. Multiple imputation of missing blood pressure covariates in survival analysis. Stat Med 1999;18:681-694

16. Rubin D. Multiple Imputation for Nonresponse in Surveys. John Wiley \& Sons, New York, 1997

17. Carlin J, Li N, Greenwood P, Coffey C. Tools for analyzing multiple imputed datasets. Stata Journal 2003;3:226-244

18. Jeffcoate WJ, Chipchase SY, Ince P, Game FL. Assessing the outcome of the management of diabetic foot ulcers using ulcer-related and person-related measures. Diabetes Care 2006;29:1784-1787

19. Beckert S, Witte M, Wicke C, Konigsrainer A, Coerper S. A new wound-based severity score for diabetic foot ulcers: A prospective analysis of 1,000 patients. Diabetes Care 2006;29: 988-992 
20. Oyibo SO, Jude EB, Tarawneh I, Nguyen HC, Armstrong DG, Harkless LB, Boulton AJ. The effects of ulcer size and site, patient's age, sex and type and duration of diabetes on the outcome of diabetic foot ulcers. Diabet Med 2001;18:133-138

21. Cardoso CR, Salles GF. Macro and microvascular complications are determinants of increased infection-related mortality in Brazilian type 2 diabetes mellitus patients. Diabetes Res Clin Pract 2007;75:51-58

22. Lipsky BA, Armstrong DG, Citron DM, Tice AD, Morgenstern DE, Abramson MA. Ertapenem versus piperacillin/tazobactam for diabetic foot infections (SIDESTEP): prospective, randomised, controlled, double-blinded, multicentre trial. Lancet 2005;366:1695-1703

23. Harkless L, Boghossian J, Pollak R, Caputo W, Dana A, Gray S, Wu D. An open-label, randomized study comparing efficacy and safety of intravenous piperacillin/tazobactam and ampicillin/sulbactam for infected diabetic foot ulcers. Surg Infect (Larchmt) 2005;6:27-40

24. Raymakers JT, Houben AJ, van der Heyden JJ, Tordoir JH, Kitslaar PJ, Schaper NC. The effect of diabetes and severe ischaemia on the penetration of ceftazidime into tissues of the limb. Diabet Med 2001;18:229-234

25. Morbach S, Quante C, Ochs HR, Gaschler F, Pallast JM, Knevels U. Increased risk of lowerextremity amputation among Caucasian diabetic patients on dialysis. Diabetes Care 2001;24: 1689-1690

26. Ince $\mathrm{P}$, Kendrick $\mathrm{D}$, Game $\mathrm{F}$, Jeffcoate $\mathrm{W}$. The association between baseline characteristics and the outcome of foot lesions in a UK population with diabetes. Diabet Med 2007;24: 977-981

27. Miyajima S, Shirai A, Yamamoto S, Okada N, Matsushita T. Risk factors for major limb amputations in diabetic foot gangrene patients. Diabetes Res Clin Pract 2006;71:272-279

28. Rajagopalan S, Dellegrottaglie S, Furniss AL, Gillespie BW, Satayathum S, Lameire N, Saito A, Akiba T, Jadoul M, Ginsberg N, Keen M, Port FK, Mukherjee D, Saran R. Peripheral arterial disease in patients with end-stage renal disease: observations from the Dialysis Outcomes and Practice Patterns Study (DOPPS). Circulation 2006;114:1914-1922

29. Boufi M, Ghaffari $P$, Allaire E, Fessi $H$, Ronco $P$, Vayssairat $M$. Foot gangrene in patients with end-stage renal disease: a case control study. Angiology 2006;57:355-361

30. Leskinen Y, Salenius JP, Lehtimaki T, Huhtala H, Saha H. The prevalence of peripheral arterial disease and medial arterial calcification in patients with chronic renal failure: requirements for diagnostics. Am J Kidney Dis 2002;40:472-479

31. Gensler SW, Haimovici H, Hoffert P, Steinman C, Beneventano TC. Study of vascular lesions in diabetic, nondiabetic patients. Clinical, arteriographic, and surgical considerations. Arch Surg 1965;91:617-622

32. Fejfarova V, Jirkovska A, Petkov V, Boucek P, Skibova J. Comparison of microbial findings and resistance to antibiotics between transplant patients, patients on hemodialysis, and other patients with the diabetic foot. J Diabetes Complications 2004;18:108-112

33. Cheung A, Wong L. Surgical infections in patients with chronic renal failure. Infect Dis Clin North Am 2001;15:775-796

34. Richards AM, Floyd DC, Terenghi G, McGrouther DA. Cellular changes in denervated tissue during wound healing in a rat model. Br J Dermatol 1999;140:1093-1099

35. Gibran NS, Jang YC, Isik FF, Greenhalgh DG, Muffley LA, Underwood RA, Usui ML, Larsen J, Smith DG, Bunnett N, Ansel JC, Olerud JE. Diminished neuropeptide levels contribute to the impaired cutaneous healing response associated with diabetes mellitus. J Surg Res 2002;108:122-128

36. Margolis DJ, Allen-Taylor L, Hoffstad O, Berlin JA. Diabetic neuropathic foot ulcers: predicting which ones will not heal. Am J Med 2003;115:627-631

37. Armstrong DG, Lavery LA, Wu S, Boulton AJ. Evaluation of removable and irremovable cast walkers in the healing of diabetic foot wounds: a randomized controlled trial. Diabetes Care 2005;28:551-554

38. Mueller MJ, Diamond JE, Sinacore DR, Delitto A, Blair VP 3rd, Drury DA, Rose SJ. Total contact casting in treatment of diabetic plantar ulcers. Controlled clinical trial. Diabetes Care $1989 ; 12: 384-388$ 
39. Nabuurs-Franssen MH, Sleegers R, Huijberts MS, Wijnen W, Sanders AP, Walenkamp G, Schaper NC. Total contact casting of the diabetic foot in daily practice: a prospective followup study. Diabetes Care 2005;28:243-247

40. Nabuurs-Franssen MH, Huijberts MS, Sleegers R, Schaper NC. Casting of recurrent diabetic foot ulcers: effective and safe? Diabetes Care 2005;28:1493-1494 


\section{Chapter}

Non-healing in diabetic foot disease is predicted by ulcer size, peripheral arterial disease, polyneuropathy and co-morbidities.

The Eurodiale risk score

Prompers L, Schaper N, Apelqvist J, Edmonds M, Jude E, Mauricio D, Uccioli K, Urbanic V, Bakker K, Holstein P, Jirkovska A, Piaggesi A, Ragnarson Tennvall G, Reike H, Spraul M, van Acker K, van Baal J, van Merode F, Ferreira I, Huijberts M 


\section{Abstract}

Aims/hypothesis

The aim of the present study was to identify, among a large set of variables easily obtained in clinical practice and covering a relevant spectrum of ulcerand disease-specific as well as co-morbidity characteristics, those that best predict non-healing in order to develop an easily applicable risk scoring rule to aid health care providers in the identification of diabetic foot patients at higher risk of non-healing.

\section{Methods}

Analyses were conducted within the Eurodiale Study, a prospective cohort study of 1088 diabetic foot ulcer patients across 14 centres in Europe. Multiple logistic regression modelling was used to identify independent predictors of outcome (i.e. non-healing of the foot-ulcer).

\section{Results/Conclusions}

We have developed a simple risk scoring rule, based on a set of variables easily assessed in clinical practice. These included not only patients' ulcer characteristics but also co-morbidities such as ESRD and heart failure. The inclusion of some co-morbidities in the final predictive model sustains the view that a holistic approach adopted by health care professionals that are familiar with the treatment of complicated diabetic patients is essential in order to identify the high-risk patient in order to start early and aggressive treatment. 


\section{Introduction}

Diabetic foot disease has significant effects on quality of life of both patients and caregivers ${ }^{1}$, involves extensive and demanding treatment and is associated with major health care costs ${ }^{2-4}$. Although much effort has been put into the development of international guidelines ${ }^{5}$ prospective studies investigating predictors of outcome in individuals with diabetic foot ulcers are relatively scarce. In particular, these studies have mainly focused on ulcer- and disease-specific characteristics and co-morbidity, that can affect wound healing, was frequently not reported. The aim of the present study was: to identify, among a large set of variables easily obtained in clinical practice and covering a relevant spectrum of ulcer- and disease-specific as well as comorbidity characteristics, those that best predict non-healing, in order to develop an easily applicable risk scoring rule to aid health care providers in the identification of diabetic foot patients at higher risk of non-healing.

\section{Research design and methods}

The EURODIALE consortium is an international European collaborative network that was created to stimulate research in the field of diabetic foot disease. The design and rationale of this study have been described in detail elsewhere ${ }^{6-8}$. Briefly, between September $1^{\text {st }} 2003$ and October $1^{\text {st }} 20041232$ patients were enrolled in 14 diabetic foot centers in 10 countries. Inclusion criteria were diabetic patients with a foot ulcer presenting for the first time within a period of 12 months to the outpatient or inpatient clinic of the participating centers. Patients treated for an ulcer on the ipsilateral foot during the past 12 months and patients with a life expectancy shorter than 1 year were excluded. All participating centers have a longstanding expertise in the field of diabetic foot disease and patients were treated according to protocols based on the International Consensus on the Diabetic Foot ${ }^{9}$, including offloading, diagnosis and treatment of infection, assessment of vascular status, treatment of peripheral artery disease and regular wound debridement.

Study main outcome was complete healing of the foot (i.e. intact skin of the whole foot at two consecutive visits), within the maximum follow-up period of one year. If more than one ulcer was present, the foot was defined as healed once all ulcers were healed. Outcome information was not obtained in 144 patients who dropped out of the study and were therefore excluded from the analyses.

Potential baseline determinants of healing were chosen based on literature, expert opinion and suitability for use in daily practice ${ }^{9,10}$. In addition to gender, age and duration of diabetes, the following characteristics were investigated: 
- $\quad$ ulcer characteristics - size, depth, location, duration, sensation and perfusion.

- disabling co-morbidities - presence of severe visual impairment, end-stage renal disease (ESRD), heart failure, any neurological disorder resulting in loss of motor or sensory function (excluding diabetic polyneuropathy), and inability to stand or walk without help.

The full details on the assessment and definitions of the predictors mentioned above have been published before ${ }^{6,7}$.

\section{Results}

Within the 1-year follow-up, $23 \%$ of the 1088 patients did not heal.

After univariate associations were examined all potential predictors were entered simultaneously in a multiple logistic regression model that was then reduced to a most parsimonious predictive model using a backward selection method based on the Akaike's Information Criterion. The following characteristics were retained in the final model and can be regarded as independent predictors of non-healing: older age, male gender, heart failure, inability to stand or walk without help, ESRD, larger ulcer size, polyneuropathy and peripheral arterial disease (Table 5.1).

Because predictive models are thought to provide too extreme estimates (i.e.over-optimism) during their derivation phase, we used bootstrapping techniques for model internal validation ${ }^{11,12}$. Random bootstrap samples (with replacement) from the original dataset consisting of the same number of subjects were drawn (250 samples). Within each bootstrap sample a prediction model was developed using the same variable selection procedure as in the original dataset. A shrinkage factor was then derived from the bootstrap samples by calculating the slope of the linear predictor in the original dataset, when the linear predictor was calculated with the regression coefficients as estimated in each the bootstrap sample. The regression coefficients of the original predictive model were then shrunk by a factor 0.868 , which resulted in an adjusted model providing less extreme predictions and can better be used in other populations.

In order to enable health care professionals with an easy applicable prediction rule, the adjusted regression coefficients of the predictive model were multiplied by a factor (10) and rounded to the nearest integer to form the scores for each of the predictors; these were then added to calculate an individual's total score (example in footnote to Table 5.1). In the current study population the estimated risk score ranged from 8.0 to 52.4 (mean 27.3 \pm 7.3 ). The discriminative performance of the risk score, i.e. the area under the receiveroperating characteristic curve (AUC), was 0.72 (95\% Cl: 0.69-0.75). 
After examination of the diagnostic and predictive values of the risk score for different cut-off points, the maximum summative sensitivity (i.e. the percentage of non-healers who are correctly identified - true positives) and specificity (i.e. the percentage of healers who are correctly identified - true negatives) was reached at a score of $\geq 30$ points $(63 \%$ and $72 \%$ respectively); the corresponding positive (+) and negative (-) predictive values were $40 \%$ and $87 \%$, respectively.

Table 5.1 Baseline characteristics and subsequent univariate and multivariate analysis of predictors of non-healing in the EURODIALE study population.

\begin{tabular}{|c|c|c|c|c|c|c|c|c|c|}
\hline \multicolumn{2}{|l|}{ Potential predictor } & \multirow[t]{2}{*}{$\begin{array}{l}\text { Characteristics } \\
\text { at baseline }\end{array}$} & \multicolumn{2}{|c|}{$\begin{array}{l}\text { Univariate } \\
\text { analyses }\end{array}$} & \multicolumn{4}{|c|}{ Multivariate analyses } & \multirow[b]{2}{*}{ Score* } \\
\hline & & & OR & $95 \% \mathrm{Cl}$ & $\beta$ & $\beta^{\prime}$ & OR & $95 \% \mathrm{Cl}$ & \\
\hline Age, yrs & & $64.7(12.5)$ & 1.32 & $1.17 ; 1.4 \mathrm{C}$ & 90.243 & 0.211 & 1.24 & $1.09 ; 1.40$ & 2 \\
\hline Male gender, \% & & 64.6 & 1.50 & $1.07 ; 1.97$ & 70.540 & 0.469 & 1.60 & $1.20 ; 2.14$ & 5 \\
\hline \multirow[t]{3}{*}{ Duration of diabetes, $\%$} & $<5$ yrs & 14.1 & 1.00 & & - & - & - & - & - \\
\hline & $5-10$ yrs & 16.1 & 0.96 & $0.56 ; 1.65$ & $5-$ & - & - & - & - \\
\hline & $>10 \mathrm{yrs}$ & 69.8 & 1.05 & $0.69 ; 1.60$ & 0 - & - & - & - & - \\
\hline \multirow[t]{3}{*}{ Size of ulcer, $\%$} & $<1 \mathrm{~cm} 2$ & 37.2 & 1.00 & & & & 1.00 & - & - \\
\hline & $1-5 \mathrm{~cm} 2$ & 52.0 & 2.25 & $1.60 ; 3.17$ & 70.814 & 0.706 & 2.03 & $1.49 ; 2.76$ & 7 \\
\hline & $>5 \mathrm{~cm} 2$ & 10.8 & 4.22 & $2.64 ; 6.72$ & 21.356 & 1.177 & 2.25 & $2.12 ; 4.97$ & 12 \\
\hline Deep ulcer, \% & & 43.8 & 1.66 & $1.25 ; 2.20$ & 0 - & - & - & - & - \\
\hline \multirow[t]{3}{*}{ Duration of ulcer, \% } & $<1$ wk & 17.0 & 1.00 & & - & - & - & - & - \\
\hline & \multicolumn{2}{|c|}{$1 \mathrm{wk}-3 \mathrm{mo} 58.1$} & 1.81 & $1.15 ; 2.85$ & & - & - & - & - \\
\hline & $>3 \mathrm{mo}$ & 24.9 & 2.61 & $1.60 ; 4.27$ & 7 - & - & - & - & - \\
\hline \multicolumn{2}{|l|}{ Plantar location, \% } & 48.2 & 0.73 & $0.55 ; 0.98$ & $8-$ & - & - & - & - \\
\hline \multicolumn{2}{|l|}{ Pretibial Oedema, \% } & 18.2 & 1.79 & $1.27 ; 2.51$ & $1-$ & - & - & - & - \\
\hline \multicolumn{2}{|c|}{ Heart failure (NYHA III-IV), \% } & 10.9 & 2.03 & $1.35 ; 3.05$ & 50.440 & 0.382 & 1.47 & $0.99 ; 2.16$ & 4 \\
\hline \multicolumn{2}{|l|}{ Neurological disorder, \% } & 6.5 & 1.44 & $0.85 ; 2.46$ & $6-$ & - & - & - & - \\
\hline \multicolumn{2}{|c|}{ Inability to stand or walk without help, \% } & 9.9 & 2.50 & $1.62 ; 3.79$ & 90.693 & 30.602 & 1.83 & $1.23 ; 2.70$ & 6 \\
\hline \multicolumn{2}{|l|}{ Visual impairment, \% } & 15.3 & 1.36 & $0.94 ; 1.98$ & $8-$ & - & - & - & - \\
\hline \multicolumn{2}{|c|}{ End Stage Renal Disease, \% } & 5.8 & 2.20 & $1.30 ; 3.73$ & 30.922 & 0.800 & 2.26 & $1.35 ; 3.68$ & 8 \\
\hline \multicolumn{2}{|l|}{ Polyneuropathy, \% } & 78.5 & 1.41 & $0.98 ; 2.04$ & 40.348 & 30.302 & 1.35 & $0.97 ; 1.89$ & 3 \\
\hline \multicolumn{2}{|l|}{ Infection, \% } & 57.2 & 1.47 & $1.09 ; 2.00$ & $0-$ & - & - & - & - \\
\hline \multicolumn{2}{|c|}{ Peripheral arterial disease, \% } & 47.5 & 2.31 & $1.72 ; 3.10$ & 0.536 & 0.465 & 1.59 & $1.20 ; 2.12$ & 5 \\
\hline
\end{tabular}

$\beta$, logistic regression coefficient in multivariate analyses; $\beta$, logistic regression after shrinkage $(=\beta \times$ shrinkage factor); Shrinkage factor $=0.868$ (calculated from bootstrapping); OR, odds ratio; $\mathrm{Cl}$, confidence interval; * obtained by multiplying the shrunk regression coefficient by 10 and rounded to the nearest integer.

Example for total risk score calculation: a 60 year-old (12 points) men ( 5 points), with an ulcer size $>5 \mathrm{~cm} 2$ (12 points), and heart failure (4 points) and PAD (5 points), and none of the remaining characteristics will have a probability of non-healing of 0.31 (score of 38 points). 


\section{Conclusions}

We have developed a simple risk scoring rule, based on a set of variables easily assessed in clinical practice. These included not only patients' ulcer characteristics but also co-morbidities such as ESRD and heart failure. The inclusion of some co-morbidities in the final predictive model sustains the view that a holistic approach adopted by health care professionals that are familiar with the treatment of complicated diabetic patients is essential in order to identify the high-risk patient (i.e. with a risk score $\geq 30$ points) in order to start early and aggressive treatment.

Although our study population is based upon a large European prospective cohort, our findings may not be generalized to all diabetic foot ulcer patients. We have excluded patients with a previous ulcer within 12 months prior to presentation (i.e. we probably excluded patients with recurrent ulcers). The estimates obtained in our models may therefore have underestimated the probability of non-healing. Nevertheless, our study has the advantage of not being restricted to a highly selected group of tertiary referrals, since most patients were directly referred from primary care $(67 \%)$. Since the study was embedded in daily clinical practice, limitations had to be set with regard to the amount and type of data collected. Finally, although we have validated internally (with bootstrapping techniques) a predictive model for use in future patients, external validation in an independent sample is still warranted. The current risk score will be made available at the Eurodiale Study website (www.eurodiale.org). 


\section{References}

1. Nabuurs-Franssen MH, Huijberts MS, Nieuwenhuijzen Kruseman AC, Willems J, Schaper NC. Health-related quality of life of diabetic foot ulcer patients and their caregivers. Diabetologia 2005;48:1906-1910

2. Apelqvist J, Ragnarson-Tennvall G, Persson U, Larsson J. Diabetic foot ulcers in a multidisciplinary setting. An economic analysis of primary healing and healing with amputation. J Intern Med 1994;235:463-471

3. Apelqvist J, Ragnarson-Tennvall G, Larsson J, Persson U. Long-term costs for foot ulcers in diabetic patients in a multidisciplinary setting. Foot Ankle Int 1995;16:388-394

4. Ragnarson Tennvall G, Apelqvist J. Health-economic consequences of diabetic foot lesions. Clin Infect Dis 2004;39 S2:S132-139

5. Apelqvist J, Bakker K, van Houtum WH, Nabuurs-Franssen MH, Schaper NC. International consensus and practical guidelines on the management and the prevention of the diabetic foot. International Working Group on the Diabetic Foot. Diabetes Metab Res Rev 2000;16 S1:S84-92

6. Prompers L, Huijberts M, Apelqvist J, Jude E, Piaggesi A, Bakker K, Edmonds M, Holstein P, Jirkovska A, Mauricio D, Ragnarson Tennvall G, Reike H, Spraul M, Uccioli L, Urbancic V, van Acker K, van Baal J, van Merode F, Schaper N. Optimal organisation of health care in diabetic foot disease. Introduction to the Eurodiale study. Int J Low Extrem Wounds 2007; 6:11-17.

7. Prompers L, Schaper N, Apelqvist J, Edmonds M, Jude E, Mauricio D, Uccioli K, Urbanic V, Bakker K, Holstein P, Jirkovska A, Piaggesi A, Ragnarson Tennvall G, Reike H, Spraul M, van Acker K, van Baal J, van Merode F, Ferreira I, Huijberts M. Predictors of outcome in individuals with diabetic foot ulcers. Focus on the differences between individuals with and without peripheral arterial disease. The Eurodiale study. Diabetologia 2008, Accepted for publication.

8. Prompers L, Huijberts M, Apelqvist J, Jude E, Piaggesi A, Bakker K, Edmonds M, Holstein P, Jirkovska A, Mauricio D, Ragnarson Tennvall G, Reike H, Spraul M, Uccioli L, Urbancic V, Van Acker K, van Baal J, van Merode F, Schaper N. High prevalence of ischaemia, infection and serious comorbidity in patients with diabetic foot disease in Europe. Baseline results from the Eurodiale study. Diabetologia 2007;50:18-25

9. Schaper NC, Apelqvist J, Bakker K. The international consensus and practical guidelines on the management and prevention of the diabetic foot. Curr Diab Rep 2003;3:475-479

10. Schaper NC. Diabetic foot ulcer classification system for research purposes: a progress report on criteria for including patients in research studies. Diabetes Metab Res Rev 2004;20 S1:S90-95

11. Van Houwelingen S, Le Cessie S. Predictive value of statistical models. Stat Med 1990; 9:1303-1325

12. Moons K. J Epidemiol Community Health 2002;56:i30-i36 


\section{Chapter 6}

Resource utilisation and costs associated with the treatment of diabetic foot ulcers. Prospective data from the Eurodiale study

Prompers L, Huijberts M, Schaper N, Apelqvist J, Bakker K, Edmonds M, Holstein P, Jude E, Jirkovska A, Mauricio D, Piaggesi A, Reike H, Spraul M, van Acker K, van Baal J, van Merode F, Uccioli L, Urbancic V, Ragnarson Tennvall G. 


\section{Abstract}

Aims/hypothesis

The aim of the study was to investigate resource utilisation and associated costs in patients with diabetic foot ulcers and to analyse differences in resource utilisation between individuals with or without PAD (peripheral arterial disease) and with or without infection.

\section{Methods}

Data on resource utilisation were collected prospectively in a European multicentre study. For the analysis of resource use 1088 patients were available and 821 patients were included in the costing analysis. Costs were calculated for each patient by multiplying the country specific direct and indirect unit costs by the number of resources used from inclusion into the study and until a defined endpoint. Country specific costs were transformed to Purchasing Power Standards (PPS).

\section{Results}

Resource use as well as costs varied between outcome groups, and between disease severity groups. The highest cost per patient was found for hospitalisation, antibiotics, amputations and other surgery. All type of resource utilisation and costs increased with the severity of disease. The total cost per patient was more than four times higher for patients with both infection and PAD at inclusion compared with patients in the least severe group.

\section{Conclusion / interpretation}

Important differences in resource use and costs were found between different patient groups. Individuals with both peripheral arterial disease and infection are most expensive, which is mainly related to substantial costs for hospital admission. Future interventions should focus on preventive and therapeutic strategies to reduce in-hospital stay. The cost-effectiveness of such strategies should be evaluated before introduced into routine clinical practice. 


\section{Introduction}

Diabetic foot disease is a relatively common complication of both type 1 and type 2 diabetes. The impact of diabetic foot disease is substantial; patients with diabetes who develop foot ulcers have a very low quality of life, treatment is long and intensive, and the associated use of resources is high. Recently a review was published on the economic aspects of diabetic foot care in a multidisciplinary setting. Average cost per treatment episode varied between 5,000 US Dollars and 15,000 US Dollars approximately. Costs for major amputation added up to more than 40,000 US Dollars ${ }^{1}$. However none of the studies that have been performed contained prospective data. In all of these studies data on resource utilisation and costs were collected retrospectively.

The pathophysiology of diabetic foot disease is complex and several factors may play a role in the development of foot ulcers such as the presence of diabetic polyneuropathy and/or peripheral arterial disease (PAD). Moreover these ulcers may or may not become infected. Therefore the population of individuals presenting with diabetic foot ulcers is relatively heterogeneous. When all patients in the Eurodiale study were grouped into stages according to the presence or absence of PAD and infection, individuals with both PAD and infection were older, more often had severe co-morbidity and frequently had larger ulcers at presentation, most of which were non-plantar ${ }^{2}$. Many of these factors also predicted non-healing ${ }^{3}$. Poor healing is likely to be associated with high resource utilisation. Because the characteristics of patients that are treated in diabetic foot units may be very different it is important to obtain prospective data on resource utilisation and associated costs in relation to specific patient characteristics.

The aim of this study was to analyse resource utilisation and associated costs in a large cohort of well-characterised patients with diabetic foot ulcers and to determine the differences in resource utilisation between individuals with or without the presence of PAD and with or without infection.

\section{Subjects, material and methods}

\section{Study design and population}

The Eurodiale consortium is an international collaborative network of fourteen European diabetic foot centres that was created to stimulate research in the field of diabetic foot disease. The design and rationale of this study have been described in detail elsewhere ${ }^{2-4}$. Briefly, between September $1^{\text {st }} 2003$ and 
October $1^{\text {st }} 2004$ patients with a new foot ulcer were included in 14 diabetic foot centres in 10 European countries. All participating centres have a longstanding expertise in the field of diabetic foot disease. A total of 1232 patients were enrolled in the study and 1088 were followed until endpoint. The mean number of included patients per centre was 88 (40-125).

\section{Inclusion criteria}

Diabetic patients with a new foot ulcer presenting for the first time within a period of twelve months at the outpatient or inpatient clinic of the participating hospitals, were included into the study.

\section{Exclusion criteria}

Patients treated for an ulcer on the ipsilateral foot during the past 12 months in the participating centres were excluded. Patients with a life expectancy shorter than 1 year were excluded on account of anticipated problems with follow up.

Subjects attended follow-up visits on a monthly basis until an endpoint was reached or for a maximum period of twelve months. Endpoints were healing of the complete foot, major amputation and death. At baseline and during all follow-up visits data were collected and recorded on standardized case record forms (CRF's), by dedicated investigators in each centre that were trained during plenary meetings and on-site visits. Main characteristics of all patients available for evaluation are presented in Table 6.1.

\section{Informed consent and ethics committee approval}

The study was approved by local ethics committees in all countries and all subjects gave written informed consent.

\section{Unit cost data}

Costing consists of two elements: measurement of the quantities of resource use and the assignment of unit costs. In the present study the analysis of resource utilisation for management of patients with diabetic foot ulcers is based on the study data for all patients followed until endpoint and available for analysis $(n=1088)$.

In order to analyse reliable and representative data, only countries with at least 80 patients available for analysis were included in the cost analysis. In addition, countries where complete information about unit costs for every type of resources used could not be provided were excluded from the cost analyses. 
Table 6.1 Patient characteristics at inclusion. ${ }^{1}$ Number of patients in each category with percentage within parentheses except for the age variable.

\begin{tabular}{lc}
\hline Patient characteristics & All patients available for evaluation \\
& $\mathrm{n}=1088$ \\
\hline Age, mean (min-max) & $65(24-95)$ \\
Gender & $704(65)$ \\
Males & $384(35)$ \\
Females & \\
Ulcer duration at inclusion & $184(17)$ \\
$<1$ week & $625(57)$ \\
$<3$ months & $269(25)$ \\
$>3$ months & \\
Ulcer size at inclusion & $403(37)$ \\
$<1.0 \mathrm{~cm}^{2}$ & $561(52)$ \\
$1.0-5.0 \mathrm{~cm}^{2}$ & $117(11)$ \\
$>5.0 \mathrm{~cm}^{2}$ & \\
Depth of ulcer at inclusion & $612(56)$ \\
superficial ulcer & $476(44)$ \\
deep ulcer & \\
Co-morbidity & $117(11)$ \\
Heart failure NYHA III-IV & $107(10)$ \\
Inability to stand or walk without help & $70(6)$ \\
Neurological disorder & $164(15)$ \\
Visual impairment & $63(6)$ \\
End stage renal disease & \\
\hline
\end{tabular}

Values for every variable were not available for all evaluated patients

Unit cost data were collected from official pricelists or from other national sources in each country. Centre representatives should normally not calculate the unit costs by themselves except for antibiotics and dressings. In these two cases they were asked to calculate the daily cost of each type of antibiotics used in the trial and the cost per dressing change for each type of dressings used. In both cases the calculations were based on prices from official pricelists. The unit costs should as far as possible reflect the "true" resource utilisation in each country. Therefore the unit cost for example of a procedure, a drug, or a visit to the clinic included the total cost, irrespectively of who is paying all costs or part of the costs. Payers could e.g. be the patient, the hospital, an authority, an insurance company, or several of them. Thus, in the present study resource utilisation and costs are analysed and described irrespectively of financing of the resources as an attempt to illustrate "the true" costs of diabetic foot disease.

Unit costs for all type of resources used in management of diabetic foot ulcers were provided by seven (Czech Republic, Denmark, Italy, the Netherlands, Slovenia, Sweden, and the UK) of the ten participating countries (ten centres) and filled in a specific unit cost form. In total, $75 \%$ of the patients available for analysis were included $(n=821)$ in the economic analysis. 
The unit cost form was based on the items present in the entry form and the follow-up form of the Eurodiale study ${ }^{2-4}$. It contained questions about local currency, year of cost data, unit costs for inpatient and outpatient care, investigations, interventions, antibiotics, different types of staff, topical dressings, transport, and income of the general population. For each type of resource it was possible to include additional comments, e.g. if any unit cost referred to another year than the majority of the other unit costs. In addition, the sources where the unit costs were collected from were given.

\section{Cost calculation}

Costs were calculated individually for each patient according to the resource utilisation indicated in the entry form and the follow-up forms. Each type of resource was multiplied with the corresponding unit cost in each country. Costs were calculated from the entry date until the final visit date. Any unrealistic values of resource utilisation have been checked and if necessary recoded in order not to overestimate resource use and costs.

\section{Diagnostic procedures}

Costs of diagnostic procedures were calculated according to the number of each type of procedure performed for a patient multiplied with the unit cost of that procedure. All costs were then added up to a total cost per patient for diagnostic procedures.

\section{Offloading}

Offloading costs were calculated according to the total number of footwear, insoles, orthoses, and casts that were prescribed for a patient and multiplied with the unit cost for each type of offloading. All costs were then added to a total cost per patient for offloading.

\section{Interventional procedures}

Costs of interventional procedures were calculated according to the number and type of procedures that were performed.

\section{Antibiotic therapy}

The number of treatment days for each prescription of antibiotics was calculated by subtracting the start date from the stop date of the prescription. The total number of treatment days per patient for all antimicrobial drugs were then multiplied with the average daily cost of the drugs used in a centre or country. For patients receiving more than one antibiotic drug at the same time 
the number of treatment days for each drug was added and is expressed as total number of daily doses.

\section{Hospitalisation}

The costs of hospitalisation were calculated according to the number of days in hospital for a patient multiplied with the unit cost for an inpatient day at the centre of admission. The cost of an inpatient day, "the hotel cost" was defined as the basic cost including food, accomodation, administration services, nursing and other staff costs.

\section{Management by clinical specialists}

Costs for management by different types of clinical specialists were calculated according to the unit cost for each type of specialist and the number of consultations. For patients treated in inpatient care and with an admission duration of one week or longer between each study visit a maximum number of one consultation per type of specialist during that period was included with the exception of visits to family doctors and internists outside hospital.

\section{Topical treatment}

Costs for topical treatment were calculated for dressing material, staff that performed dressing changes, and transportation. Staff costs were calculated for dressing changes performed by health care workers inside or outside the hospital. If the patient or a relative or a friend performed dressing changes no staff costs were calculated. Material costs were calculated for all dressing changes and differentiated according to type of dressing. A specified list of dressings was included in the CRF, if "other" dressing or "not known" was indicated the average cost of all other type of dressings used in that centre was applied in the calculations. Transportation costs were calculated based on the information in the entry data form about distance between the patient's home and the hospital. Transportation costs were included for all dressing changes that were performed by health care workers outside or inside hospital. That means that transportation costs are included in the analysis irrespectively of whether it was the patient or a health care worker who travelled.

\section{Indirect costs}

Indirect costs related to loss of production were analysed for patients who had an employment and who had been on sickness leave because of the foot ulcer. Costs were calculated according to the number of weeks a patient had been on 
sickness leave multiplied with the average income per week of the general population in the country of residence.

\section{Cost conversions and currency}

All costs are expressed in Euro $(€)$ in 2005 years prices. If the unit cost for a specified resource was not available for 2005 the unit cost from another year was adjusted to 2005 years prices with country specific consumer price index. Information about consumer price index was collected from official statistics in each country or from the European Central Bank. Local currencies were converted to Euro with the official exchange rates at the end of 2005 collected from the European Central Bank. In addition, to adjust for differences in price levels between countries, conversions of costs were made by a volume index of GDP (gross domestic product) per capita in Purchasing Power Standards (PPS). The viewpoint or perspective of the study is the society, i.e. both direct and indirect costs are considered irrespectively of source of financing of resources.

\section{Statistical analyses}

Statistical analysis and cost calculations were performed using the SPSS statistical package version 12.0.2 (SPSS, Chicago, III., USA).

\section{Results}

\section{Resource utilisation for management of diabetic foot ulcers}

Resource utilisation for the different disease severity groups is shown in Table 6.2. The disease severity score is based on the presence at baseline of PAD (peripheral arterial disease) and infection; group $A$ contains patients without infection and PAD, group $B$ patients with infection but without PAD, group $C$ patients with PAD but without infection and group $D$ patients with both infection and PAD. A number of patients $(n=71)$ could not be classified into any disease severity score because of missing data. The average number of procedures used for diagnoses and investigations was generally low. Microbiology was the most frequently used diagnostic procedure and temporary footwear and orthopaedic shoes were the most frequently used offloading techniques in all groups (data not shown). The resource use differed a lot between individual patients illustrated by the large differences between minimum and maximum values for many of the variables. A rather high percentage of patients were treated in inpatient care, from $22 \%$ of patients in the group with the least severe disease (Grade A) to 67 percent of patients with both infection and PAD (Grade 
D). Not surprisingly treatment with antibiotics was most frequent in patients with infection (69\%) and patients with both infection and PAD (70\%) but it was common in all outcome groups. Consultations with medical specialists and paramedics were frequent in all groups too.

Table 6.2 Resource utilisation in relation to ulcer severity score. Average (min-max) number of procedures per patient except for inhospital care and antibiotics where the number of patients treated and percentage of patients are shown.

\begin{tabular}{|c|c|c|c|c|c|c|}
\hline Resources & $\begin{array}{l}\text { Grade A } \\
\text { Without } \\
\text { infection } \\
\text { and PAD } \\
n=245\end{array}$ & $\begin{array}{l}\text { Grade B } \\
\text { With } \\
\text { infection } \\
\mathrm{n}=276\end{array}$ & $\begin{array}{l}\text { Grade C } \\
\text { With PAD }\end{array}$ & $\begin{array}{l}\text { Grade } D \\
\text { With both } \\
\text { infection } \\
\text { and PAD } \\
n=290\end{array}$ & No grading ${ }^{a}$ & $\begin{array}{l}\text { All patients } \\
\text { available for } \\
\text { evaluation } \\
n=1088\end{array}$ \\
\hline \multicolumn{7}{|l|}{ Inhospital care } \\
\hline $\begin{array}{l}\text { - patients treated in inpatient } \\
\text { care }\end{array}$ & $55(22.4)$ & $118(42.8)$ & $86(46.0)$ & $199(68.6)$ & $39(43.3)$ & $497(45.7)$ \\
\hline -inhospital weeks & $0.66(0-12)$ & $1.91(0-31)$ & $2.53(0-36)$ & $3.90(0-52)$ & $2.32(0-36$ & $2.30(0-52)$ \\
\hline \multicolumn{7}{|l|}{ Amputations } \\
\hline - contralateral amputation & $0.02(0-4)$ & $0.04(0-4)$ & $0.02(0-2)$ & $0.03(0-2)$ & $0.04(0-2)$ & $0.03(0-4)$ \\
\hline $\begin{array}{l}\text {-ipsilateral amputation below } \\
\text { the ankle }\end{array}$ & $0.10(0-2)$ & $0.18(0-2)$ & $0.22(0-4)$ & $0.40(0-4)$ & $0.19(0-3)$ & $0.23(0-4)$ \\
\hline - above the ankle (lower leg) & $0.01(0-1)$ & $0.00(0-1)$ & $0.03(0-1)$ & $0.08(0-1)$ & $0.02(0-1)$ & $0.03(0-1)$ \\
\hline \multicolumn{7}{|l|}{ Other interventions and surgery } \\
\hline - re-vascularisation ${ }^{\mathrm{b}}$ & $0.03(0-2)$ & $0.02(0-1)$ & $0.22(0-3)$ & $0.41(0-8)$ & $0.28(0-8)$ & $0.18(0-8)$ \\
\hline $\begin{array}{l}\text { - other interventions and } \\
\text { surgery }\end{array}$ & $0.68(0-32)$ & $1.33(0-20)$ & $1.28(0-34)$ & $1.87(0-49)$ & $1.37(0-23)$ & $1.32(0-49)$ \\
\hline $\begin{array}{l}\text { Diagnostic procedures and } \\
\text { investigations } s^{d}\end{array}$ & $2.24(0-18)$ & $3.20(0-23)$ & $3.35(0-25)$ & $4.54(0-22)$ & $4.00(0-25)$ & $3.43(0-25)$ \\
\hline \multicolumn{7}{|l|}{ Antibiotic therapy } \\
\hline - patients treated with antibiotics & $117(47.8)$ & $191(69.2)$ & $101(54.0)$ & $204(70.3)$ & $49(54.4)$ & $662(60.8)$ \\
\hline - total number of daily doses & $29.8(0-619)$ & $43.1(0-350)$ & $35.4(0-327)$ & $46.7(0-361)$ & $36.9(0-305)$ & $39.21(0-619)$ \\
\hline Offloading ${ }^{e}$ & $1.90(0-11)$ & $2.40(0-15)$ & $2.29(0-14)$ & $2.38(0-12)$ & $2.14(0-20)$ & $2.24(0-20)$ \\
\hline Dressing changes & $74.3(0-349)$ & $69.2(0-336)$ & $74.4(0-355)$ & $79.0(0-348)$ & $70.7(0-337)$ & $73.98(0-355)$ \\
\hline \multicolumn{7}{|l|}{ Consultations/outpatient visits } \\
\hline - medical specialists ${ }^{f}$ & $5.60(0-36)$ & $7.01(0-60)$ & $6.50(0-101)$ & $9.52(0-106)$ & $7.09(0-62)$ & $7.28(0-106)$ \\
\hline - wound care specialist $^{g}$ & $1.00(0-31)$ & $1.36(0-25)$ & $1.12(0-36)$ & $1.01(0-26)$ & $0.49(0-16)$ & $1.08(0-36)$ \\
\hline - paramedics ${ }^{\mathrm{h}}$ & $5.51(0-69)$ & $7.72(0-80)$ & $6.72(0-91)$ & $7.50(0-106)$ & $12.10(0-133)$ & $7.35(0-133)$ \\
\hline Sickness leave (weeks) & $1.37(0-38)$ & $2.38(0-39)$ & $0.78(0-43)$ & $0.72(0-34)$ & $0.74(0-24)$ & $1.30(0-43)$ \\
\hline
\end{tabular}

a 71 patients could not be linked to any of the four types of severity scores. ${ }^{b}$ Re-vascularisation: vascular surgery, PTA. ${ }^{c}$ Other interventions and surgery: surgical debridement, plastic surgery, orthopaedic surgery, other surgery. ${ }^{\mathrm{d}}$ Diagnostic procedures and interventions: pressure platform, toe pressure, ankle pressure, $\mathrm{TcPO}_{2}$, duplex, $\mathrm{X}$-ray, contrast angiography, scintigram, MRA, MRI, CT-scan, bone biopsy, microbiology. ${ }^{\mathrm{e}}$ Offloading: temporary footwear, orthopaedic shoes, TCC, insoles, orthoses, other casts. ${ }^{f}$ Medical specialist: family doctor, internist working inside or outside hospital, diabetologist, general surgeon, vascular surgeon, orthopaedic surgeon, plastic surgeon, infectious disease specialist, radiologist, dermatologist, rehabilitation specialist. ${ }^{9}$ Wound care specialist could be either medical specialist or paramedics according to local practice. ${ }^{\mathrm{h}}$ Paramedics: podiatrist or chiropodist, orthopaedic shoemaker or orthotist, cast technician, diabetic nurse, district nurse or home care nurse, dietician.

\section{Costs of diabetic foot ulcers}

The total treatment cost per patient in relation to disease severity is illustrated in Table 6.3. In all disease severity groups the costs of hospitalisation and 
antibiotics represented a large part of the total direct costs. In addition, the average costs of amputation, re-vascularisation, and other interventions and surgery were high in patients with both infection and PAD (grade D). For patients in the most severe group (Grade D) the average total costs were almost four times as high as for patients with the least severe disease (Grade A). On the other hand, the indirect costs were higher in the two groups with the least severe disease ( $A$ and $B$ ) than in the two more severe groups ( $C$ and $D)$. This illustrates a higher extent of employment in patients with less severe disease.

Table 6.3 Resource utilisation in relation to ulcer severity score. Direct and indirect costs per patient with diabetic foot ulcers (Euro, 2005 prices, weighted PPS).

\begin{tabular}{|c|c|c|c|c|c|c|c|c|c|c|c|c|}
\hline Resource use & $\begin{array}{l}\text { Grade } \\
\text { Withou } \\
\text { infectic } \\
\text { PAD } \\
n=204\end{array}$ & $\begin{array}{l}\text { A } \\
\text { ut } \\
\text { on and } \\
(\%)\end{array}$ & $\begin{array}{l}\text { Grade } \\
\text { With } \\
\text { infectic }\end{array}$ & & $\begin{array}{l}\text { Grade } \\
\text { With P }\end{array}$ & $\begin{array}{l}C \\
A D\end{array}$ & \multicolumn{2}{|c|}{$\begin{array}{l}\text { Grade D } \\
\text { With both } \\
\text { infection and } \\
\text { PAD }\end{array}$} & No gra & $\begin{array}{l}\text { ading }^{a} \\
(\%)\end{array}$ & \multicolumn{2}{|c|}{$\begin{array}{l}\text { All patients } \\
\text { included in } \\
\text { costing } \\
\text { analysis }\end{array}$} \\
\hline \multicolumn{13}{|l|}{ Direct costs } \\
\hline - hospitalisation & 808 & $(18)$ & 3703 & $(40)$ & 4433 & $(45)$ & 6787 & $(40)$ & 4599 & $(40)$ & 3892 & (39) \\
\hline - amputations & 198 & $(4)$ & 499 & (5) & 594 & (6) & 2411 & (14) & 687 & (6) & 889 & (9) \\
\hline - re-vascularisation & 44 & 1 & 62 & (1) & 685 & $(7)$ & 1309 & (8) & 1213 & $(11)$ & 554 & (5) \\
\hline $\begin{array}{l}\text { - other interventions and } \\
\text { surgery }\end{array}$ & 550 & $(12)$ & 992 & (11) & 897 & (9) & 1553 & (9) & 937 & (8) & 986 & $(10)$ \\
\hline $\begin{array}{l}\text { - diagnostic procedures and } \\
\text { investigations }\end{array}$ & 74 & $(2)$ & 111 & (1) & 190 & (2) & 260 & (2) & 225 & (2) & 160 & (2) \\
\hline - antibiotics & 847 & (19) & 1146 & $(12)$ & 1147 & $(12)$ & 1846 & (11) & 764 & /7) & 1197 & $(12)$ \\
\hline $\begin{array}{l}\text { - offloading/orthopaedic } \\
\text { appliances }\end{array}$ & 435 & $(10)$ & 448 & (5) & 447 & (5) & 503 & (3) & 445 & (4) & 457 & (5) \\
\hline - topical treatment & 368 & $(8)$ & 446 & (5) & 679 & $(7)$ & 1057 & (6) & 1029 & (9) & 658 & $(7)$ \\
\hline - consultations/outpatient visits & 448 & $(10)$ & 707 & (8) & 549 & (6) & 687 & (4) & 1221 & $(11)$ & 653 & (6) \\
\hline Total direct costs & 3771 & & 8113 & & 9622 & & 16414 & (3) & 11120 & & 9446 & \\
\hline Indirect costs & 743 & $(16)$ & 1160 & $(13)$ & 229 & 82) & 421 & & 335 & (3) & 645 & $(6)$ \\
\hline Total direct and indirect cost & 4514 & $(100)$ & 9273 & (100) & 9851 & $(100)$ & 16835 & $(100)$ & 11455 & $5(100)$ & ) 10091 & $(100)$ \\
\hline
\end{tabular}

${ }^{a} 71$ patients could not be linked to any of the four types of severity scores.

A similar cost pattern between different types of resources as shown in Table 6.3 can be seen also when costs are related to the clinical outcome during the one year study period (Table 6.4). The highest costs in all outcome groups were found for hospitalisation. Other resources with high costs were other interventions and surgery, and antibiotics. In patients who did not heal within the observation period of 12 months costs of topical treatment and consultations were high, underscoring the influence of the treatment duration for this type of resources. The highest total costs were found in patients who had undergone major amputations and the lowest in the group of patients who healed. The costs of diagnostic procedures, investigations, offloading or 
orthopaedic appliances were rather low in all groups irrespectively of disease severity or outcome (Table 6.3 and 6.4).

Table 6.4 Direct and indirect costs per patient in relation to outcome (Euro, 2005 prices, weighted PPS).

\begin{tabular}{|c|c|c|c|c|c|c|c|c|}
\hline \multirow[t]{2}{*}{ Resource use } & \multicolumn{2}{|l|}{ Healed } & \multicolumn{2}{|c|}{$\begin{array}{l}\text { Deceased } \\
\text { unhealed }\end{array}$} & \multicolumn{2}{|c|}{$\begin{array}{l}\text { Major } \\
\text { amputation }\end{array}$} & \multicolumn{2}{|c|}{$\begin{array}{l}\text { Not healed } \\
\text { within12 months }\end{array}$} \\
\hline & $\mathrm{n}=647$ & $(\%)$ & $n=34$ & $(\%)$ & $\mathrm{n}=36$ & $(\%)$ & $n=104$ & \\
\hline \multicolumn{9}{|l|}{ Direct costs } \\
\hline - hospitalisation ( & 2647 & (349 & 4771 & (55) & 10953 & (43) & 8907 & (44) \\
\hline - amputations & 602 & (8) & 498 & (6) & 6907 & (27) & 718 & $(4)$ \\
\hline - re-vascularisation & 538 & (7) & 238 & (3) & 624 & (2) & 734 & $(4)$ \\
\hline $\begin{array}{l}\text { - other interventions and } \\
\text { surgery }\end{array}$ & 712 & (9) & 949 & $(11)$ & 2894 & $(11)$ & 2042 & (10) \\
\hline $\begin{array}{l}\text { - diagnostic procedures and } \\
\text { investigations }\end{array}$ & 126 & $(2)$ & 104 & (1) & 289 & (1) & 345 & (2) \\
\hline - antibiotics & 1060 & (14) & 959 & (11) & 1208 & (5) & 2120 & (11) \\
\hline $\begin{array}{l}\text { - offloading/orthopaedic } \\
\text { appliances }\end{array}$ & 449 & (6) & 165 & $(2)$ & 360 & (1) & 636 & (3) \\
\hline - topical treatment & 473 & (6) & 470 & (5) & 922 & $(4)$ & 1780 & (9) \\
\hline - consultations/outpatient visits & 540 & (7) & 473 & (5) & 383 & (2) & 1508 & $(8)$ \\
\hline Total direct costs & 7147 & & 8628 & & 24540 & & 18790 & \\
\hline Indirect costs & 574 & (7) & 25 & $(0.3)$ & 681 & (3) & 1275 & (6) \\
\hline Total direct and indirect cost & 7722 & $(100)$ & 8653 & $(100)$ & 25222 & $(100)$ & 20064 & $(100)$ \\
\hline
\end{tabular}

Out of the 1088 patients who were available for evaluation, 821 were included in the costing analysis.

\section{Discussion}

In this study we have collected prospective data on resource use and costs associated with the treatment of diabetic foot ulcers. Costs are high with an average total direct and indirect cost of approximately 10,000 Euro, based on the costing data of 821 patients from the participating countries. Resource utilisation and costs varied importantly between the different outcome groups as well as between individuals with and without PAD and/or infection at baseline.

The average costs as reported in this study cannot easily be compared to data published in the current literature in view of the differences in included patients, duration of follow-up, and methods for analyses. The data may be compared to the single centre data from the early nineties in which costs for primary healing were approximately 8,950 US Dollars ${ }^{5}$ corresponding to about 7,412 Euro in 2005 prices. The results as reported by an American group based on medical and pharmaceutical claims data 2000 and 2001 include both in- and outpatients with and without PAD. The average direct cost per ulcer episode 
was 13,179 US Dollars (approximately 10,914 Euro), ranging from 5,218 US Dollars (4,321 Euro) in patients with adequate vascular status to 23,372 US Dollars(19,357 Euro) in individuals with inadequate vascular status ${ }^{6}$. In the present European study costing data are averaged from several countries including both low cost countries as well as high cost countries although costs were weighted to Purchasing Power Standards to compensate for that. These data demonstrate very clearly that treatment of diabetic foot disease is a major determinant of diabetes related resource utilisation and costs throughout Europe: If taken into account the 2003 prevalence data of 48 million people with diabetes in Europe and an ulcer incidence of $2 \%$ per year ${ }^{7}$, the costs associated with the treatment of diabetic foot ulcers may be as high as ten billion Euro per year.

It is clear from the present study that the costs for the treatment of individuals with PAD, especially in combination with infection are substantially higher than in patients without PAD. This is hardly related to higher costs for diagnostic procedures and interventions. Most of the excess costs in individuals with PAD and infection are related to higher rate of hospitalisation and higher costs of antibiotics, amputations, re-vascularisation, and other surgery. We have demonstrated previously that characteristics and predictors of outcome are very different in patients with and without PAD which suggest that these conditions should be regarded as separate disease states ${ }^{3}$. These resource and cost data support this concept.

It is remarkable that the majority of costs for the treatment of diabetic foot disease are related to hospital admissions. In the Eurodiale study $27 \%$ of the patients were admitted at baseline ${ }^{3}$. Traditionally these admissions are related to progressive tissue loss in context of PAD and/or infection. Probably strategies aimed at early referral, timely institution of antibiotic therapy and early vascular intervention may contribute to prevention of progressive tissue loss and may thereby reduce admission rates. The developments of such strategies should be one of the main priorities in diabetic foot care in the next years.

The costs for lower leg amputations found in this study are not completely comparable with previous studies. One of the explanations is that patients in the present study with a lower leg amputation were only followed until this amputation was performed, while for example in previous Swedish studies patients were followed and costs were calculated until the amputated leg was completely healed $^{5,8}$. This is one reason why the average costs of a major amputation was lower in the present study compared with previous publications. Another difference is that patients in the present study who had undergone minor amputations below the ankle are included into the group of 
healed patients while in the previous Swedish studies ${ }^{5,8}$ the costs of minor amputations were presented separately. The total average costs of the patients in the group who healed are therefore probably higher than if only patients who had healed primarily without a minor amputation had been included.

Another difference in comparison with a Swedish study is the relatively high proportion of antibiotic costs. In the present study the average costs of antibiotics were between $11 \%$ to $14 \%$ of the total direct costs for patients with infection, while the corresponding share in the previous study was $4.5 \%{ }^{8}$. One reason for this could be the use of more expensive antibiotics, more parenteral drugs, and longer treatment periods today. This stress the importance of performing multi-national studies since it is known that policies of prescribing antibiotics differ substantially between countries.

Advantages of the present economic analysis are the large number of patients included and that 10 European countries participated in the resource use analysis and data from 7 countries and 10 centres were available for the cost analysis. Another advantage in comparison with some other costing studies of the diabetic foot is that patients were referred to the participating centres with a new foot ulcer and were followed prospectively until a defined endpoint.

One limitation of the study is that unit cost data could not be collected from all participating countries because of too low numbers ( $<80$ patients included per country) and difficulties in obtaining such data in some countries. However cost calculations were possible for seven of the ten countries or $75 \%$ of the patients included. Difficulties to collect reliable unit costs for cost calculation have previously been described and should not be neglected when planning healtheconomic studies ${ }^{9}$. These difficulties indicate the importance of illustrating resource utilisation in physical quantities too. Another limitation is that the analysis of resource utilisation and costs do not include the total resources used for management of diabetic foot disease because patients could have been treated for their present foot ulcer somewhere else before they were included into the study. That means that the resource use and costs illustrated in this report are probably even higher. It is generally difficult to catch information about this type of resource use retrospectively. This problem can also be seen in many other cost analyses. Another reason why costs and resource use probably are underestimated is that the follow-up forms for practical reasons had questions with an alternative answer with a maximum number of resources, e.g. $>10$ visits since the last visit. In such cases the visits were calculated as 11 visits but they could have been even more.

There is still a need for future studies on diabetic foot disease with a healtheconomic approach. The collected data from the present study are unique thanks to the large patient population that was monitored prospectively in 
clinical practice until a final treatment outcome, or for a period of 12 months, with no predetermined intervention options. The present information is important in illustrating the magnitude of the problem in economical terms for decision makers both within and outside the health care system. Moreover, it can help us to define target groups were improvement in care could result in major savings in health care expenditure. Up to now many publications in the field of diabetic foot disease are related to wound healing in patients with a neuropathic foot ulcer, the group with the lowest costs in our analyses. Although several studies have been published on the treatment of infection, patients with PAD were usually excluded or not specifically analysed in these studies. Our data suggest that to reduce the high costs of diabetic foot disease, major efforts should be undertaken to improve the treatment in this subgroup of patients, who have the highest costs and the poorest outcome.

This health-economic study is mainly descriptive but the materials and data base on which it is based form an exclusive and valuable source for future health-economic model simulations, making it possible to analyse the costeffectiveness of different management strategies. Such studies may be helpful to achieve a more cost-effective use of the resources in health care and in the society.

In conclusion, the costs of diabetic foot ulcers are highly related to the outcome and the severity of the disease and the cost increases sharply in patients with both PAD and infection. Given these high costs there is an urgent need for efforts to prevent these conditions and for new strategies to treat them more effectively, at an earlier stage. 


\section{References}

1. Matricali GA, Dereymaeker G, Muls E, Flour M, Mathieu C. Economic aspects of diabetic foot care in a multidisciplinary setting: a review. Diabetes Metab Res Rev DOI 2007;23:339-347

2. Prompers L, Huijberts M, Apelqvist J, Jude E, Piaggesi A, Bakker K, Edmonds M, Holstein P, Jirkovska A, Mauricio D, Ragnarson Tennvall G, Reike H, Spraul M, Uccioli L, Urbancic V, Van Acker K, van Baal J, van Merode F, Schaper N. High prevalence of ischaemia, infection and serious comorbidity in patients with diabetic foot disease in Europe. Baseline results from the EURODIALE study. Diabetologia 2007;50:18-25

3. Prompers L, Huijberts M, Apelqvist J, Jude E, Piaggesi A, Bakker K, Edmonds M, Holstein P, Jirkovska A, Mauricio D, Tennvall GR, Reike H, Spraul M, Uccioli L, Urbancic V, Van Acker K, Van Baal J, Van Merode F, Schaper N. Optimal organization of health care in diabetic foot disease: introduction to the Eurodiale study. Int J Low Extrem Wounds 2007;6: 11-17

4. Apelqvist J, Ragnarson Tennvall G, Persson U, Larsson J. Diabetic foot ulcers in a multidisciplinary setting. An economic analysis of primary healing and healing with amputation. J Intern Med 1994;235:463-471

5. Stockl K, Vanderplas A, Tafesse E, Chang E. Costs of lower-extremity ulcers among patients with diabetes. Diabetes Care 2004;27:2129-2134

6. Boulton AJ, Vileikyte L, Ragnarson Tennvall G, Apelqvist J. The global burden of diabetic foot disease. Lancet 2005;366:1719-1724

7. Prompers L, Schaper N, Apelqvist J, et al. Predictors of outcome in individuals with diabetic foot ulcers. Focus on the differences between individuals with and without peripheral arterial disease. 2007, submitted

8. Ragnarson Tennvall G, Apelqvist J, Eneroth M. Costs of deep foot infections in patients with diabetes mellitus. Pharmacoeconomics 2000;18:225-238

9. Schulman K, Burke J, Drummond M, Davies L, Carlsson P, Gruger J, Harris A, Lucioni C, Gisbert R, Llana T, Tom E, Bloom B, Willke R, Glick H. Resource costing for multinational neurologic clinical trials: methods and results. Health Economics 1998;7:629-638 


\section{Chapter 7}

Delivery of care to diabetic foot ulcer patients in daily practice: Results of the Eurodiale study, a prospective cohort study

Prompers L, Huijberts M, Apelqvist J, Jude E, Piaggesi A, Bakker K, Edmonds M, Holstein P, Jirkovska A, Mauricio D, Ragnarson Tennvall G, Reike H, Spraul M, Uccioli L, Urbancic V, van Acker K, van Baal J, van Merode F, Schaper N.

Diabetic Medicine, 2008, accepted for publication 


\section{Abstract}

Objective

To determine current management and to identify patient related factors and barriers that influence management strategies in diabetic foot disease.

Patients and methods

The Eurodiale Study is a prospective cohort study of 1232 consecutive individuals presenting with a new diabetic foot ulcer in 14 centres across Europe.

Main outcome measures

Use of management strategies in terms of referral, use of offloading, vascular imaging and revascularisation.

\section{Results}

$27 \%$ of the patients had been treated for more than 3 months before referral to a foot clinic. This varied considerably between countries (6-55\%). At study entry $77 \%$ of the patients had no or inadequate offloading. During follow-up casting was used in $35 \%(0-68 \%)$ of the plantar fore- or midfoot ulcers. Predictors of use of casting were male gender, large ulcer size and being employed. Vascular imaging was performed in 56\% (14-86\%) of the patients with severe limb ischemia; revascularisation was performed in $43 \%$. Predictors of use of vascular imaging were the presence of infection and ischemic restpain.

\section{Conclusion}

Treatment of many patients is not in line with current guidelines and large differences between countries and centres are observed. Our data suggest that current guidelines are too general and that health care organisational barriers and personal beliefs result in underuse of recommended therapies. Action should be undertaken to overcome these barriers and to guarantee the delivery of optimal care for the many individuals with diabetic foot disease. 


\section{Introduction}

Diabetic foot disease is a common and serious complication of diabetes ${ }^{1}$. Treatment of diabetic foot disease is demanding as long-term hospitalisation, frequent outpatient visits and loss of mobility pose a great burden on the patient $^{2}$ and on the health care system ${ }^{3}$. The quality of life of these patients is low and gradually declines as long as the ulcer has not healed ${ }^{4}$. In recent years many efforts have been made to improve and standardize care for patients with diabetic foot disease; these initiatives have resulted in multidisciplinary guidelines such as the International Consensus on the Diabetic Foot ${ }^{5}$. These guidelines contain recommendations on the management of diabetic foot ulcers and stress the importance of early referral, offloading of the ulcer, restoration of skin perfusion and aggressive treatment of infection. However, many of these recommendations were formulated based on expert opinion for reasons of lack of scientific evidence. One can speculate that this still leaves space for health care professionals to follow their personal beliefs. In addition, it is known that management of diabetic foot ulcers is influenced by local health care organization and the availability of resources. Therefore it is important to evaluate the actual management of diabetic foot disease in Europe, and to get insight into the barriers that may prevent the delivery of appropriate care. The aim of this study was to determine the current management of diabetic foot ulcers in a large cohort of patients presenting with a new foot ulcer in diabetic foot clinics throughout Europe, and to identify patient-related factors and specific barriers that influence management strategies. In this report we will focus on three domains that are addressed in the International Consensus document: early referral, offloading of the ulcer and restoration of skin perfusion.

\section{Patients and methods}

The design, methodology of this study and the definitions that were used, have been described in detail in a separate publication ${ }^{6}$. A summary of the methodology that is relevant to this report is given below.

\section{Study design and population}

Briefly, 1232 consecutive patients with a new foot ulcer were included in 14 diabetic foot centres in 10 European countries, between September $1^{\text {st }} 2003$ and October $1^{\text {st }}$ 2004. The mean (range) number of included patients per centre was 88 (40-125). Included were diabetic patients with a new foot ulcer presenting for the first time within a period of twelve months to the outpatient or 
inpatient clinic of the participating centres. Excluded were patients treated for an ulcer on the ipsilateral foot during the past 12 months in the participating centres; patients with a life expectancy shorter than one year were also excluded on account of anticipated problems with follow-up.

The local ethics committees of the 14 hospitals approved the study protocol and all patients gave written informed consent.

All participating centres are centres with a longstanding expertise and high professional standards in the field of diabetic foot disease and are familiar with the International Consensus on the Diabetic Foot ${ }^{5}$. All patients were treated according to protocols based on this international guideline, which include offloading, assessment of vascular status, treatment of PAD and diagnosis and treatment of infection, but which also take into account local health care organization and availability of resources.

Of the 1232 included individuals, 1088 patients were prospectively followed (until healing, death or lower leg amputation) or for a maximum period of one year. 144 patients were lost to follow-up. General patient characteristics of the patients that reached an endpoint can be found in Table 7.1.

Table 7.1 Baseline characteristics.

\begin{tabular}{lc}
\hline Variable & $(\mathrm{n}=1088)$ \\
\hline Age, years & $64.7 \pm 12.5$ \\
Male gender & $704(64.6)$ \\
Neurological disorder & $70(6.5)$ \\
Inability to stand or walk without help & $107(9.9)$ \\
Visual impairment & $164(15.3)$ \\
End Stage Renal Disease & $63(5.8)$ \\
Deep ulcer & $476(43.8)$ \\
Size of ulcer & \\
$<1 \mathrm{~cm}^{2}$ & $403(37.2)$ \\
$1-5 \mathrm{~cm}^{2}$ & $563(52.0)$ \\
$>5 \mathrm{~cm}^{2}$ & $117(10.8)$ \\
Duration of ulcer & \\
$<1$ week & $184(17.0)$ \\
1 week -3 months & $625(58.1)$ \\
$>3$ months & $269(24.9)$ \\
PNP & $826(78.5)$ \\
PAD & $505(47.5)$ \\
Infection & $591(57.2)$ \\
Employment & \\
Yes & $211(19.6)$ \\
No & $190(17.6)$ \\
Retired & $678(62.8)$ \\
\hline
\end{tabular}

Data are mean values \pm standard deviation or $n(\%)$. NYHA, New York Heart Association; PNP, polyneuropathy; PAD, peripheral artery disease. 


\section{Collection of data on management}

Subjects attended follow-up visits on a monthly basis. At baseline and during all follow-up visits data were collected and recorded on standardized case record forms (CRFs), by dedicated investigators in each centre that were trained during plenary meetings and on-site visits. On each subsequent monthly visit a standardised examination was performed and management in the previous month was evaluated. Data were collected on patient characteristics, and diagnostic and intervention procedures. The definitions and assessments used in this study were based on international guidelines and classification systems $\mathrm{s}^{5,7}$ and were chosen on the basis of their suitability for use in daily clinical practice.

\section{Multivariable models}

After describing management strategies and centre differences, multivariable models were built to determine which baseline characteristics of the patients predict the use of management strategies. The use of total contact casting (TCC) or alternative casting techniques in patients with plantar fore- or midfoot ulcers and the use of vascular imaging in individuals with severe limb ischemia or patients that did not heal within the follow-up period of one year or who underwent a major (i.e. above the ankle level) amputation were selected for these analyses.

\section{Potential predictive factors}

Potential determinants of use of the management strategies assessed in the multivariable models were chosen based on current literature and expert opinion after extensive discussions during Eurodiale meetings. Potential predictors were age, gender, the presence of disabling co-morbidities, depth, size and duration of ulcer, the presence of PAD and infection and whether the patient was employed. In the vascular-imaging model, the presence of PAD was left out of the model and the presence of restpain was added (a complete list of definitions has been published earlier $)^{6}$.

\section{Statistics}

Statistical analyses were performed using the SPSS statistical package version 12.01 (SPSS, Chicago, III., USA). Comparisons between groups were made using the Chi-square test; statistical significance was defined as a p-value $<0.05$. All analysis regarding baseline characteristics and study entry were based on the complete cohort of 1232 patients. All analyses regarding management during follow-up were based on the cohort of 1088 patients that 
reached an endpoint. Dropouts (patients that did not reach endpoint) were excluded from the latter analysis since dropout can be a reason for underuse of management strategies.

\section{Multivariable models}

Firstly, univariable logistic regression analyses were performed for all potential predictor variables with the outcome of interest (use of casting and use of vascular imaging) and univariable odds ratios (ORs) along with the respective $95 \%$ confidence intervals $(\mathrm{Cl})$ were presented. Secondly, before multivariable analyses were performed, the co-linearity between potential predictors (i.e. any correlation - Spearman $r$ - between two potential predictors larger that 0.5 ) was investigated; no such correlations were found and therefore all potential predictors with $p<0.1$ in univariable models were entered simultaneously in a multivariable logistic regression model.

\section{Evaluation of the predictive models}

The reliability of the multivariable models was determined by the HosmerLemeshow goodness-of-fit statistic (with a $p$-value $<0.1$ indicating inadequate fit of the model $)^{8}$.

\section{Retrospective survey}

After analysis of the data on management strategies in the different centres, a survey was performed to obtain more insight into the reasons for not working in line with recommendations in current guidelines. To this end two management topics were selected: total contact casting (TCC) or alternative casting techniques in patients with neuropathic plantar forefoot ulcer and angiography I revascularisation in individuals with severe limb ischemia (Ankle Brachial Pressure Index (ABPI) <0.5). All CRF's and medical files of all patients with plantar forefoot ulceration in which no casting was performed, and all files of patients with severe limb ischemia in whom no vascular imaging (duplex, conventional angiography and/or MR-angiography) and/or revascularisation was performed were checked and data were obtained on reasons for not following current consensus documents. These data were collected during a plenary Eurodiale meeting; the aim was to gather qualitative data on reasons for not following guidelines, rather than gathering quantitative data. In view of the retrospective nature of this part of the study and the fact that there could be several reasons for non-adherence in the same patient, no further quantitative data were collected. 


\section{Results}

\section{Referral}

More than one in four individuals $(27 \%, \mathrm{n}=334)$ had been treated for more than three months before referral to the participating foot clinic. Almost half of these individuals $(44 \%, \mathrm{n}=147)$ were treated in primary care until referral; in $35 \%$ of these patients the general practitioner was involved in foot ulcer care and in $12 \%$ a chiropodist / podiatrist was involved. Fifty-five percent $(n=187)$ of these patients had an (neuro-) ischemic ulcer. Nineteen percent had an ulcer-size $>5 \mathrm{~cm}^{2}$. The percentage of patients with late referral (ulcers with a duration $>3$ months) varied considerably between the 10 countries (6-55\%), but also within countries (Figure 7.1).
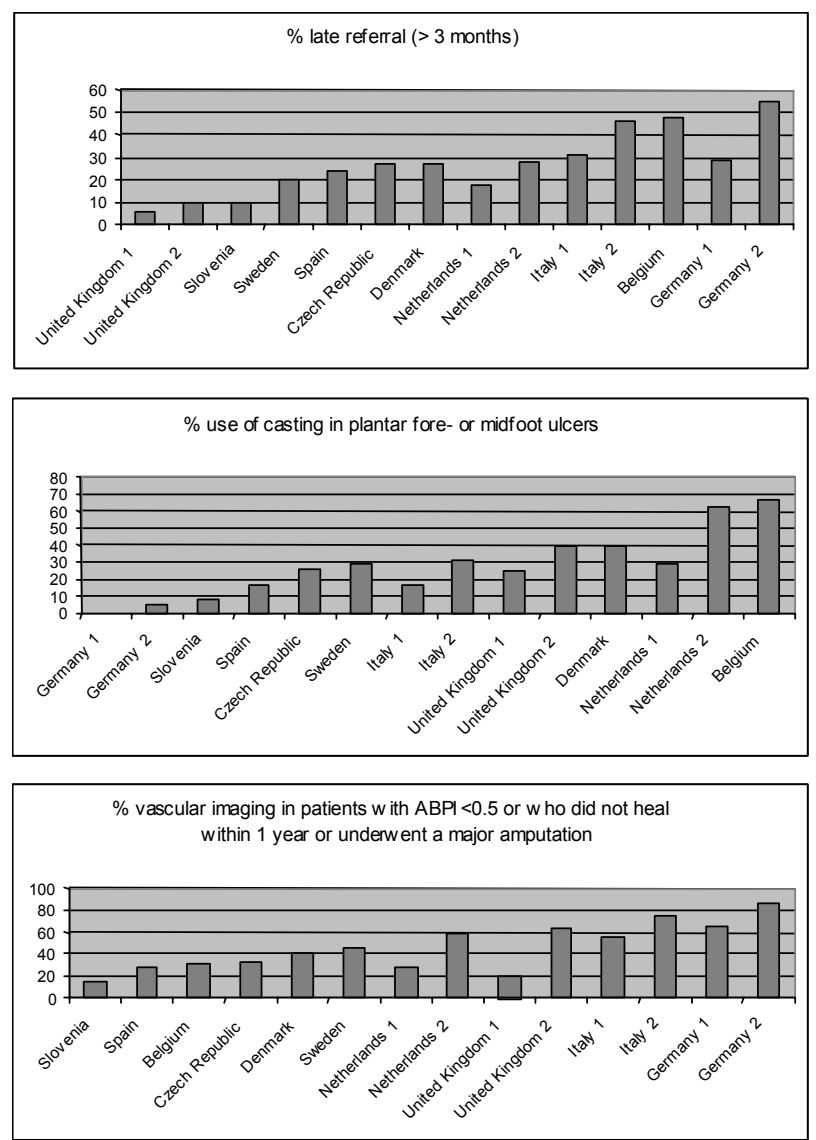

Figure 7.1 Delivery of care in the participating countries. 


\section{Offloading}

At study entry $41 \%(n=505)$ was already treated with offloading; however only in half of these patients offloading was considered adequate by the treating physician and was considered to result in pressure relief at the site of the ulcer $(56 \%, n=283)$. Therefore, at study entry inadequate or no offloading was found in $77 \%(n=948)$ of the patients. Remarkably, in patients with an ulcer duration of $>3$ months, similar high rates of no or inadequate offloading were observed $(78 \%, \mathrm{n}=261)$.

After study-entry, during the follow-up period of the study, $78 \%(n=845)$ of all patients received some kind of offloading therapy. Regarding the subgroup of patients with a neuropathic plantar forefoot or midfoot ulcer $(n=139)$, total contact cast was prescribed in 18\% $(n=25)$. An additional 17\% $(n=24)$ of these patients were treated with alternative casting modalities, but most of the plantar ulcers were treated with temporary footwear. There was a marked difference in the use of casting between countries ranging from $0-68 \%$, but also between centres in the same country (Figure 7.1). Independent predictors for use of casting-treatment in patients with plantar fore- or midfoot ulcers $(n=229)$ were male gender, large ulcer size and being employed (Table 7.2).

The retrospective survey in the centres revealed that the underuse of casting was related to reimbursement policies, to lack of qualified staff, to lack of acceptance by health care workers (personal beliefs) and lack of patient acceptance.

Table 7.2 Univariable and multivariable models of use of casting in patients with plantar foreor midfoot ulcers $(n=229)$.

\begin{tabular}{|c|c|c|c|c|c|c|}
\hline \multirow[t]{2}{*}{ Potential predictor variables } & \multicolumn{3}{|c|}{ Univariable models } & \multicolumn{3}{|c|}{ Multivariable model } \\
\hline & OR & $95 \% \mathrm{Cl}$ & $p$-value & OR & $95 \% \mathrm{Cl}$ & $p$-value \\
\hline Age (per 10 years increase) & 0.757 & $0.589-0.974$ & 0.030 & 0.875 & $0.625-1.225$ & 0.437 \\
\hline Gender (women vs. men) & 0.356 & $0.151-0.840$ & 0.018 & 0.239 & $0.084-0.682$ & 0.007 \\
\hline Co-morbidities (yes vs. no) & 0.651 & $0.318-1.332$ & 0.240 & & & \\
\hline Depth of ulcer (deep vs. superficial) & 1.279 & $0.712-2.300$ & 0.410 & & & \\
\hline Size of ulcer & & & 0.073 & & & 0.038 \\
\hline $1-5 \mathrm{~cm}^{2}$ vs. $<1 \mathrm{~cm}^{2} *$ & 2.254 & $1.120-4.535$ & & 2.878 & $1.269-6.530$ & \\
\hline$>5 \mathrm{~cm}^{2}$ vs. $<1 \mathrm{~cm}^{2 *}$ & 2.044 & $0.662-6.314$ & & 2.829 & $0.731-1.317$ & \\
\hline Duration of ulcer & & & 0.356 & & & \\
\hline 1 week to 3 months vs. $<1$ week * & 1.210 & $0.476-3.079$ & & & & \\
\hline$>3$ months vs. $<1$ week & 1.786 & $0.683-4.670$ & & & & \\
\hline PAD (yes vs. no) & 0.714 & $0.384-1.324$ & 0.285 & & & \\
\hline Infection (yes vs. no) & 1.430 & $0.782-2.616$ & 0.245 & & & \\
\hline Employment & & & $<0.001$ & & & 0.001 \\
\hline no vs. yes* & 2.406 & $1.010-5.730$ & & 3.212 & $1.181-8.738$ & \\
\hline retired vs. yes* & 0.452 & $0.216-0.946$ & & 0.535 & $0.217-1.317$ & \\
\hline
\end{tabular}

OR, odds ratio; $\mathrm{Cl}$, confidence interval; * reference category 


\section{Restoration of skin perfusion}

At the time of referral to the study centres a vascular work-up had been performed in only $53 \%(n=93)$ of the (neuro-) ischemic ulcers with a duration $>3$ months $(n=178)$. In patients previously treated in primary care this percentage was significantly lower compared to patients treated by medical specialists (39\% vs. $67 \%, p<0.001)$.

During follow-up in the study centres, almost all patients $(93 \%, n=468)$ with PAD $(n=505)$ underwent functional vascular assessment $\left(\mathrm{TcPO}_{2}\right.$, ankle pressure and/or toe pressure) as part of their diagnostic work-up. In $41 \%$ $(n=208)$ of the patients with PAD, vascular imaging (duplex, conventional angiography and/or MR-angiography) was performed during follow-up. In patients who did not heal after a follow-up period of one year or patients who underwent a major amputation $(n=181)$, vascular imaging was performed in only $40 \%$. In patients with severe limb ischemia ( $n=94)$, defined as an ABPI below 0.5 , vascular imaging was performed in $56 \%$. There was a marked difference in the use of vascular imaging in patients with severe limb ischemia ranging from $14-86 \%$ between countries, but also between centres in the same country (Figure 7.1). In patients with severe limb ischemia a revascularisation procedure was performed in $43 \%$ (22\% endovascular procedure and/or $27 \%$ peripheral bypass surgery). A flow-chart of different patient-groups undergoing vascular assessment and revascularisation can be found in Figure 7.2. Independent predictors for use of vascular imaging in patients with severe limb ischemia and /or patients who did not heal within one year or who underwent a major amputation $(n=250)$ were the presence of infection and the presence of ischemic rest pain (Table 7.3).

The retrospective survey in the centres revealed that the underuse of vascular procedures was related to the presence of a non-functional leg, spontaneous healing of the ulcer, very poor health status of the patient and professional beliefs.

\section{Evaluation of multivariable models}

The p-values of Hosmer-Lemeshow goodness-of-fit statistics for all models were $>0.1$. 

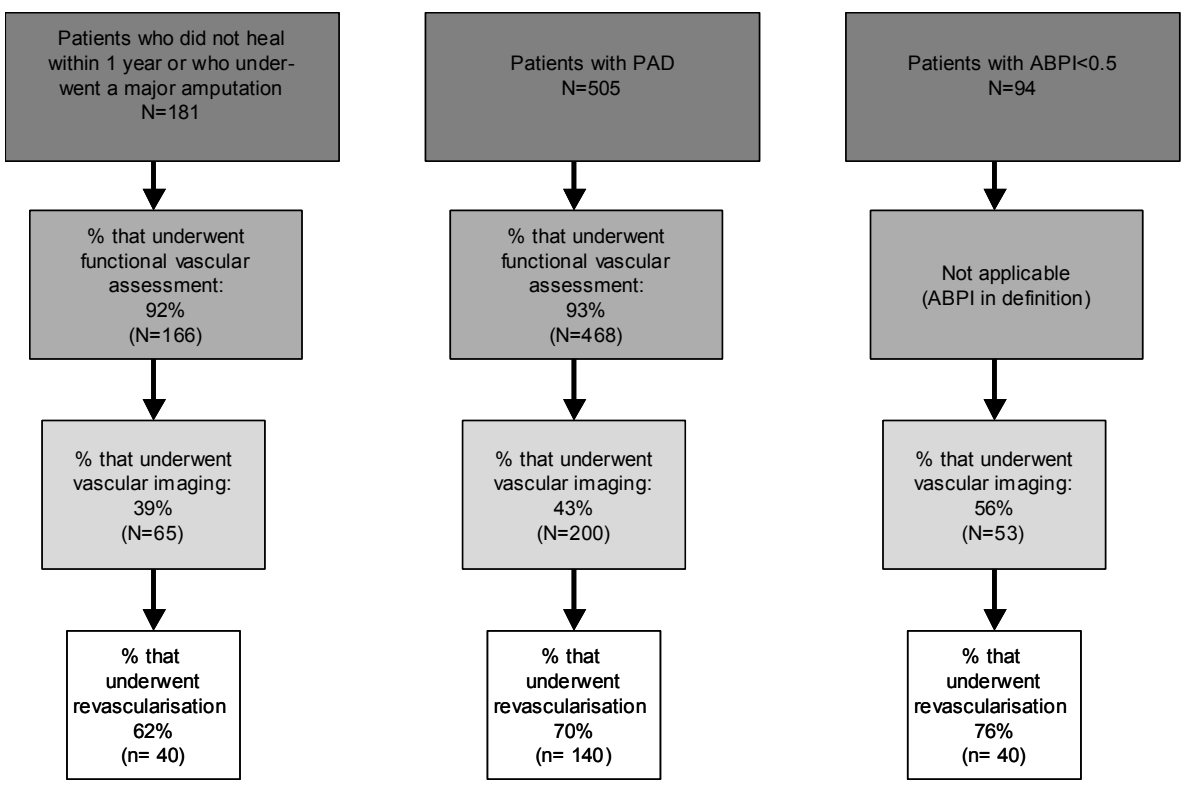

Figure 7.2 Flow-chart of different patient-groups undergoing vascular assessment and revascularisation.

Table 7.3 Univariable and multivariable models of use of vascular imaging in patients with ABPI $<0.5$ and/or patients who did not heal within the follow up period of one year or who underwent a major amputation $(n=250)$.

\begin{tabular}{lcccccc}
\hline \multirow{2}{*}{ Potential predictor variables } & \multicolumn{3}{c}{ Univariable models } & \multicolumn{3}{c}{ Multivariable model } \\
\cline { 2 - 7 } & OR & $95 \% \mathrm{Cl}$ & $\mathrm{p}$-value & OR & $95 \% \mathrm{Cl}$ & $\mathrm{p}$-value \\
\hline Age (per 10 yrs increase) & 1.340 & $1.090-1.647$ & 0.005 & 1.220 & $0.941-1.158$ & 0.133 \\
Gender (women vs. men) & 0.857 & $0.503-1.463$ & 0.537 & & & \\
Co-morbidities (yes vs. no) & 1.498 & $0.884-2.536$ & 0.133 & & & \\
Depth of ulcer (deep vs. superficial) & 1.432 & $0.865-2.368$ & 0.162 & & & \\
Size of ulcer & & & 0.656 & & & \\
$\quad 1-5 \mathrm{~cm}^{2}$ vs. $<1 \mathrm{~cm}^{2 *}$ & 0.976 & $0.535-1.777$ & & & & \\
$>5 \mathrm{~cm}^{2}$ vs. $<1 \mathrm{~cm}^{2 *}$ & 1.333 & $0.615-2.890$ & & & & \\
Duration of ulcer & & & 0.567 & & & \\
$\quad 1$ week to 3 months vs. <1 week* & 1.610 & $0.614-4.219$ & & & & \\
$\quad>3$ months vs. <1 week* & 1.721 & $0.628-4.716$ & & & & \\
Ischemic restpain (yes vs. no) & 5.922 & $2.844-12.330$ & $<0.001$ & 4.961 & $2.303-10.685$ & 0.000 \\
Infection (yes vs. no) & 2.286 & $1.317-3.967$ & 0.003 & 2.095 & $1.150-3.815$ & 0.016 \\
Employment & & & 0.085 & & & 0.327 \\
$\quad$ no vs. yes & 2.065 & $0.617-6.361$ & & 3.104 & $0.702-13.729$ & \\
$\quad$ Retired vs. yes* & 2.844 & $1.087-7.441$ & & 2.529 & $0.622-10.289$ & \\
\hline
\end{tabular}

$\mathrm{OR}$, odds ratio; $\mathrm{Cl}$, confidence interval; * reference category. 


\section{Discussion}

Our data on referral patterns and management of diabetic foot ulcers show that current multidisciplinary guidelines are not followed in a significant number of patients. Management of foot ulcers in terms of early referral, the use of casting and vascular evaluation was much lower than expected. There were clear differences in resource use between different countries and as well as between centres, also when different patient characteristics were taken into account. These findings are remarkable in view of the substantial expertise which is present in the participating centres, and the level of awareness of these specific guidelines. This may suggest that there is a gap between the recommendations in current consensus documents and everyday clinical practice.

Although most national and international guidelines stress the importance of early referral, and late referral is considered a risk factor for lower extremity amputation ${ }^{9}$, referral was delayed in many patients, including both neuropathic and neuro-ischemic patients. Few studies report on patterns of referral in diabetic foot disease. MacFarlane and Jeffcoate found that the median time between onset of the foot ulcer and referral to their specialist clinic was 19 days; significant delays occurred in only $6 \%$ of the patients. In our study late referral was observed in $27 \%$ of all patients, ranging from $6 \%$ in the UK to $55 \%$ in Germany ${ }^{10}$. These substantial differences suggest that organization of the surrounding primary care region is highly variable between countries and centres. Factors that hamper early referral may include lack of awareness of the importance of prompt institution of care, lack of clear referral guidelines as well as financial barriers.

Only $35 \%$ of patients with plantar forefoot or midfoot ulcers were treated with casting, and in only half of them classic total contact casting was prescribed, despite the fact that this therapy is considered the gold standard for patients with plantar ulcers ${ }^{11}$. By using total contact cast, favourable healing rates of $90 \%$ in neuropathic and $69 \%$ in non-infected ulcers with PAD can be achieved $^{12-14}$. If the classic total contact casting is not available there are currently alternatives that are almost as effective, such as the DH-walker or Aircast device. Recent studies have shown that these devices have adequate healing rates, especially when they are made irremovable ${ }^{15,16}$. Therefore there are actually no reasons for the limited use of these techniques, unless for reimbursement issues. With respect to the use of casting, lack of qualified staff and reimbursement problems were the most frequently mentioned reasons for underuse of this therapy. Why women were less likely to receive casting treatment is difficult to explain, but could be related to a general underuse of 
therapeutic strategies in women ${ }^{17}$ or to other factors such as gender specific problems with loss of mobility, or cosmetic reasons. Current guidelines indicate that offloading is one of the most important cornerstones in the treatment of neuropathic or neuro-ischemic foot ulcers ${ }^{18}$. Our data suggest that casting techniques are still underused in Europe and that these techniques should be introduced on a larger scale with training of staff and free accessibility to all patients in whom this therapy is indicated.

Insufficient skin perfusion as a result of PAD is a major determinant of nonhealing and is associated with a poor outcome ${ }^{19,20}$. Evaluation of the possibility to restore skin perfusion is generally recommended in patients with an $\mathrm{ABPI}<0.5^{5,21}$, as well as in case of non-healing ulcers and before the decision to perform a major lower extremity amputation. It is generally believed that PAD in diabetes is often multi-vessel and distal in nature, making it technically more difficult to perform a revascularisation. However, in a recent large study in diabetic patients with foot ulcers and obstructive PAD, PTA was performed in $84 \%$ of all patients with angiographic evidence of stenosis ${ }^{22}$. Our data also show that the majority of patients in whom vascular imaging was performed, underwent a revascularisation procedure afterwards, indicating that technical limitations are relatively uncommon. The most important step in decision making in these patients is therefore the choice to perform vascular imaging. Probably the main determinant of this decision is whether the healthcare professional considers revascularisation indicated. Apparently this is often not the case; the retrospective survey indicated that in some patients the ulcer healed with conservative therapy or that a revascularisation was, according the treating physician not possible due to severe co-morbidities. The low rate of vascular imaging in patients with unhealed ulcers after one year or with a lower leg amputation is of more concern as current guidelines clearly recommend that vascular imaging should almost always be performed in these patients and a revascularisation should always be considered prior to amputation. Our data indicate that there is still room for improvement in the vascular management of diabetic foot ulcers in Europe. In particular, a more aggressive approach in vascular imaging should be advocated.

Substantial country differences regarding the delivery of care in the three domains assessed in this study were observed. The comparison of data on management strategies from countries with two participating centres demonstrate that in all domains country specific characteristics can be observed: late referral was very uncommon in the UK; in patients with plantar for- or midfoot ulcers the use of any form of casting is very infrequent in Germany; however, patients with severe limb ischemia and/or a non-healing ulcer or a major amputation were most likely to undergo vascular imaging in 
Germany. In addition to these inter-country differences also intra-country differences were observed, suggesting that organization of care is highly variable between countries as well as between different centres. This was confirmed by the retrospective survey that was performed, which revealed that reasons for underuse of care were country-related such as reimbursement, as well as centre-related such as personal beliefs and lack of qualified staff.

One of the limitations of this study is that although the total study group is relatively large, and many European centres were involved, there were also European countries that were not represented. Moreover, in view of the substantial differences between centres in the same country, it remains difficult to extrapolate these data to other European centres that treat patients with diabetic foot disease.

Our data on delivery of care to patients with diabetic foot disease in Europe indicate that treatment of many patients is not in line with current recommendations. These data might indicate that these recommendations in guidelines are too general. In daily clinical practice treatment choices are made for every single patient, taking both patient characteristics into account, as well as the possibilities and experience in these centres. However, our data on country and centre differences and the conclusions from the retrospective survey also demonstrate that there are several health care organisational barriers that influence the delivery of optimal care. Moreover, the personal beliefs of treating physicians are not always in line with worldwide accepted guidelines resulting in an underuse of effective treatment modalities in some patients. In the coming years both health care professionals working in this field, as well as patients, insurance companies and policymakers should join forces to overcome these barriers and guarantee the delivery of optimal care for the many individuals with diabetic foot disease. 


\section{References}

1. Reiber GE. The epidemiology of diabetic foot problems. Diabet Med 1996;13 S1:S6-11

2. Boulton AJ, Vileikyte L, Ragnarson-Tennvall G, Apelqvist J. The global burden of diabetic foot disease. Lancet 2005;366:1719-1724

3. Ragnarson Tennvall G, Apelqvist J. Health-economic consequences of diabetic foot lesions. Clin Infect Dis 2004;39 S2:S132-139

4. Nabuurs-Franssen MH, Huijberts MS, Nieuwenhuijzen Kruseman AC, Willems J, Schaper NC. Health-related quality of life of diabetic foot ulcer patients and their caregivers. Diabetologia 2005;48:1906-1910

5. Schaper NC, Apelqvist J, Bakker K. The international consensus and practical guidelines on the management and prevention of the diabetic foot. Curr Diab Rep 2003;3:475-479

6. Prompers L, Huijberts M, Apelqvist J, Jude E, Piaggesi A, Bakker K, Edmonds M, Holstein P, Jirkovska A, Mauricio D, Tennvall GR, Reike H, Spraul M, Uccioli L, Urbancic V, Van Acker K, Van Baal J, Van Merode F, Schaper N. Optimal organization of health care in diabetic foot disease: introduction to the Eurodiale study. Int J Low Extrem Wounds. 2007;6:11-17

7. Schaper NC. Diabetic foot ulcer classification system for research purposes: a progress report on criteria for including patients in research studies. Diabetes Metab Res Rev 2004;20 S1:S90-95

8. Hosmer DW, Lemeshow S. Assessing the fit of the model. In Hosmer DW, Lemeshow S, eds. Applied Logistic Regression 2nd ed. New York: John Wiley \& Sons; 2000

9. Jeffcoate WJ, van Houtum WH. Amputation as a marker of the quality of foot care in diabetes. Diabetologia 2004;47:2051-2058

10. Macfarlane RM, Jeffcoate WJ. Factors contributing to the presentation of diabetic foot ulcers Diabet Med 1997; 14:867-870

11. Cavanagh PR, Lipsky BA, Bradbury AW, Botek G. Treatment for diabetic foot ulcers. Lancet 2005;366:1725-1735

12. Mueller MJ, Diamond JE, Sinacore DR, Delitto A, Blair VP 3rd, Drury DA, Rose SJ. Total contact casting in treatment of diabetic plantar ulcers. Controlled clinical trial. Diabetes Care 1989; $12: 384-388$

13. Armstrong DG, Nguyen HC, Lavery LA, van Schie CH, Boulton AJ, Harkless LB. Off-loading the diabetic foot wound: a randomized clinical trial. Diabetes Care 2001;24:1019-10122

14. Nabuurs-Franssen MH, Sleegers R, Huijberts MS, Wijnen W, Sanders AP, Walenkamp G, Schaper NC. Total contact casting of the diabetic foot in daily practice: a prospective followup study. Diabetes Care 2005;28:243-7

15. Piaggesi A, Macchiarini S, Rizzo L, Palumbo F, Tedeschi A, Nobili LA, Leporati E, Scire V, Teobaldi I, Del Prato S. An off-the-shelf instant contact casting device for the management of diabetic foot ulcers: a randomized prospective trial versus traditional fiberglass cast. Diabetes Care 2007;30:586-590

16. Armstrong DG, Lavery LA, Wu S, Boulton AJ. Evaluation of removable and irremovable cast walkers in the healing of diabetic foot wounds: a randomized controlled trial. Diabetes Care 2005;28:551-554

17. Ayanian JZ, Epstein AM. Differences in the use of procedures between women and men hospitalized for coronary heart disease. N Engl J Med 1991;325:221-225

18. Apelqvist J, Bakker K, van Houtum WH, Nabuurs-Franssen MH, Schaper NC. International Consensus on the Diabetic Foot. Maastricht: Schaper NC; 1999.

19. Armstrong DG, Lavery LA, Harkless LB. Validation of a diabetic wound classification system. The contribution of depth, infection, and ischemia to risk of amputation. Diabetes Care 1998; 21:855-859

20. Boulton AJ. The pathogenesis of diabetic foot problems: an overview. Diabet Med 1996;13 $\mathrm{S} 1: \mathrm{S} 12-16$

21. Dormandy JA, Rutherford RB. Management of peripheral arterial disease (PAD). TASC Working Group. TransAtlantic Inter-Society Concensus (TASC). J Vasc Surg 2000;31:S1S296 
22. Faglia E, Dalla Paola L, Clerici G, Clerissi J, Graziani L, Fusaro M, Gabrielli L, Losa S, Stella A, Gargiulo M, Mantero M, Caminiti M, Ninkovic S, Curci V, Morabito A. Peripheral angioplasty as the first-choice revascularization procedure in diabetic patients with critical limb ischemia: prospective study of 993 consecutive patients hospitalized and followed between 1999 and 2003. Eur J Vasc Endovasc Surg 2005;29:620-627 
102 


\section{Chapter 8}

Are there best practices in the treatment of diabetic foot disease? Centre differences in outcome, health care organization and management strategies. The Eurodiale study

Prompers L, Schaper N, Apelqvist J, Edmonds M, Jude E, Mauricio D, Uccioli L, Urbancic V, Bakker K, Holstein P, Jirkovska A, Piaggesi A, Ragnarson Tennvall G, Reike H, Spraul M, van Acker K, van Baal J, van Merode F, Ferreira I, Huijberts M. 


\section{Abstract}

Aim

The aim of the present study is to determine whether substantial differences in outcome are present between fourteen European diabetic foot centres when correcting for patient characteristics. Moreover, since it is known that management of diabetic foot ulcers is influenced by local health care organization and the availability of resources, we were interested whether possible centre differences can be explained by the management strategies used during follow up or by local health care organizational aspects.

Methods

Analyses were conducted within the Eurodiale Study, a prospective cohort study of 1088 diabetic foot ulcer patients across 14 centres in Europe.

Results

Although the overall outcome of diabetic foot ulcers compares favourably to earlier studies, differences in healing rates between the different centres that have participated in this European study are present. These differences could not be explained by differences in patient characteristics between these centres. Centres with the most favourable corrected outcomes were characterized by significantly higher use of revascularisation and surgical procedures although this could not solely explain the observed differences in outcome.

\section{Conclusion}

The results of this study suggest that even in dedicated foot centres, differences in outcome exist when correcting for common patient characteristics. Efficient health care organization and proactive revascularisation and surgical strategies seem to be important keys to success. By implementing such strategies very favourable outcomes, with major amputation rates below 3\% may be achieved in all individuals with diabetic foot ulcers. 


\section{Introduction}

Diabetic foot disease is a serious complication of diabetes. The lifetime risk of the development of a foot ulcer in diabetic individuals may be as high as $25 \%{ }^{1}$. Foot ulceration requires long and intensive treatment and has a major impact on patients and caregivers in terms of quality of life ${ }^{2}$. Moreover, diabetic foot disease is associated with high health care costs ${ }^{3-5}$. It is known that the benefits of optimal care in terms of clinical outcome can be substantial ${ }^{6,7}$. In the limited number of large studies on outcome in diabetic foot disease, marked differences in healing- and amputation-rates have been reported ${ }^{8-14}$. The variability of the reported outcomes may be due to differences in patient characteristics in these studies. Recently, the Eurodiale consortium, an international collaborative network that was created to stimulate research in the field of diabetic foot disease, published data on clinical outcome and a predictive model on clinical predictors of healing in a cohort of 1088 patients ${ }^{15}$ The population of foot ulcer patients in the Eurodiale cohort was also heterogeneous and important differences in patient, foot and ulcer characteristics were observed between subgroups with and without peripheral arterial disease and with and without infection were observed ${ }^{16}$. We have also demonstrated substantial differences in delivery of care between the participating European centers ${ }^{17}$. The results of the predictive model ${ }^{15}$ allow us to compare outcome between centres, corrected for patient characteristics. The aim of the present study is to determine whether substantial differences in outcome are present between the participating centres when correcting for patient characteristics. Moreover, since it is known that management of diabetic foot ulcers is influenced by local health care organization and the availability of resources, we were interested whether possible centre differences can be explained by the management strategies used during follow up or by local health care organizational aspects.

\section{Methods}

\section{Study design and population}

The design and rationale of the Eurodiale study have been described in detail elsewhere ${ }^{15,18}$.

Briefly, between September $1^{\text {st }} 2003$ and October $1^{\text {st }} 2004,1232$ patients with a new foot ulcer were included in 14 diabetic foot centres in 10 European countries. The mean (range) number of included patients per centre was 88 (40-125). All participating centres have a longstanding expertise in the field of diabetic foot disease. Included were diabetic patients with a new foot ulcer 
presenting for the first time within a period of twelve months to the outpatient or inpatient clinic of the participating centres. Excluded were patients treated for an ulcer on the ipsilateral foot during the past 12 months in the participating centres; patients with a life expectancy shorter than one year were also excluded on account of anticipated problems with follow-up. Subjects attended follow-up visits on a monthly basis. 1088 patients were followed until complete healing of the foot, major amputation or death, within the maximum follow-up period of one year ${ }^{15}$. Outcome information was not obtained in 144 patients (11.7\% of the patients included) who dropped out of the study and were therefore excluded from the analyses.

At baseline and during all follow-up visits data were collected and recorded on standardized case record forms (CRFs), by dedicated investigators in each centre that were trained during plenary meetings and on-site visits. Recorded data included demographics, data on co-morbidities, foot and ulcer characteristics as well as management. The local ethics committees of the 14 hospitals approved the study protocol and all patients gave written informed consent.

\section{Statistical analyses}

Statistical analyses were carried out using the SPSS statistical package version 12.01 (SPSS, Chicago, III., USA). Comparisons between groups' characteristics were made with Chi-square tests (frequency data) or Student's t-test (continuous data).

\section{Predictive models}

In a recent study the Eurodiale group presented a predictive model for healing of the foot ${ }^{15}$. This model yielded a set of variables that best predict (and can be regarded as) independent predictors of outcome. Independent predictors of poorer healing were older age, male gender, heart failure, the inability to stand or walk without help, end stage renal disease, larger ulcer size, polyneuropathy and PAD. Based on this model predicted probabilities of healing were calculated for each patient according to the following formula:

$$
P_{\text {(healing) }}=1 /\left[1+\exp ^{-}\left(\beta_{0}+\beta_{1} x_{1}+\beta_{2} x_{2}+\ldots+\beta_{j} x_{j}\right)\right. \text {, }
$$

where $P_{\text {(healing) }}$ is the probability of healing , $\beta_{0}$ is the constant and $\beta_{1}, \beta_{2}$ and $\beta_{j}$ represent the regression coefficients for each predictor $x_{1}, x_{2}$ and $x_{j}$ (observed values). Because predictive models are thought to provide too extreme estimates (i.e. over-fitting or over-optimism), a post hoc heuristic shrinkage method was used to adjust the models regression coefficients for overoptimism $^{15,19}$. 


\section{Determination of centre differences}

A mean predicted probability of healing per centre was calculated by determining the average of the individual predicted probabilities of all patients included in that centre. Since the predicted probability takes into account all patient characteristics that are independent predictors of healing, the mean predicted probability of healing per centre is an outcome-measure that is corrected for most important individual and disease specific patient characteristics. The mean predicted probability of healing per centre (predicted healing) was compared to the actual mean healing-rate that was observed in that centre during follow up (observed healing).

\section{Exploration of centre differences}

Centres were ranked based on the difference between predicted healing and observed healing. A Cluster was made of the four centres with observed healing-rates that were most close tot the predicted healing rates (group $A$, $n=278$ ). A second cluster was made of the four centres with the largest difference between observed healing-rates and predicted healing rates (group $B, n=349$ ). Subsequently, more detailed patient characteristics on severity of peripheral arterial disease (PAD), severity of infection and location (heel ulcers), were compared between group $A$ and group $B$, in order to support the data based on the predictive model that our outcome-comparisons are optimally corrected for patient characteristics. These more detailed patient characteristics were left out of the predictive model because of anticipated colinearity with other variables. (Ankle Brachial Pressure Index (ABPI) and the clinicians opinion on the presence of limb threatening PAD are co-linear with the presence of PAD; osteomyelitis, CRP-levels and probing to bone are colinear with the presence of infection; and heel ulcers are co-linear with plantar foot ulcers).

The use of the most important management strategies in treatment of diabetic foot disease ${ }^{20}$ was compared between group A and group B. Subsequently we verified whether the centres with the highest use of management strategies were also the centres with best outcome. The management strategies assessed in this study include:

Vascular imaging in patients with $P A D$ : duplex, conventional angiography and/or MR-angiography.

Revascularisation in patients with PAD: endovascular procedure and/or peripheral bypass surgery.

Other imaging. X-ray, CT-scan, MRI

Casting in patients with plantar fore- or midfoot ulcers: total contact cast and any other cast. 
Surgery: surgical debridement, minor amputation, orthopedic surgery, skin grafts, other surgical procedures.

Minor amputations only: amputations below the ankle level.

Other management strategies that were taken into account included nonsurgical debridement, \% of hospital admissions, number of days of hospital admission and antibiotic use.

Furthermore local health care organizational aspects were compared between group A and group B.

\section{Results}

\section{Centre differences}

The observed outcome of all participating centres in terms of healing, major amputation, death and non-healing after twelve months follow-up, can be found in Table 8.1. Table 8.2 illustrates the differences between the observed healing-rates and the predicted healing- rates based on the predictive model (which are corrected for patient characteristics) ${ }^{15}$.

Table 8.1 Observed clinical outcome.

\begin{tabular}{lcccc}
\hline Centre & Observed healing & Major Amputation Rate & Death & Non-healing \\
\hline 1 & $86 \%$ & $0 \%$ & $4 \%$ & $10 \%$ \\
2 & $86 \%$ & $2 \%$ & $8 \%$ & $4 \%$ \\
3 & $85 \%$ & $3 \%$ & $8 \%$ & $4 \%$ \\
4 & $82 \%$ & $0 \%$ & $9 \%$ & $9 \%$ \\
\hline 5 & $84 \%$ & $1 \%$ & $4 \%$ & $11 \%$ \\
6 & $76 \%$ & $11 \%$ & $2 \%$ & $11 \%$ \\
7 & $77 \%$ & $2 \%$ & $8 \%$ & $13 \%$ \\
8 & $78 \%$ & $5 \%$ & $10 \%$ & $7 \%$ \\
9 & $78 \%$ & $6 \%$ & $3 \%$ & $13 \%$ \\
10 & $73 \%$ & $7 \%$ & $8 \%$ & $12 \%$ \\
\hline 11 & $74 \%$ & $4 \%$ & $3 \%$ & $19 \%$ \\
12 & $64 \%$ & $4 \%$ & $19 \%$ & $13 \%$ \\
13 & $68 \%$ & $9 \%$ & $5 \%$ & $18 \%$ \\
14 & $66 \%$ & $13 \%$ & $4 \%$ & $17 \%$ \\
\hline
\end{tabular}

\section{Patient characteristics}

A comparison of more detailed patient characteristics that are associated with poor outcome and that could not be taken into account in the predictive model because of anticipated co-linearity, can be found in Table 8.3. Patients in group 
$B$ did not suffer from more severe PAD than patients in group A, nor did more often suffer from heel ulcers. A severe foot infection was more often present in patients in group $A$ than in patients in group $B$.

Table $8.2 \quad$ Differences between predicted and observed healing.

\begin{tabular}{lccc}
\hline Centre & Predicted healing & Observed healing & Observed-Predicted \\
\hline 1 & 83,8 & 86,4 & 2,6 \\
2 & 84,1 & 86,4 & 2,3 \\
3 & 83,6 & 85,3 & 1,7 \\
4 & 84,2 & 82,4 & $-1,8$ \\
\hline 5 & 88,3 & 84 & $-4,3$ \\
6 & 82 & 75 & -7 \\
7 & 84,7 & 77,3 & $-7,4$ \\
8 & 86,4 & 78 & $-8,4$ \\
9 & 87 & 78 & -9 \\
10 & 83 & 73,3 & $-9,7$ \\
\hline 11 & 88,3 & 74,3 & -14 \\
12 & 79,7 & 63,6 & $-16,1$ \\
13 & 84,5 & 68,2 & $-16,3$ \\
14 & 83,2 & 66,1 & $-17,1$ \\
\hline
\end{tabular}

Table 8.3 Patient characteristics.

\begin{tabular}{lccc}
\hline & Group A & Group B & p-value \\
\hline Severity of PAD* & & & \\
ABPI $<0.5$ & $14 \%$ & $9 \%$ & n.s \\
ABPI 0.5-0.9 & $26 \%$ & $25 \%$ & n.s \\
Limb threatening ischemia & $14 \%$ & $15 \%$ & n.s \\
Severity of Infection & & & \\
$\quad$ Probing to bone & $36 \%$ & $23 \%$ & p $<0.001$ \\
Osteomyelitis & $28 \%$ & $15 \%$ & p \\
CRP >3x upper limit & $51 \%$ & $49 \%$ & n.s. \\
Location & & & n.s \\
Heel ulcers & $9,4 \%$ & $10,3 \%$ & \\
\hline
\end{tabular}

* PAD: Peripheral arterial disease

\section{Management strategies}

A comparison of use of important management strategies between group $A$ and group B can be found in Table 8.4. Significantly more use was made of interventions in terms of vascular imaging, revascularisation, surgery and other imaging in group A compared to group B. We verified whether individual centres with the highest use of management strategies in terms of revascularisation, and surgery were also the centres with the highest corrected outcome. The four centres with the most frequent use of revascularisation had a mean difference between predicted and observed outcome of -7.3 , 
compared to a mean difference of -12 of the four centres with the less frequent use of revascularisation. The four centres with the most frequent use of surgery had a mean difference between predicted and observed outcome of -2.5 compared to a mean difference of -7.1 of the four centres with the less frequent use of surgery.

Table 8.4 Management strategies.

\begin{tabular}{lccc}
\hline & Group A & Group B & p-value \\
\hline Vascular Imaging in patients with PAD* & $54 \%$ & $35 \%$ & $p<0.001$ \\
Other general imaging & $59 \%$ & $41 \%$ & $\mathrm{p}<0.001$ \\
Revascularization in patients with PAD* & $39 \%$ & $25 \%$ & $\mathrm{p}=0.004$ \\
Casting in plantar fore- or midfoot ulcers & $18 \%$ & $22 \%$ & n.s. \\
Surgery & $61 \%$ & $38 \%$ & $\mathrm{p}<0.001$ \\
Minor amputation & $25 \%$ & $19 \%$ & 0.058 \\
Non-surgical debridement & $72 \%$ & $73 \%$ & n.s \\
Admission & $53 \%$ & $50 \%$ & n.s \\
\hline
\end{tabular}

* PAD: Peripheral arterial disease

\section{Local health care organization}

A comparison of local health care organizational aspects between group $A$ and group B outcome centres can be found in Table 8.5.

Table 8.5 Local health care organization.

\begin{tabular}{|c|c|c|c|}
\hline & Group A & Group B & p-Value \\
\hline Multidisciplinary team & Present & Present & n.a. \\
\hline Protocols available & All & All & n.a. \\
\hline Available resources & All & All & n.a. \\
\hline Teamleader with $>1$ & $2 / 4$ & $0 / 4$ & n.a. \\
\hline Competence & & & \\
\hline Emergency service & All & All & n.a. \\
\hline Available & & & \\
\hline Distance $>15 \mathrm{~km}$ & $62 \%$ & $41 \%$ & $p<0.001$ \\
\hline
\end{tabular}

\section{Discussion}

Although the overall outcome of diabetic foot ulcers compares favourably to earlier studies, we have demonstrated that there are indeed differences in healing rates between the different centres that have participated in this large European study that could not be explained so far by differences in patient characteristics between these centres. Centres with the most favourable corrected outcomes were characterized by significantly higher use of 
revascularisation and surgical procedures although this could not solely explain the observed differences in outcome.

Predicted healing rates were relatively similar between centres, indicating that although the population of foot ulcers patients throughout Europe is quite heterogeneous, the proportions of patients with poor prognostic factors is relatively comparable. Therefore, the most favourable outcomes as obtained in this study can probably be regarded as future targets for diabetic foot care. In the well known St. Vincent declaration dating from 1989 a reduction in major amputations by $50 \%$ was declared a primary objective for diabetes care in Europe. However in recent years several studies could not find an unequivocal decrease in the incidence of major lower extremity amputations ${ }^{21,22}$. Several centres in our study had major amputation rates below 3\%; when combining these rates with an expected incidence of $2 \%$ of new foot ulcers per year ${ }^{23}$, it may be possible to obtain incidence rates of major amputations in the order of 60 per 100,000 diabetic patients.

When evaluating the use of specific management strategies between the group most close to expected outcomes with the centres with lower healing rates, it appeared that centres with the highest healing rates more often performed revascularisation procedures and surgical interventions. Insufficient skin perfusion as a result of $P A D$ is a major determinant of non-healing and is associated with a poor outcome ${ }^{10,24}$. Evaluation of the possibility to restore skin perfusion is generally recommended in patients with an $\mathrm{ABPI}<0.5^{20,25}$, as well as in case of non-healing ulcers. So far there is no scientific evidence for the most effective strategy in individuals with foot ulcers and moderate ischemia. It is known that these ulcers can heal spontaneously but it is has never been evaluated whether early aggressive revascularisation will improve healing rates. It is generally believed that peripheral arterial disease in diabetes is often multi-vessel and distal in nature, thereby making it technically more difficult to perform a revascularisation. It is known from the recent literature that substantial differences exist between current revascularisation practices in diabetic patients. In the BASIL study audit, performed in the top six recruiting centres, only $70(15 \%)$ of 456 patients with critical limb ischemia and infrainguinal disease (both diabetics and non-diabetics) were regarded as suitable for revascularisation; $82 \%$ of the patients were not revascularised because of technical problems ${ }^{26,27}$. However, in a recent large study in diabetic patients with foot ulcers and obstructive PAD, PTA was performed in $84 \%$ of all patients with angiographic evidence of stenosis ${ }^{28}$. Similar differences in both imaging and revascularisation procedures were also observed in this study. The observed favourable outcomes in these centres suggest that aggressive revascularisation is a cornerstone of optimal treatment of the diabetic foot. This should however be evaluated in a randomised clinical trial comparing early revascularisation to a conservative wait and see strategy. 
Surgical intervention is regarded as an important measure in the control of deep tissue infection and is considered mandatory if pus in an enclosed space is present or a fulminant soft tissue infections exists ${ }^{29}$. Some hospitals routinely perform surgery in patients with deep foot infections ${ }^{30}$, and in one (although retrospective) study it was shown that early aggressive surgical treatment of diabetic foot infections reduce the need for lower extremity amputation ${ }^{31}$. Our data do not allow to discriminate between the specific reasons for foot surgery; it is therefore speculative to attribute the effects of more aggressive surgical interventions to better control of infection or removal of necrosis and wound bed preparation. Also in this area randomised studies may be of interest.

It has been shown that health care organization is related to outcome in diabetic foot disease $e^{6,7}$. However, the centres that participated in this study are all dedicated centres with a longstanding experience in the field of diabetic foot disease. In all centres a multidisciplinary team approach was one of the cornerstones of treatment and all resources that are considered necessary according to recent guidelines ${ }^{20}$ were present. A frequent characteristic of the centres with the most favourable outcome was the combination of several competences within one person. These professionals were diabetologists but also performed surgical interventions and or revascularisations themselves. Such organizational structures may facilitate the timing of appropriate care. It is however difficult to get relevant information on the quality and experience of the personnel involved, and the logistic aspects of the care in everyday practice. One study from the US reported on provider coordination as measured with the FootSAT instrument and diabetes related foot outcomes ${ }^{32}$ and observed relations between levels of programming coordination and total number of amputations. Similar data on coordination in the participating centres in this study are currently not available.

One of the major limitations of this study is the possibility that patient characteristics that have not been taken into account may be different between the participating centres. Another limitation is that non-healing was a combined endpoint of death, major amputation and non-healing. It may be possible that centres with lower death rates ended up with higher amputation and nonhealing rates. However this was not obvious form the cumulative rates in these centres.

In conclusion, the results of this study suggest that even in dedicated foot centres differences in outcome exist when correcting for common patient characteristics. Efficient health care organization and proactive revascularisation and surgical strategies seem to be important keys to success. By implementing such strategies very favourable outcomes, with major amputation rates below $3 \%$ may be achieved in all individuals with diabetic foot ulcers. 


\section{References}

1. Singh N, Armstrong DG, Lipsky BA. Preventing foot ulcers in patients with diabetes. JAMA 2005;293:217-228

2. Nabuurs-Franssen MH, Huijberts MS, Nieuwenhuijzen Kruseman AC, Willems J, Schaper NC. Health-related quality of life of diabetic foot ulcer patients and their caregivers. Diabetologia 2005;48:1906-1910

3. Apelqvist J, Ragnarson-Tennvall G, Larsson J, Persson U. Long-term costs for foot ulcers in diabetic patients in a multidisciplinary setting. Foot Ankle Int 1995;16:388-394

4. Apelqvist J, Ragnarson-Tennvall G, Persson U, Larsson J. Diabetic foot ulcers in a multidisciplinary setting. An economic analysis of primary healing and healing with amputation. J Intern Med 1994;235:463-471

5. Ragnarson Tennvall G, Apelqvist J. Health-economic consequences of diabetic foot lesions. Clin Infect Dis 2004;39 S2:S132-139

6. Dargis V, Pantelejeva O, Jonushaite A, Vileikyte L, Boulton AJ. Benefits of a multidisciplinary approach in the management of recurrent diabetic foot ulceration in Lithuania: a prospective study. Diabetes Care 1999;22:1428-1431

7. Edmonds ME, Blundell MP, Morris ME, Thomas EM, Cotton LT, Watkins PJ. Improved survival of the diabetic foot: the role of a specialized foot clinic. Q J Med 1986;60:763-771

8. Apelqvist J, Larsson J, Agardh CD. The importance of peripheral pulses, peripheral oedema and local pain for the outcome of diabetic foot ulcers. Diabet Med 1990;7:590-594

9. Apelqvist J, Agardh CD. The association between clinical risk factors and outcome of diabetic foot ulcers. Diabetes Res Clin Pract 1992;18:43-53

10. Armstrong DG, Lavery LA, Harkless LB. Validation of a diabetic wound classification system. The contribution of depth, infection, and ischemia to risk of amputation. Diabetes Care 1998;21:855-859

11. Oyibo SO, Jude EB, Tarawneh I, Nguyen HC, Armstrong DG, Harkless LB, Boulton AJ. The effects of ulcer size and site, patient's age, sex and type and duration of diabetes on the outcome of diabetic foot ulcers. Diabet Med 2001;18:133-138

12. Margolis DJ, Allen-Taylor L, Hoffstad O, Berlin JA. Diabetic neuropathic foot ulcers: predicting which ones will not heal. Am J Med 2003;115:627-631

13. Jeffcoate WJ, Chipchase SY, Ince P, Game FL. Assessing the outcome of the management of diabetic foot ulcers using ulcer-related and person-related measures. Diabetes Care 2006;29:1784-1787

14. Beckert S, Witte M, Wicke $C$, Konigsrainer A, Coerper S. A new wound-based severity score for diabetic foot ulcers: A prospective analysis of 1,000 patients. Diabetes Care 2006;29: 988-992

15. Prompers $\mathrm{L}$, Schaper $\mathrm{N}$, Apelqvist $\mathrm{J}$, et al. Predictors of outcome in individuals with diabetic foot ulcers. Focus on the differences between individuals with and without peripheral arterial disease. The Eurodiale study. Diabetologia 2008; accepted for publication

16. Prompers L, Huijberts M, Apelqvist J, Jude E, Piaggesi A, Bakker K, Edmonds M, Holstein P, Jirkovska A, Mauricio D, Ragnarson Tennvall G, Reike H, Spraul M, Uccioli L, Urbancic V, Van Acker K, van Baal J, van Merode F, Schaper N. High prevalence of ischaemia, infection and serious comorbidity in patients with diabetic foot disease in Europe. Baseline results from the Eurodiale study. Diabetologia 2007;50:18-25

17. Prompers L, Huijberts M, Apelqvist J, et al. Delivery of care to diabetic foot ulcer patients in daily practice: Results of the Eurodiale study, a prospective cohort study. Diabetologia 2008; accepted for publication

18. Prompers L, Huijberts M, Apelqvist J, Jude E, Piaggesi A, Bakker K, Edmonds M, Holstein P, Jirkovska A, Mauricio D, Tennvall GR, Reike H, Spraul M, Uccioli L, Urbancic V, Van Acker K, Van Baal J, Van Merode F, Schaper N. Optimal organisation of health care in diabetic foot disease. Introduction to the Eurodiale study. Int J Low Extrem Wounds 2007;6:11-17

19. Van Houwelingen S, Le Cessie S. Predictive value of statistical models. Stat Med 1990;9:1303-1325 
20. Schaper NC, Apelqvist J, Bakker K. The international consensus and practical guidelines on the management and prevention of the diabetic foot. Curr Diab Rep 2003;3:475-479

21. van Houtum WH, Lavery LA, Harkless LB. The impact of diabetes-related lower-extremity amputations in The Netherlands. J Diabetes Complications 1996;10:325-330

22. Stiegler H, Standl E, Frank S, Mendler G. Failure of reducing lower extremity amputations in diabetic patients: results of two subsequent population based surveys 1990 and 1995 in Germany. Vasa 1998;27:10-14

23. Boulton AJ, Vileikyte L, Ragnarson-Tennvall G, Apelqvist J. The global burden of diabetic foot disease. Lancet 205;366:1719-1724

24. Boulton AJ. The pathogenesis of diabetic foot problems: an overview. Diabet Med 1996;13 $\mathrm{S} 1: \mathrm{S} 12-16$

25. Dormandy JA, Rutherford RB. Management of peripheral arterial disease (PAD). TASC Working Group. TransAtlantic Inter-Society Concensus (TASC).J Vasc Surg 2000;31:S1S296

26. Lazaris AM, Tsiamis AC, Fishwick G, Bolia A, Bell PR. Clinical outcome of primary infrainguinal subintimal angioplasty in diabetic patients with critical lower limb ischemia. $J$ Endovasc Ther 2004;11:447-453

27. Adam DJ, Beard JD, Cleveland T, Bell J, Bradbury AW, Forbes JF, Fowkes FG, Gillepsie I, Ruckley CV, Raab G, Storkey H; BASIL trial participants. Bypass versus angioplasty in severe ischaemia of the leg (BASIL): multicentre, randomised controlled trial. Lancet 2005;366:1925-1934

28. Faglia E, Dalla Paola L, Clerici G, Clerissi J, Graziani L, Fusaro M, Gabrielli L, Losa S, Stella A, Gargiulo M, Mantero M, Caminiti M, Ninkovic S, Curci V, Morabito A. Peripheral angioplasty as the first-choice revascularization procedure in diabetic patients with critical limb ischemia: prospective study of 993 consecutive patients hospitalized and followed between 1999 and 2003. Eur J Vasc Endovasc Surg 2005;29:620-627

29. Lipsky BA, Berendt AR. Principles and practice of antibiotic therapy of diabetic foot infections. Diabetes Metab Res Rev 2000;16 S1:S42-46

30. Eneroth M, Larsson J, Apelqvist J. Deep foot infections in patients with diabetes and foot ulcer: an entity with different characteristics, treatments, and prognosis. J Diabetes Complications 1999;13:254-263

31. Tan JS, Friedman NM, Hazelton-Miller C, Flanagan JP, File TM, Jr. Can aggressive treatment of diabetic foot infections reduce the need for above-ankle amputation? Clin Infect Dis 1996;23:286-291

32. Wrobel JS, Charns MP, Diehr P, Robbins JM, Reiber GE, Bonacker KM, Haas LB, Pogach L. The relationship between provider coordination and diabetes-related foot outcomes. Diabetes Care 2003;26:3042-3047 
Chapter 9

Summary, conclusions and discussion 
116 Chapter 9 


\section{Summary and Conclusions}

As summarized in the introduction the mains research questions of the work described in this thesis were the following:

1. What are the patient demographics and foot and ulcer characteristics of individuals treated for diabetic foot disease?

2. What are the current clinical outcomes of these patients?

3. Which major factors influence clinical outcome?

4. What is the current resource utilization and associated cost in diabetic foot disease throughout Europe?

5. Are there differences in management strategies and clinical outcome.

The results of our study are summarized and discussed in the first part of this chapter. In the second part the implications for clinical care and research are discussed more in detail, focusing on the most important findings of these studies: the importance of concurrent co-morbidities, the poor outcome of individuals with both $\mathrm{PAD}$ and infection, and the role of health care organisation.

\section{Patient demographics, foot characteristics and ulcer characteristics of individuals treated for diabetic foot disease}

In chapter 3 the most important patient, foot and ulcer characteristics of the Eurodiale cohort are described. Our data confirm previous studies ${ }^{1,2}$ that diabetic foot disease affects mostly elderly, male, patients with longstanding diabetes. The integrated approach of describing both patient and disease specific characteristics that was chosen, clearly showed that many patients with diabetic foot disease are severely ill. This is reflected by the severe underlying pathology and the presence of disabling co-morbidities in at least one-third of our patients. Forty-nine percent of the patients suffered from PAD at presentation and $58 \%$ suffered from infection; the combination of PAD and infection were present in $31 \%$. Our results indicate that the ulcer and patient characteristics of this large group of patients with both PAD and infection are different from those of patients with neither PAD nor infection. The ulcers in the former patients were mainly non-plantar (65\%) and were associated with more extensive tissue loss as they were also deeper and larger. Moreover, these patients were older and frailer, since serious comorbidity also clustered in this group. 


\section{Clinical outcome in diabetic foot disease}

In chapter 4 and 5 we demonstrate that despite the severity of the underlying disease and the important co-morbidity as discussed in chapter 3 , clinical outcome of the Eurodiale population within 1-year follow up is more favourable than reported in older studies ${ }^{3}$. In our cohort $77 \%$ of the patients healed, $5 \%$ underwent a major amputation and $6 \%$ died. Recent studies have shown similar outcome rates ${ }^{4,5}$. All together these recent studies provide benchmarkdata that can be used in the improvement of clinical care. Both ulcer characteristics and several patient-related characteristics affected healing of the foot. A novel finding was the large impact of co-morbidities on healing. Furthermore, to our surprise, depth was not associated with outcome, although a similar finding was recently reported by Jeffcoate et al. ${ }^{4}$ In contrast to depth, ulcer-size was a very strong predictor of outcome, which confirms earlier findings ${ }^{1}$. Although it is sometimes believed that the presence of PNP is a condition sine qua non for the development of foot ulcers, we found that there are diabetic foot ulcer patients in which neither PNP nor PAD is present (chapter 3). The absence of PNP was associated with a higher probability of healing. This may be due to the conservation of pain sensation and intact natural reflex to offload the ulcer, but may also be related to specific effects of PNP on wound healing, as has been described previously ${ }^{6}$. In chapter 5 we describe the development of the Eurodiale risk score, which is based on the main determinants of non-healing described in chapter 4 .

Although overall outcome in our cohort was rather encouraging, healing-rates in patients with PAD were considerably worse. In addition, predictors of healing differed between the groups with and without PAD. The presence of infection, which is generally regarded as an important predictor of healing was only a predictive factor in individuals with PAD and patients with the combination of infection and PAD had the poorest prognosis.

\section{Current resource utilisation and associated costs in diabetic foot disease throughout Europe}

In chapter 6 the prospective data on resource utilisation and associated costs in diabetic foot disease are presented. As could be expected in view of the high number of patients with severe foot disease at presentation (chapter 3 ), resource utilisation and costs for the treatment of this condition throughout Europe is substantial. Health care costs were high with an average total direct and indirect cost of approximately 10000 Euro, based on the costing data of 821 patients from the participating countries. Overall the majority of costs were 
related to hospitalisation and antibiotic use. However, resource utilisation and costs varied importantly between the different outcome groups. Major amputations as well as non-healing during twelve months are two conditions related to high costs, although in these calculations the costs of following amputation were not taken into account. Also we show that treatment of individuals with PAD, especially in combination with infection are twice as high than in patients without PAD. These high costs were to a limited extent related to higher costs for diagnostic procedures and interventions, most of the excess costs in individuals with PAD and infection are related to higher rate of hospitalisation and higher costs of antibiotics, amputations, revascularisation, and other surgery.

\section{Management strategies and clinical outcome in the different centres}

The data in chapter 7 demonstrate that there is a substantial gap between recommendations in multidisciplinary guidelines and every day clinical practice in foot centres when it comes to referral patterns, management of ulcers in terms of the use of casting and vascular evaluation/ revascularisation. Many patients were referred from primary care to centres of expertise with substantial delay, and in many of these patients diagnostic (vascular evaluation) and therapeutic procedures (offloading) were not used. For example, international guidelines state that the total contact cast in the gold standard for the treatment of neuropathic plantar foot ulcers ${ }^{7}$. However, in the subgroup of patients with a neuropathic plantar forefoot or midfoot ulcer $(n=139)$, total contact cast was prescribed in only $18 \%(n=25)$. An additional $17 \%(n=24)$ of these patients were treated with alternative casting modalities, but most of the plantar ulcers were treated with temporary footwear. There was a marked difference in the use of casting between countries ranging from $0-68 \%$. Also in contrast to international guidelines, in patients with severe limb ischemia a revascularisation procedure was performed in only $43 \%$. In a survey the reasons for this apparent undertreatment were further explored. This survey showed that there are several health care organisational barriers that influence the delivery of optimal care. Factors related to undertreatment were reimbursement policies, lack of qualified staff, lack of acceptance by health care workers (personal beliefs), lack of patient acceptance, a non-functional leg, spontaneous healing of the ulcer, and very poor health status of the patient.

The observed differences in health care delivery between the centres raise the question whether this also translates into substantial differences in outcome between these centres. In chapter 8 we have demonstrated that there are 
indeed differences in healing rates between the different centres that have participated in this European study. However, these differences could not be explained by differences in patient characteristics between these centres. Centres with the most favourable corrected outcomes were characterised by significantly higher use of revascularisation and surgical procedures although this could not solely explain the observed differences in outcome. Efficient health care organization and proactive revascularisation and surgical strategies seem to be important keys to success. By implementing such strategies very favourable outcomes, with major amputation rates below 3\% may be achieved.

\section{Diabetic foot ulceration: a typical complication of the frail elderly diabetic individual ?}

Current literature does not discriminate between neuropathic and neuroischemic ulcers when discussing issues as outcome and suggested therapies in diabetic foot disease. Our study however clearly shows that patients with PAD have a distinct profile compared to patients without PAD; Patients with $P A D$ are older, and many of them have serious co-morbidity; foot ulcers are mostly non-plantar, and tissue loss is more extensive. Many studies in the field of diabetic foot disease focus on biomechanics, plantar ulceration, offloading, total contact cast therapy and immobilisation ${ }^{8-10}$, which all suggest that diabetic foot ulceration is a disease of individuals with preserved mobility and an active lifestyle. This picture is in sharp contrast with the typical phenotype of the frail elderly diabetic individual that we have observed. In our opinion it is important to embrace this new model in order to improve the quality of care and outcome of individuals with diabetic foot disease. The proposed concept of a condition of frail elderly patients shows many similarities with the features of patients with pressure ulcers ${ }^{11}$. In addition to the typical patient characteristics that can be observed in both populations, it is also known that in pressure ulcers the presence of co-morbidities has a major influence on outcome ${ }^{12}$. In many health care systems the development of pressure ulcers is seen as one of the most important indicators of the quality of in-hospital care, and much effort has been put in early identification of patients at risk, in the development of preventive measures, and in specific treatment modalities across the different stages of the disease. Probably professionals working in the field of diabetic foot disease can adopt strategies as used in the field of pressure ulcers. An important item in treatment and also in prevention is holistic risk assessment of patients ${ }^{12}$. This risk assessment has a central role in choosing and implementing preventive measures in pressure ulcers ${ }^{12}$. The minimum components of risk assessment scales in pressure ulcers are age, mobility, activity, general health status, level of consciousness, nutrition, continence, skin status and illness 
severity (based on NICE recommendations 2003, www.nice.org.uk). In current guidelines for diabetes care annual foot examination is advocated and patients are classified according to the modified Simm's classification which stratifies patient's according to the presence or absence PAD, in which patients with either PAD or polyneuropathy receive similar preventive care. However, these assessments focus mainly on local aspects of the foot an do not take into account general health status of patients. Also the recently published Scottish foot ulcer risk score focuses on foot and ulcer characteristics only ${ }^{13}$. The characteristics of this European cohort suggest that older patients with longstanding diabetes and co-morbidities are at increased risk of foot ulceration; since data on the background diabetic population of the participating centres are not known further research is needed to support this concept. Probably a more comprehensive assessment of both patient, foot and ulcer characteristics may improve the identification of the patients with the highest risk of foot ulceration. Once an ulcer has developed most guidelines recommend classification according to the underlying pathology, direct cause of the ulcers, size and depth, location and the presence of infection ${ }^{7}$. Although this classification is helpful in the choice of diagnostic and therapeutic strategies, it does not contribute to the identification of individuals with a highrisk of non-healing. The Eurodiale Risk score, a risk score that predicts the healing potential of an ulcer as presented in chapter 5 , although not externally validated, is a first effort towards a comprehensive risk assessment in the field of diabetic foot disease. We feel that this risk-score can be of important value to assist health care professionals in identifying patient with a high risk of poor outcome and reduce the significant delays in referral to a specialized foot centre as discussed in chapter 7. For example, a 80-year-old male diabetic patient, with a history of heart failure presents to the GP with just a small, superficial wound of $1 \mathrm{~cm}^{2}$ on the dorsal side of the toe, without signs of infection. To many health care workers such a small, superficial wound may seem an insignificant problem and the patient will be sent home with non evidence based local wound therapy. However, if the risk of non-healing of this patient would have been systematically assessed, the presence of polyneuropathy and PAD would have been evaluated, and the general health status of this patient would have been taken into account, it can be calculated that according to the Eurodiale risk score the risk of non-healing is $35 \%$. This patient thus has a high risk at non-healing and should be immediately referred to a specialized foot centre with his so-called "insignificant," small, superficial, ulcer. As described in chapter 6, non-healing of ulcers will result in high costs for our society and in low quality of life for the patient ${ }^{14}$. We feel that further studies are needed to improve and simplify the assessment of healing pontential of an ulcer in diabetic foot disease. From a pathophysiological point of view more insight is needed into the relation between co-morbidities and 
progressive tissue loss in order to define new objective (circulating) markers for healing potential of ulcers and new strategies to treat these patients.

\section{Improving outcome in diabetic foot disease: management of PAD and infection}

\section{PAD}

Almost half of the patients that present at foot clinics suffer from PAD. In the limited number of large studies on outcome in diabetic foot disease the percentage of patients with PAD on whom data were reported was less than $1 \%{ }^{1,3-5,15-18}$. We showed that, although overall outcome-rates were rather favourable, healing-rates in PAD patients much lower. In view of the high prevalence of PAD in diabetic foot patients and lower healing rates, it is important to detect the presence of PAD in these patients as early as possible. Since physical examination is of limited value ${ }^{19}$, further assessments are required to identify the presence of PAD. ABPI-measurement is the cornerstone of evaluation of PAD. However, in diabetic patients noncompressibility of the lower leg arteries can occur as a consequence of media calcification (Mönckeberg's sclerosis), resulting in a non-interpretable measurement. Non-compressible lower leg arteries (defined as and ankle brachial pressure index $(\mathrm{ABPI})>1.2$ ) were observed in $32 \%$ of our patients. This supports the need for additional techniques such as toe-pressure measurement or transcutaneous oxygen pressure measurement $\left(\mathrm{TcPO}_{2}\right)$. Measurement of $\mathrm{TcPO}_{2}$ can give additional information on the probability of wound healing ${ }^{20}$. Wound healing is very unlikely if $\mathrm{TcPO}_{2}$ values are below 20 $\mathrm{mmHg}$ and healing is likely with a $\mathrm{TcPO}_{2}$ value above $40 \mathrm{mmHg}^{21}$. The tables of the likelihood of non-healing for given values of these measures mask the fact that outcome is strongly determined by the concurrent presence or absence of infection. Current guidelines recommend vascular imaging in case of critical limb ischemia ${ }^{22}$. Awaiting further research in this area we advocate for the group of patients with moderate PAD and concomitant infection a similar policy is followed.

Pro-active revascularisation seems an important key to successful treatment of foot ulcer patients (chapter 8). Endovascular treatment of peripheral arterial disease has a number of advantages over bypass surgery, including the low morbidity and mortality of the procedure, the short preparation time and the limited hospital stay ${ }^{23}$. The main contra-indications are problems with haemostasis, severe heart failure or renal disease and specific anatomical characteristics such as long occlusions of iliac or femoral arteries ${ }^{23}$. The 
restenosis rate might be relatively high, especially in procedures below the knee in which restenosis over a 5 -year period in $50 \%$ of cases has been reported $^{23}$. However, in patients with a foot ulcer the main aim is to heal the ulcer and to save the limb. The temporary improvement of skin perfusion can be sufficient to promote healing of a chronic ulcer and to avoid amputation, certainly in a patient with a short life expectancy. Moreover, once the ulcer is healed lower perfusion pressures are probably necessary to maintain skin integrity. Faglia et.al. reported on the results of peripheral angioplasty as first line revascularisation therapy in 993 patients with diabetic foot ulcers ${ }^{24}$. All patients with absent foot pulses and $\mathrm{TcPO}_{2}$ below $50 \mathrm{mmHg}$ and stenosis $>50 \%$ of vessel diameter underwent angiography and if possible PTA. In $62 \%$ of patient's obstructions both in the femoro-popliteal and infrapopliteal axis were present. With a mean follow-up of more than two years relatively good outcomes were reported: All but six ulcers healed, and major amputation was performed in only 17 patients $(1.7 \%)$. The number of minor amputations was however high with almost $50 \%$ (478 patients). The estimate of clinical restenosis was $2.2 \%$ per year, but in most of these patients PTA could be repeated successfully. $12 \%$ of the patients died during follow-up. The complication rate was $3.4 \%$, including 10 cases of distal thrombosis, seven cases of cardiac events (chest pain, myocardial infarction) and one death.

In addition to endovascular treatment, peripheral bypass surgery remains an effective treatment in many diabetic patients with PAD and critical limb ischemia. The basic principles of this type of surgery are that any artery can be used for the proximal anastomosis provided inflow is uncompromised. The graft should bypass the major obstructive lesions and for the distal anastomosis an artery relatively free of occlusive disease, providing the best outflow into the arteries of the foot, should be selected. The crural and pedal arteries are common outflow sites of the graft in diabetic patients, given the characteristic anatomic pattern of PAD. Long-term results of these distal procedures in diabetic patients are good, with 5-year secondary patency rates of $\geq 70 \%$ and limb salvage rates of $75-85 \%{ }^{25,26}$. In addition, such distal procedures in diabetic patients are more cost-effective than primary amputation ${ }^{27}$.

In the multicentre randomised controlled BASIL trial, results of bypass surgery versus angioplasty in patients with severe limb ischemia with or without tissue loss have been evaluated ${ }^{28}$. Fourty-two percent of this cohort consisted of patients with known diabetes. The median results for the outcomes amputationfree survival, all cause mortality and Health Related Quality of Life (HR-QOL) were quite similar. However, in the first year bypass surgery resulted in increased morbidity, mortality and higher costs, but in the long-term patients who underwent surgery seemed to have a reduced risk of future amputation 
and death ${ }^{28}$. The results of this study are highly relevant for the population of individuals with diabetic foot ulcers. In many of the patients life-expectancy is reduced and significant co-morbidities are usually present, therefore endovascular therapy should in our opinion be the treatment of choice in these patients. We therefore recommend that centres that treat diabetic foot ulcer patients have access to state of the art endovascular therapies. Very recent studies suggest that new techniques as subintimal angioplasty should be the first-choice revascularisation technique in patients with critical limb ischemia ${ }^{29}$. However, further research on this topic is needed. In addition, future research should focus on the cost effectiveness of early endovascular treatment versus a wait-and-see policy in individuals with moderate PAD.

\section{Infection}

Infection was present at baseline in half of the patients that present at foot clinics (chapter 3 ) and our results show (chapter 4 and 5 ) that in patients without PAD infection had no major influence on non-healing of the ulcer, suggesting that treatment was adequate in our patients. Our study clearly shows that patients with PAD and infection have the worst outcome (chapter 4 ), implying that precisely in this patient-group current treatment standards fail. This group is substantial: one third of all foot ulcer patients presents with these features, and many more PAD patients will develop infection in the course of the disease. Why in patients with PAD infection is diagnosed more often is, to our knowledge, unclear and is an area that needs to be explored further. Possibly the ischemic wound environment predisposes to wound infection. Baseline data of the Eurodiale study show that tissue loss is most extensive in patients with both PAD and infection. Since the diagnosis of infection in diabetic foot disease remains partly subjective it is also possible that because of this more extensive tissue loss the presence of infection is more often considered. The poor outcome in these patients may be related to the more extensive tissue loss at presentation. We hypothesize that in case of infection the increased metabolic requirements of the lower extremity can not be fulfilled in patients with PAD, which results in a downward spiral of progressive tissue loss. On the other hand also inadequate treatment of infection may explain the poor outcome observed in these patients. In trials on infection ${ }^{30,31}$, PAD was present in only a minority of the patients, and it can be concluded that these trials are significantly biased because the most relevant target group was not included. In fact there is little evidence on the antibiotic(s) of choice, nor the duration of treatment in patients with PAD and infection. In our opinion both basic and clinical studies are needed to define appropriate antibiotic therapy in the context of PAD. For current clinical practice we advocate close monitoring 
of the occurrence and/or course of infection in patients with PAD, and the use of prolonged regimens of antibiotic therapy.

\section{"Quick" wins ? Reducing costs by changing health care organisation}

In chapter 4 and 5 we have identified several important determinants of clinical outcome in diabetic foot disease. Although many of these predictors are not modifiable, the most important predictor, size at presentation, can be influenced by proper education of patients and early installation of adequate treatment. As shown in chapter 6 the majority of costs for the treatment of diabetic foot disease are related to hospital admissions. Traditionally these admissions are related to progressive tissue loss in context of PAD and/or infection. The Dutch Guidelines on the diabetic foot states that only patients with superficial wounds, which are not infected, in patients without PAD can be treated in primary care ${ }^{32}$. They should heal within two weeks; all other patients must be referred to specialised foot clinics. In chapter 7 we haven shown that in many patients referral to a specialised foot clinic was substantially delayed. Only $18 \%$ of the 1232 patients that were recruited for the Eurodiale cohort had a superficial, non-infected ulcer, and did not suffer from PAD. When the presence of co-morbidities also is taken into account, only $13 \%$ of our patients fulfil these criteria. In our opinion very early referral to centres with the necessary expertise and facilities is an important key to better outcomes and reduction of costs in diabetic foot disease. This should be effectuated by the development of regional agreements and monitoring of admissions for diabetic foot disease. Taking into account that primary care professionals will see 1-2 patients per year with a foot ulcer, it can be argued whether it is realistic to expect from these professionals the necessary skills to classify these patients. It may be more easy to implement the rule to refer every patient with a diabetic foot ulcer as soon as possible to a diabetic foot clinic. It is evident that not every hospital meets the requirements as summarized in current guidelines. Dedicated clinics should at least be able to see patients on an acute basis, have the availability of a dedicated specialist around the clock, have access to vascular assessment, state of the art vascular imaging and endovascular treatment, and have experience with the use of (total contact) casting. It appeared from our results (chapter 8) that clinics with both medical and surgical competences in one person have better outcome rates. In our opinion this is related to the timing of both diagnostic and interventional procedures, and support the concept that time ("'quick"' wins) is an important factor in the treatment of patients with diabetic foot disease. We advocate that in patients referred to foot clinics the process of diagnosis of PAD and revascularisation, 
as well as the start of antibiotic therapy is as short as possible. It may be of interest to study the optimal balance between costs associated with aggressive early diagnostic evaluation (such as the use of MR-angiography in many patients) and costs associated with delayed treatment (more hospitalisation) in this condition. In a time in which improved outcomes are mostly obtained by the development of new but expensive therapies, it should be very motivating for all the parties involved that in this condition significant improvement in outcomes, as well as reductions in costs, may result from a better organisation of the disease chain. 


\section{References}

1. Oyibo SO, Jude EB, Tarawneh I, Nguyen HC, Armstrong DG, Harkless LB, Boulton AJ. The effects of ulcer size and site, patient's age, sex and type and duration of diabetes on the outcome of diabetic foot ulcers. Diabet Med 2001;18:133-138

2. Reiber GE. The epidemiology of diabetic foot problems. Diabet Med 1996;13 S1:S6-11

3. Margolis DJ, Allen-Taylor L, Hoffstad O, Berlin JA. Diabetic neuropathic foot ulcers: the association of wound size, wound duration, and wound grade on healing. Diabetes Care 2002;25:1835-1839

4. Jeffcoate WJ, Chipchase SY, Ince P, Game FL. Assessing the outcome of the management of diabetic foot ulcers using ulcer-related and person-related measures. Diabetes Care 2006;29:1784-1787

5. Beckert S, Witte M, Wicke C, Konigsrainer A, Coerper S. A new wound-based severity score for diabetic foot ulcers: A prospective analysis of 1,000 patients. Diabetes Care 2006;29:988992

6. Barker AR, Rosson GD, Dellon AL. Wound healing in denervated tissue. Ann Plast Surg 2006; $57: 339-342$

7. Schaper NC, Apelqvist J, Bakker K. The international consensus and practical guidelines on the management and prevention of the diabetic foot. Curr Diab Rep 2003;3:475-479

8. Armstrong DG, Nguyen HC, Lavery LA, van Schie CH, Boulton AJ, Harkless LB. Off-loading the diabetic foot wound: a randomized clinical trial. Diabetes Care 2001;24:1019-1022

9. Lavery LA, Vela SA, Lavery DC, Quebedeaux TL. Total contact casts: pressure reduction at ulcer sites and the effect on the contralateral foot. Arch Phys Med Rehabil 1997; 78:1268-1271

10. Nabuurs-Franssen MH, Sleegers R, Huijberts MS, Wijnen W, Sanders AP, Walenkamp G, Schaper NC. Total contact casting of the diabetic foot in daily practice: a prospective followup study. Diabetes Care 2005;28:243-247

11. Landi F, Onder G, Russo A, Bernabei R. Pressure ulcer and mortality in frail elderly people living in community. Arch Gerontol Geriatr 2007;44 S1: 217-223

12. Grey JE, Harding KG, Enoch S (2006) Pressure ulcers. BMJ 2006;332:472-475

13. Leese G, Schofield C, McMurray B, Libby G, Golden J, MacAlpine R, Cunningham S, Morris A, Flett M, Griffiths G. Scottish foot ulcer risk score predicts foot ulcer healing in a regional specialist foot clinic. Diabetes Care 2007;30:2064-2069

14. Nabuurs-Franssen MH, Huijberts MS, Nieuwenhuijzen Kruseman AC, Willems J, Schaper NC. Health-related quality of life of diabetic foot ulcer patients and their caregivers. Diabetologia 2005;48:1906-1910

15. Apelqvist J, Larsson J, Agardh CD. The importance of peripheral pulses, peripheral oedema and local pain for the outcome of diabetic foot ulcers. Diabet Med 1990;7:590-594

16. Apelqvist J, Agardh $\mathrm{CD}$. The association between clinical risk factors and outcome of diabetic foot ulcers. Diabetes Res Clin Pract 1992;18:43-53

17. Armstrong DG, Lavery LA, Harkless LB. Validation of a diabetic wound classification system. The contribution of depth, infection, and ischemia to risk of amputation. Diabetes Care 1998;21:855-859

18. Margolis DJ, Allen-Taylor L, Hoffstad O, Berlin JA. Diabetic neuropathic foot ulcers: predicting which ones will not heal. Am J Med 2003;115:627-631

19. Schaper NC, Nabuurs-Franssen MH. The diabetic foot: pathogenesis and clinical evaluation. Semin Vasc Med 2002;2:221-228

20. Takolander R, Rauwerda JA. The use of non-invasive vascular assessment in diabetic patients with foot lesions. Diabet Med 1996;13 S1:S39-42

21. Dormandy JA, Rutherford RB. Management of peripheral arterial disease (PAD). TASC Working Group. TransAtlantic Inter-Society Concensus (TASC). J Vasc Surg 2000;31:S1S296 
22. Norgren L, Hiatt WR, Dormandy JA, Nehler MR, Harris KA, Fowkes FG, Rutherford RB; TASC II Working Group. Inter-society consensus for the management of peripheral arterial disease. Int Angiol 2007;26:81-157

23. Balmer H, Mahler F, Do DD, Triller J, Baumgartner I. Balloon angioplasty in chronic critical limb ischemia: factors affecting clinical and angiographic outcome. J Endovasc Ther 2002;9:403-410

24. Faglia E, Dalla Paola L, Clerici G, Clerissi J, Graziani L, Fusaro M, Gabrielli L, Losa S, Stella A, Gargiulo M, Mantero M, Caminiti M, Ninkovic S, Curci V, Morabito A. Peripheral angioplasty as the first-choice revascularization procedure in diabetic patients with critical limb ischemia: prospective study of 993 consecutive patients hospitalized and followed between 1999 and 2003. Eur J Vasc Endovasc Surg 2005;29:620-627

25. Akbari CM, Pomposelli FB Jr, Gibbons GW, Campbell DR, Pulling MC, Mydlarz D, LoGerfo FW. Lower extremity revascularization in diabetes: late observations. Arch Surg 2000;135:452-456

26. Panneton JM, Gloviczki P, Bower TC, Rhodes JM, Canton LG, Toomey BJ. Pedal bypass for limb salvage: impact of diabetes on long-term outcome. Ann Vasc Surg 2000;14:640-647

27. Panayiotopoulos YP, Tyrrell MR, Arnold FJ, Korzon-Burakowska A, Amiel SA, Taylor PR. Results and cost analysis of distal crural/pedal] arterial revascularisation for limb salvage in diabetic and non-diabetic patients. Diabet Med 1997;14:214-220

28. Adam DJ, Beard JD, Cleveland T, Bell J, Bradbury AW, Forbes JF, Fowkes FG, Gillepsie I, Ruckley CV, Raab G, Storkey H; BASIL trial participants. Bypass versus angioplasty in severe ischaemia of the leg (BASIL): multicentre, randomised controlled trial. Lancet 2005;366:1925-1934

29. Tartari S, Zattoni L, Rizzati R, Aliberti C, Capello K, Sacco A, Mollo F, Benea G. Subintimal angioplasty as the first-choice revascularization technique for infrainguinal arterial occlusions in patients with critical limb ischemia. Ann Vasc Surg 2007;21:819-828

30. Harkless L, Boghossian J, Pollak R, Caputo W, Dana A, Gray S, Wu D. An open-label, randomized study comparing efficacy and safety of intravenous piperacillin/tazobactam and ampicillin/sulbactam for infected diabetic foot ulcers. Surg Infect (Larchmt) 2005;6:27-40

31. Lipsky BA, Armstrong DG, Citron DM, Tice AD, Morgenstern DE, Abramson MA. Ertapenem versus piperacillin/tazobactam for diabetic foot infections (SIDESTEP): prospective, randomised, controlled, double-blinded, multicentre trial. Lancet 2005;366:1695-1703

32. Richtlijn Diabetische voet. Van Zuiden Communications B.V., Alphen aan den Rijn, 2006 
Samenvatting 


\section{Samenvatting}

Complicaties van de onderste extremiteit, in het bijzonder voetulcera (voetwonden), veroorzaken een zeer grote ziektelast en een grote mate van verlies van kwaliteit van leven bij mensen met diabetes (suikerziekte); daarnaast zijn de kosten samenhangend met de behandeling zeer hoog. In de afgelopen jaren is door 14 Europese centra gespecialiseerd in de behandeling van deze complicaties, de Eurodiale onderzoeksgroep, een internationale multi-center studie uitgevoerd. Achtergrond voor dit onderzoek was het gebrek aan gegevens over kenmerken van deze patiëntengroep, hun behandeling en het beloop van hun ziekte. In deze studie, uitgevoerd met steun van de Europese commissie, zijn op grote schaal (1232 patiënten) prospectieve data (een jaar vervolgd) over deze patiënten verzameld.

Deze multi-center studie heeft een grote hoeveelheid aan nieuwe gegevens opgeleverd, zoals gegevens over de te verwachten uitkomst van de behandeling van deze patiënten, die gebruikt kunnen worden voor benchmarking, bovendien geven de data meer inzicht in de factoren die van belang zijn voor het al dan niet genezen van de wond, als ook betrouwbare gegevens over de factoren die bepalend zijn voor de zeer hoge kosten die samenhangen met de behandeling.

De belangrijkste onderzoeksvragen van dit proefschrift zijn:

1. Wat zijn de patiënt, ulcus en voet karakteristieken van diabetespatiënten met een voet ulcus?

2. Hoe is de klinische uitkomst van deze patiënten?

3. Welke factoren bepalen deze klinische uitkomst?

4. Wat is de medische consumptie en wat zijn de kosten verbonden aan een voet ulcus bij een diabetespatiënt?

5. Zijn er verschillen in diagnostiek/behandeling en klinische uitkomst in Europa?

\section{Patiënt, ulcus en voet karakteristieken van diabetespatiënten met een voet ulcus}

Onze data bevestigen eerdere studies waarin vermeld wordt dat diabetische voet ulcera met name voorkomen bij oudere, mannelijke patiënten die langdurig aan diabetes lijden. Wat echter nieuw is, is dat onze data laten zien dat $1 / 3$ van de patiënten aan ernstige bijkomende aandoeningen lijdt, $49 \%$ aan bloedvatvernauwing en dat in $58 \%$ van de patiënten het ulcus gecompliceerd 
wordt door infectie. Eénendertig procent van de patiënten lijdt aan de combinatie van bloedvatvernauwing en infectie. Onze resultaten laten zien dat deze laatste groep patiënten verschilt van de groep zonder bloedvatvernauwing of infectie; de patiënten met bloedvatvernauwing en infectie hebben vaker ulcera aan de bovenzijde van de voet en de tenen en de ulcera zijn geassocieerd met uitgebreider weefselverlies. Bovendien zijn de patiënten ouder en lijden vaker aan bijkomende aandoeningen.

\section{Klinische uitkomst van patiënten met een diabetisch voet ulcus}

De klinische uitkomst van de Eurodiale populatie na een jaar follow-up is beter dan gerapporteerd in eerdere studies. Zevenenzeventig procent van de patiënten was compleet genezen, $5 \%$ onderging een amputatie van het (onder)been, en $6 \%$ overleed. De overige patiënten hadden een ulcus dat nog steeds niet genezen was. Deze uitkomst-data zouden als benchmark kunnen dienen voor klinieken die diabetespatiënten met voet ulcera willen behandelen om zo een verbetering van zorg voor deze patiënten te bewerkstelligen. Een belangrijke, nieuwe bevinding van de Eurodiale studie, is de grote invloed van bijkomende aandoeningen op klinische uitkomst. Naast bijkomende aandoeningen, is met name grootte van het ulcus belangrijk voor de prognose.

Alhoewel de uitkomst van het cohort in het algemeen goed lijkt, was de uitkomst van de patiënten die lijden aan de combinatie van bloedvatvernauwing en infectie beduidend slechter. Bovendien verschilden de voorspellers van genezing tussen patiënten met en zonder bloedvatvernauwing. Infectie, waarvan altijd wordt aangenomen dat het een belangrijke rol speelt in de uitkomst van het ulcus, blijkt enkel een rol te spelen in patiënten met bloedvatvernauwing, niet in patiënten zonder bloedvatvernauwing.

\section{Medische consumptie en kosten geassocieerd met diabetische voet ulcera in Europa}

Er werden prospectieve data over het gebruik van medische consumptie en kosten verbonden aan voet ulcera bij diabetespatiënten verzameld. De kosten voor de gezondheidszorg bleken hoog; 10.000 Euro voor een gemiddeld ulcus. Kosten blijken met name gerelateerd aan ziekenhuisopname en gebruik van antibiotica. De medische consumptie en kosten verschilden aanzienlijk tussen de verschillende uitkomst-groepen. De hoogste kosten waren geassocieerd met patiënten die een (onder)been amputatie ondergingen en met patiënten die na twaalf maanden follow-up nog steeds een niet genezen ulcus hadden. De kosten van een ulcus bij patiënten die lijden aan bloedvatvernauwing en infectie bleken vier maal zo hoog als bij patiënten zonder bloedvatvernauwing en infectie. 


\section{Diagnostiek/behandeling en klinische uitkomst in de verschillende centra}

Onze data laten zien dat er een groot gat is tussen aanbevelingen in multidisciplinaire richtlijnen en de dagelijkse praktijk als het gaat om verwijzing, het gebruik van gipstechnieken en vasculaire evaluatie/ revascularisatie. Ook is er sprake van grote verschillen tussen landen en centra. Uit een retrospectief overzicht bleek dat redenen voor het niet volgen van richtlijnen waren: vergoedingen, gebrek aan gekwalificeerd personeel, persoonlijke meningen van artsen/ paramedici en patiënten, spontaan genezen van het ulcus en zeer slechte gezondheidstoestand van de patiënt.

Er worden verschillen gezien in klinische uitkomst tussen de verschillende centra. Deze verschillen kunnen niet verklaard worden door verschillen in patiënten karakteristieken maar lijken gerelateerd te zijn aan pro-actieve revascularisatie en pro-actieve chirurgische interventie. Het lijkt aannemelijk dat door het pro-actief gebruiken van dergelijke interventies amputaties voorkomen kunnen worden. In één centrum met een dergelijke benadering werd bij een relatief grote groep patiënten met een minder goede prognose geen onder(been) amputaties verricht. 
Dankwoord 


\section{Dankwoord}

Het is klaar! Ik kan het bijna niet geloven, maar mijn boekje is eindelijk af! Ik ben ongelooflijk trots op het werk dat voor $u$ ligt. Trots dat ik een promotietraject heb weten te combineren met mijn opleiding, specialisatie en de geboorte van onze dochter Elise. Maar vooral ook ben ik trots op alle mensen wier bijdrage onmisbaar was voor de totstandkoming van dit proefschrift. Hierbeneden doe ik een poging om al die mensen te bedanken. Ik hoop dat jullie allemaal net zo trots zijn als ik!

Lieve Maya. Het is heel simpel, hoe had ik dit kunnen doen zonder jou? Jij was degene die me op de Eurodiale-weg bracht en je hebt me al die jaren dag en nacht gesteund en gestimuleerd. De uren op de kinder-stoelen achter de laptop zijn ontelbaar. Net als de vele nachtelijke werkuurtjes op de Eurodiale meetings. Al hebben we daar vooral ook veel lol gehad! Niet alleen bij de totstandkoming van de uiteindelijke artikelen was je van onmisbare waarde, je stond ook garant voor het oefenen van presentaties op onze hotelkamer, het föhnen van mijn haar voor het galadiner, tranen en frustraties, het uitzoeken van de juiste trouwjurk....hoe moet ik je bedanken? Ik heb nooit eerder van zo'n allround copromotor gehoord! Door de jaren heen ben je een zeer bijzondere vriendin geworden waarvoor ik diepe bewondering koester en die een speciale plek heeft gekregen in mijn hart. Lieve Marc, via Maya kom ik natuurlijk meteen bij jou terecht. Graag wil ik je bedanken dat ik je vrouw zoveel uurtjes van je heb mogen lenen (al had je weinig keus) en voor je verdiensten als paranimf. Bovendien een speciaal woord van dank voor de goede zorgen voor mijn familieleden. Ook jij bent een dierbare vriend van Jörgen en mij geworden.

Geachte prof. dr. Schaper, beste Nicolaas, het waren jouw plannen en ideeën die je jaren geleden in een achteraf kamertje besprak met enkele van onze Eurodiale-vrienden die hebben geleid tot de inhoud van dit proefschrift. Ik denk dat dat wel één van jouw meest uitgesproken kwaliteiten is, je bent altijd vol van inspirerende en heel goede ideeën. Het was geen gemakkelijke klus om de Eurodiale groep te leiden, maar ik denk dat we uiteindelijk een bijzondere klus geklaard hebben, met als resultaat niet alleen dit proefschrift maar ook een enorme dataset en levenslange Europese vrienden. Heel hartelijk bedankt!

Dear Eurodiale friends, it was a tremendous amount of work for all of you to gather all these high quality data and to be present at every meeting, again and again. I will certainly not only remember my Eurodiale period as a period of developing my research skills, but also as a period of becoming a woman of the world; the parties on the roof tops in Rome, the superb restaurants in Tuscany and Barcelona, the outdoor theatre in Slovenia, philosophical 
discussions in Malmö and many, many more. I will never forget your hospitality during all my centre visits. Pod'akovanie Vilma, podekování Alexandra, tak Per, tacksägelse Jan and Gunnel, thank you Mike and Ed, grazie (e baso!) Luigi and Alberto, danke Heinrich und Max, bedankt Kristien, Karel, Sjef en Johan, e gracias Didac! I hope we will be friends for life!

Geachte prof. dr. van Merode, beste Frits, jou wil ik graag bedanken voor je bijdrage op het gebied van organisatie en zorg. Het was prettig met je naar de verschillende Europese bestemmingen te reizen. Ik heb veel van je geleerd!

Dear Isabel Ferreira, your statiscal help was indispensable! Furthermore I am happy that I got acquainted with such a nice person as you are. Thanks a lot!

De leden van de beoordelingscommissie: prof. dr. P. Kitslaar, dr. W. Van Houten, dr. A. Sanders, prof. dr. C. Spreeuwenberg en prof. dr. C. Stehouwer dank ik voor het kritisch door lezen van het manuscript.

Een woord van dank voor alle leden van de werkgroep endocrinologie. Als zeer ervaren medewerkers dank ik prof. dr. Arie Nieuwenhuijzen Kruseman, dr. Jean-Pierre Sels en drs. Sabine Landewe voor hun wijze raad en bijstand. Een speciaal woord voor drs. Patrick van Battum die mij zal opvolgen als spin in het web van de Eurodialegroep. Ik wens je heel veel succes met je eigen promotieonderzoek!

De afdeling nulceaire geneeskunde, prof. dr. Jaap Teule, dr. Boudewijn Brans, dr. Marinus van Kroonenburgh, Audrey, Nanda, Sakar en alle overige medewerkers, wil ik graag bedanken voor de prettige ontvangst op de afdeling en voor de mogelijkheden die ik kreeg om hier en daar nog een uurtje tijd in dit proefschrift te steken en de voorbereidingen voor de promotie. Ik hoop dat wij in de komende jaren op een soortgelijk prettige manier kunnen samenwerken.

Het secretariaat van de afdeling endocrinologie, Hanny, Marleen en Dany Simon, bedankt voor jullie ondersteuning!

Tiny Wouters, natuurlijk wordt jij ook genoemd in mijn boekje! Bedankt voor de vele (vrije) uren die je in dit proefschrift stak. Zonder jou was het nooit zo mooi geworden!

Beste Sjef Hutschemakers, na onze trouwkaart nu ook de kaft van mijn proefschrift; ik vind het geweldig dat wij ook af en toe een beroep mogen doen op "onze" bijzondere kunstenaar. Heel veel dank! 
Lieve Ed en Mia, jullie onbegrensde liefde voor jullie zoons en kleinkinderen is heel bijzonder en ik respecteer jullie daar enorm voor. Bedankt dat ik me in jullie familie, samen met Dietmar, Naima, Lars en Aiden, zo thuisvoelen mag! Bovendien bedankt voor alle goede zorgen voor Elise en bij ons thuis!

Michielke, klein broertje, inmiddels grote broer. Als klein kind heb je altijd moeten opboksen tegen je grote zus die het altijd meer dan goed wilde doen. Sinds een aantal jaar heb je inmiddels je eigen weg gevonden in de grote wereld van Londen. Je mag echt trots zijn op de manier waarop je jezelf daar hebt neergezet! lk ben in ieder geval buitengewoon trots op je, maar vooral ook heb ik goede herinneringen aan een lieve broer in de heerlijke jeugd die we samen hebben gehad. Ik hoop dat we dat altijd hoog kunnen blijven houden. Ik hoop je samen met Karla, ondanks de afstand, toch vaak te mogen begroeten in Schimmert!

Lieve pap en mam, om jullie te bedanken schieten woorden tekort. Jullie zijn de basis van alles wat ik nu ben. Wat jullie in mijn leven voor mij gedaan hebben en nu nog steeds iedere dag ook voor Jörgen en Elise doen, is onbeschrijfelijk. Zonder jullie continue steun hadden Jörgen en ik de motor de afgelopen jaren niet op zo'n hoge toeren kunnen laten draaien. Om nog maar te zwijgen over de ontelbare uren werk aan de boerderij.... Pap daarvoor kunnen we je nooit genoeg bedanken! Ik hoop dat jullie net zo genieten van alles als wij dat nu doen, en dat jullie net zo trots zijn op alles als ik!

Lieve Elise, jouw hartje klopte recht onder het mijne tijdens misschien wel de meest belangrijke fase van de totstandkoming van dit proefschrift. Voor je geboorte ben je al met mij meegereisd naar menige overzeese bestemming voor het geven van een "oral presentation". Alhoewel een goede professionele ambitie onmisbaar is voor mij (een onrustige vrouw als jouw moeder is!), heb je me in die korte tijd dat je nu bij ons bent geleerd dat het echte levensgeluk uiteindelijk in een goed thuis te vinden is. Aan jou wil ik dit proefschrift opdragen. "Für Elise"; ooit heb ik met dit prachtige pianostuk nog eens succesvol examen gedaan voor "piano-graad C". Ik hoop dat ik net zo succesvol zal zijn om jou te stimuleren jezelf te ontwikkelen, in welk interessegebied je ook zal kiezen. Maar vooral ook wens ik je toe dat je iedere dag opnieuw weer een "thuis" zult vinden waar je welkom bent en waar je je goed voelt.

Lieve Jör, wat wij de laatste jaren samen letterlijk en figuurlijk hebben opgebouwd hadden we nooit kunnen dromen. Je bent een buiten gewone levensgezel die me steunt door dik en dun. Er is niets waarvan ik zo geniet als de aanblik van jouw enorme liefde voor onze kleine Elise en tot onze grote vreugde krijgt ze dit jaar als alles goed gaat ook nog een broertje of een zusje. 
Bijna dagelijks zeg je tegen me "wat hebben we het toch goed samen" of "wat kom ik iedere dag opnieuw toch graag thuis". Ik hoop dat we dat ons leven lang kunnen vasthouden, want niets is zo mooi en belangrijk als ons heerlijke thuis.... 
Curriculum vitae 
${ }_{112} \mid$ 


\section{Curriculum vitae}

Leonne Marie Prompers werd op 15 maart 1979 geboren in het ziekenhuis van Heerlen. Ze groeide op in Meerssen, waar ze in 1997 haar VWO diploma behaalde aan het Stella Maris College. Na een propedeuse jaar tandheelkunde en geschiedenis aan de Katholieke Universiteit Nijmegen, startte ze in 1998 met de studie geneeskunde aan de Universiteit Maastricht. Tijdens haar coschap interne geneeskunde maakte zij kennis met Prof. dr. N.C. Schaper en dr. M.S.P. Huijberts, die haar aanboden om lid te worden van het Eurodiale consortium en als promovendus aangesteld te worden op het eerste onderzoeksproject van deze studiegroep. Simultaan aan het afronden van de studie geneeskunde coördineerde ze het project "Optimal health care in diabetic foot disease. The Eurodiale Study". De resultaten van dit Europese project zijn onderwerp van dit proefschrift. In april 2007 startte zij met de opleiding nucleaire geneeskunde in het academisch ziekenhuis Maastricht (opleider Prof. dr. G.J.J. Teule). Zij is getrouwd met Jörgen Ricksen en samen hebben zijn een prachtige dochter, Elise (2007). 